\title{
The clinical effectiveness and cost-effectiveness of a behavioral graded exercise therapy programme for patients with chronic shoulder complaints in primary care
}

Citation for published version (APA):

Geraets, J. J. X. R. (2006). The clinical effectiveness and cost-effectiveness of a behavioral graded exercise therapy programme for patients with chronic shoulder complaints in primary care. [Doctoral Thesis, Maastricht University]. Maastricht University. https://doi.org/10.26481/dis.20060309jg

Document status and date:

Published: 01/01/2006

DOI:

10.26481/dis.20060309jg

Document Version:

Publisher's PDF, also known as Version of record

Please check the document version of this publication:

- A submitted manuscript is the version of the article upon submission and before peer-review. There can be important differences between the submitted version and the official published version of record. People interested in the research are advised to contact the author for the final version of the publication, or visit the DOI to the publisher's website.

- The final author version and the galley proof are versions of the publication after peer review.

- The final published version features the final layout of the paper including the volume, issue and page numbers.

Link to publication

\footnotetext{
General rights rights.

- You may freely distribute the URL identifying the publication in the public portal. please follow below link for the End User Agreement:

www.umlib.nl/taverne-license

Take down policy

If you believe that this document breaches copyright please contact us at:

repository@maastrichtuniversity.nl

providing details and we will investigate your claim.
}

Copyright and moral rights for the publications made accessible in the public portal are retained by the authors and/or other copyright owners and it is a condition of accessing publications that users recognise and abide by the legal requirements associated with these

- Users may download and print one copy of any publication from the public portal for the purpose of private study or research.

- You may not further distribute the material or use it for any profit-making activity or commercial gain

If the publication is distributed under the terms of Article 25fa of the Dutch Copyright Act, indicated by the "Taverne" license above, 


\section{THE CLINICAL EFFECTIVENESS AND}

\section{COST-EFFECTIVENESS OF A BEHAVIORAL}

Graded Exercise Therapy Programme FOR PATIENTS WITH CHRONIC

\section{SHOULDER COMPLAINTS IN PRIMARY CARE}


The clinical effectiveness and cost-effectiveness of a behavioral Graded Exercise Therapy programme for patients with chronic shoulder complaints in primary care - Jacques Geraets Thesis Maastricht University - with references - with summary in Dutch

All rights reserved. No part of this book may be reported, stored in a retrieval system or transmitted in any form or by any means, without written permission from the author, or when appropriate, from the publishers of the publications.

(1) 2006 I.J.X.R.Geraets, Maastricht, the Netherlands

ISBN-10: 9085900085

ISBN-13: 9789085900085

The studies presented in this thesis were funded by the Netherlands Organisation for Scientific Research (NWO-MW, grant number 904-65-901) and by the "De Drie Lichten Foundation", Hilversum, the Netherlands (grant 00/60).

Printed by:

Schrijen Lippetz-Huntjens

Coverdesign and lay-out:

D\&\& graphics 


\title{
THE CLINICAL EFFECTIVENESS AND
}

\section{COST-EFFECTIVENESS OF A BEHAVIORAL}

\section{GRADED EXERCISE THERAPY PROGRAMME}

\author{
FOR PATIENTS WITH CHRONIC
}

\section{SHOULDER COMPLAINTS IN PRIMARY CARE}

\section{PROEFSCHRIFT}

\author{
ter verkrijging van de graad van doctor \\ aan de Universiteit Maastricht, \\ op gezag van de Rector Magnificus, \\ Prof. mr. G.P.M.F. Mols,
}

volgens het besluit van het College van Decanen,

in het openbaar te verdedigen

op donderdag 9 maart 2006 om 16.00 uur

door

Jacques Jan Xavier Rosalie Geraets 


\section{Promotores:}

Prol.dr. W.I.A. van den Heuvel

Prof.dr. G.J. Dinant

\section{Co-promotores:}

Dr. M.E. E. B. Goossens

Dr. G.J.M.G. van der Heijden (Juliuscentrum, Universiteit Utrecht)

\section{Beoordelingscommissie:}

Prof.dr. J.F.M. Metsemakers (voorzitter)

Prof.dr. K. Postema (Universitair Medisch Centrum, Groningen)

Prof.dr. J.L. Severens

Prof.dr. J.W.S. Vlaeyen.

Dr. D.A.W.M. van der Windt (Vrije Universiteit, Amsterdam) 


\section{CONTENTS}

Chapter $1 \quad$ General introduction

$\begin{array}{lll}\text { Chapter } 2 & \text { Concepts, development, and study design } & 21\end{array}$

$\begin{array}{lll}\text { Chapter } 3 & \text { Short-term effectiveness } & 37\end{array}$

$\begin{array}{lll}\text { Chapter } 4 \quad \text { Long-term effectiveness } & 53\end{array}$

$\begin{array}{lll}\text { Chapter } 5 & \text { Cost-effectiveness } & 73\end{array}$

$\begin{array}{lll}\text { Chapter } 6 & \text { Process evaluation } & 87\end{array}$

$\begin{array}{lll}\text { Chapter } 7 & \text { Comparison of recruitment strategies } & 105\end{array}$

$\begin{array}{lll}\text { Chapter } 8 & \text { General discussion } & 121\end{array}$

$\begin{array}{ll}\text { Summary / Samenvatting } & 135\end{array}$

$\begin{array}{ll}\text { Dankwoord } & 147\end{array}$

Curriculum vitae $\quad \mathbb{1 5 5}$

List of publications $\quad 159$ 



\section{CHAPTER 1}

\section{General introduction}

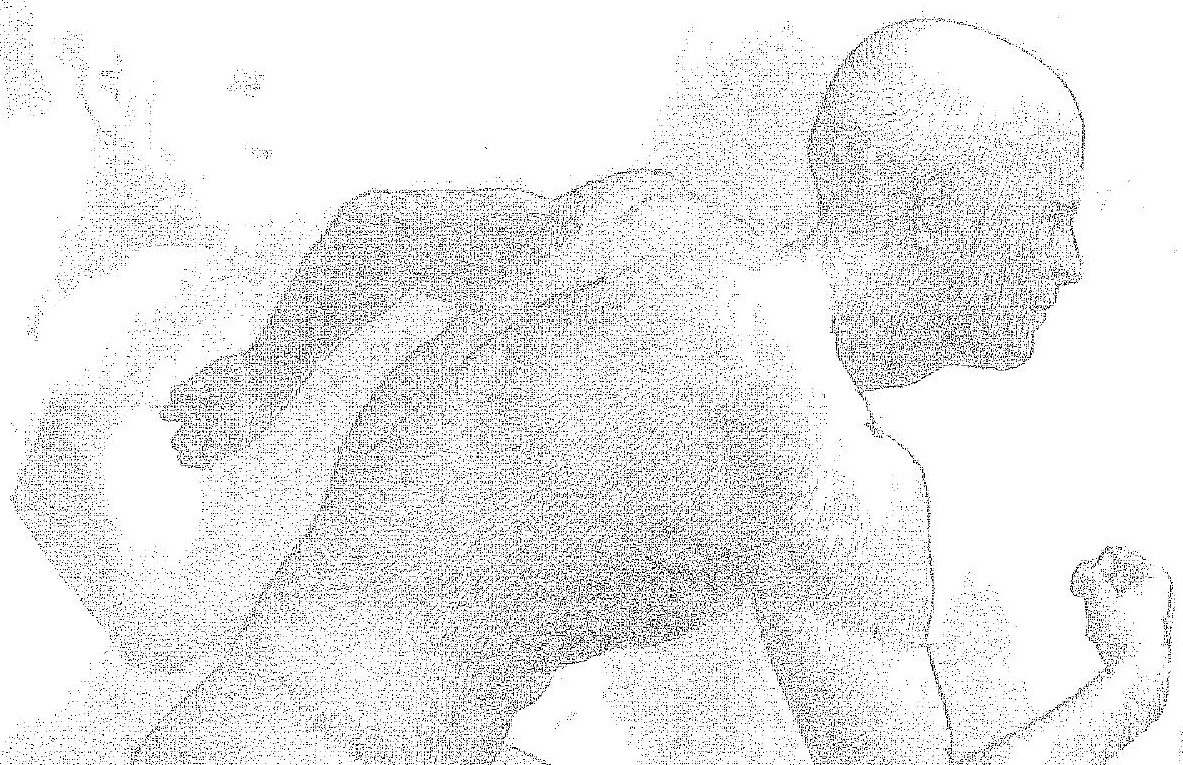




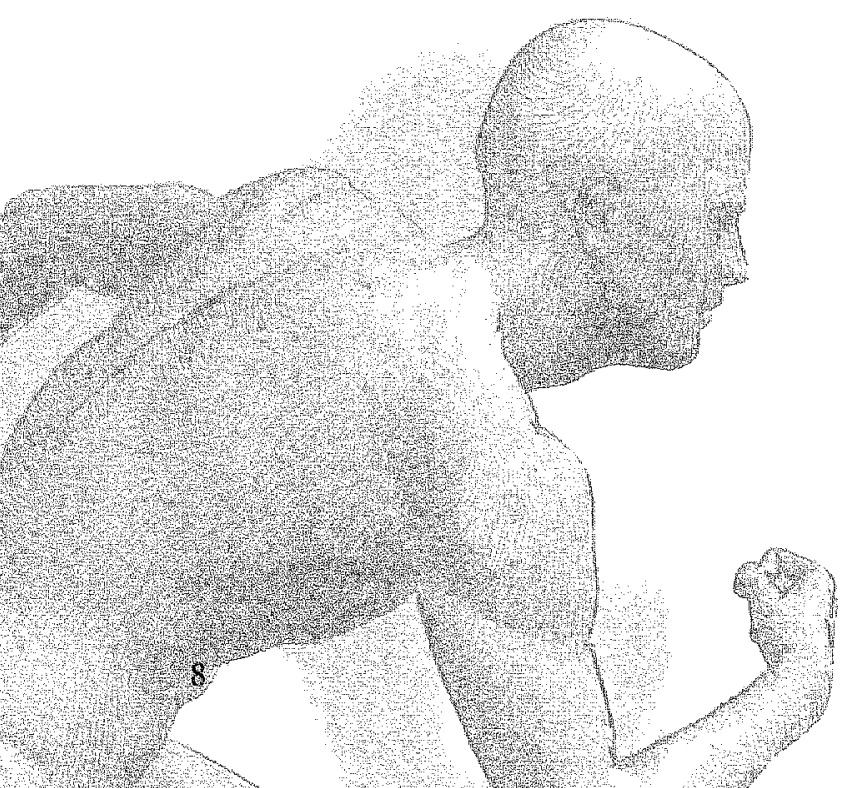




\section{SHOULDER COMPLAINTS}

\section{Definition}

Shoulder complaints involve pain and stiffness located in the deltoid region and upper arm (van der Heijden 1999). They often cause problems when patients are lying on the affected side, and patients may be limitated in the performance of daily activities relating to personal hygiene, work, hobby and sports (Croft et al 1996, van der Windt et al 1996). In addition to causing personal suffering, shoulder complaints impose an enormous social and economic burden due to patients' inability to manage their household, loss of productivity; sick leave and utilisation of health care resources (Meerding et al 1998). In this thesis, shoulder complaints are defined as chronic if they last for at least three months.

\section{Occurrence and course}

Shoulder complaints are a relatively common disorder in view of their occurrence, course and persistence. Reported prevalence rates and incidence rates of shoulder complaints vary greatly, depending on the definition used in terms of location and duration of pain and limited movements (Luime et al 2004a). The one-year period prevalence of shoulder complaints in the Dutch general population aged 25 years and older has been estimated at $30 \%$ (Picavet et al 2003). The annual prevalence of chronic shoulder complaints in this population was $15 \%$. Forty-one percent of these patients with shoulder complaints had visited a general practitioner because of shoulder complaints in the past 12 months. Patients who consult their general practitioner for neck-shoulder complaints have greater risks of long-term pain and disability than non-consulters (Badicock et al 2003). The annual cumulative incidence of shoulder complaints recorded in general practices in the Netherlands has been reported to be as much as 25 per 1000 patients (Sobel et al 1996). Approximately $50 \%$ of all patients who visit their general practitioner with a new episode of shoulder complaints report persistent complaints after six months, and up to $40 \%$ endure complaints up to 12 months (Windt et al 1996, Winters et al 1997, Winters et al 1999a). Forty-six percent of these patients report previous episodes. Recurrence rates for shoulder complaints vary from $31 \%$ (after 12 months) to $85 \%$ (after 12 years) (Luime et al 2004b, Macfarlane et al 1998a, Andersson 2004).

\section{Costs of shoulder complaints}

The economic burden of shoulder complaints can be assessed in terms of the direct health care costs (e.g. costs of utilisation of health care services and prescribed medication), non-direct health care costs (e.g. costs of home care, housekeeping or out-of-pocket expenses) and indirect costs (e.g. loss of productivity or absenteeism from paid or unpaid work). In the Netherlands, musculoskeletal disorders, of which shoulder complaints constitute the second largest group after low back pain, also account for the second largest share in healthcare costs (Picavet et al 2003, Meerding et al 1998). In low back pain patients indirect costs far exceed the direct costs and most expenses (more than 80\%) are incurred for a minority of patients (less than $25 \%$ ) in whom low back pain develops into a chronic disorder (Goossens et al 1997). Musculoskeletal disorders are the main reasons for workrelated consultations in Dutch general practice (Weevers et al 2005). In Sweden, 18\% of disability payment made for musculoskeletal disorders relates to shoulder complaints (Nygren et al 1995). 


\section{Causes and prognosis}

At present, there is a lack of information on the causes and prognosis of shoulder complaints. It is unclear what factors contribute to the initiation of shoulder complaints, what factors are involved in the transition from acute to chronic complaints and what factors play a role in the persistence of chronic complaints (van der Heijden 1999). In the traditional diseaseoriented biomedical model, it is hypothesised that shoulder pain and disability are caused by acute or chronic injury of articular or periarticular soft tissues of the shoulder due to anatomic or biomechanical changes (Cyriax 1981). Although this model is useful when explaining the involvement of biomedical factors in pain at the onset of complaints, through straightforward somato-sensory stimulation, it only partly explains the prolonged pain and reduced performance of activities in chronic pain patients. The 'gate control theory' (Meizack and Wall 1965) broke with the traditional biomedical model of pain. It is based on the hypothesis that neurophysiological and psychological activity - ascending from peripheral sources or descending from the brain - can modulate the pathway of pain stimuli through the 'gate' located in the dorsal horn of the spine. In 1976, Fordyce hypothesised that factors involved in the persistence of pain do not have to correspond with the factors involved in its initiation (Fordyce 1976). He assumed that pain behaviour and the consequences of this behaviour determine to a large extent whether or not pain develops into a chronic pain problem. In the new bio-psychosocial model of pain, biological, psychological and social factors are closely related and involved in the development and maintenance of pain (Engel 1980, Nielson and Weir 2001, Turk et al 1997). Pain has sensory, affective and cognitive dimensions (Loeser 1980). Nowadays, there is strong evidence and general agreement that both biological and psychosocial factors are involved in chronic pain (Vlaeyen and Linton 2000, Keefe et al 2004, Pincus et al 2002). The International Association for the Study of Pain defines pain as 'an unpleasant sensory and emotional experience associated with actual or potential tissue damage, or described in terms of such damage' indicating that pain is subjective (Merskey and Bogduk 1994). However, it is unclear whether and to what extent biological, psychological or social aspects are involved in the initiation and persistence of shoulder complaints. More severe long-term shoulder disability and pain seem to correlate with higher disability and pain scores at the start of the complaints, concomitant neck problems, a gradual onset and a longer duration of complaints (MacFarlane et all 1998a, Kuipers et al 2004, Thomas et al 2005). Furthermore, there is growing evidence that both biomechanical and psychosocial factors are associated with the occurrence of work-related shoulder complaints (van der Windt et al 2000, Andersen et al 2003, Pope et al 1997, Bongers et al 2003, Harkness et al 2003).

\section{MANAGEMENT OF SHOULDER COMPLAINTS IN PRIMARY CARE}

\section{Usual care}

In the Netherlands, the general practitioner is the gatekeeper in the professional management of patients with shoulder complaints, and is responsible for usual care and referrals to physicians and paramedical therapists. Usual care mainly focuses on pain relief and the treatment of disability in patients with shoulder complaints. Traditionally, usual care was based on signs and diagnostic classifications of shoulder complaints as described by Cyriax (Cyriax 1981). The first clinical guidelines for shoulder complaints of the Dutch College of 


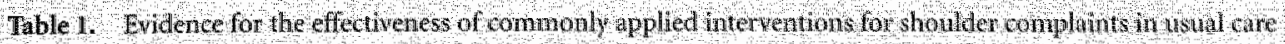

\begin{tabular}{|c|c|c|}
\hline Treatment & Level of evidence & Reference \\
\hline MSADS & $\begin{array}{l}\text { Limited evidence for shontertu } \\
\text { effectweness }\end{array}$ & vander Windt 1995 \\
\hline $\begin{array}{l}\text { Sub acromial or ntra-articular } \\
\text { conticosterod injection }\end{array}$ & $\begin{array}{l}\text { Linited evidence for short-erm } \\
\text { effectiveness }\end{array}$ & $\begin{array}{l}\text { Arolland Goodyear } 2005, \\
\text { Bernsteil } 2001 \text { Buchlahder at al } 2003\end{array}$ \\
\hline Exercise therapy & Linited or conflicting eviclence & $\begin{array}{l}\text { Smitet al } 2005 \text {, Desmedles et al } 2003 \\
\text { Mior } 2001 \text {, Grant et al } 2004 \text {, } \\
\text { Midenener et al } 2004\end{array}$ \\
\hline Mantal therapy & Inited or conllicing evidence & Bergnan 1 al 2004 \\
\hline cultresound & Insulficient or conflicting evidence & $\begin{array}{l}\text { Robientson and Baker } 2001, \\
\text { van der Heidden el al } 1997 \\
\text { Michener et al } 20 \text {, } \\
\text { van de Windt et al } 1999\end{array}$ \\
\hline Electrotherapy & conficting evidence & Grant et al 2004 , van der Hejoder 1999 \\
\hline Laser therapy. & Insufficient or conflicting evidence & $\begin{array}{l}\text { vat der feíden } 1999 \\
\text { Michener et a/2004 }\end{array}$ \\
\hline Acupuncture & Insufficient or conflicting exidence & $\begin{array}{l}\text { Grant et al 2004; Green et al } 2005 \text {, } \\
\text { Michener et al } 2004\end{array}$ \\
\hline Open and primary surgery & Limited evidence & $\begin{array}{l}\text { Grant e al 2004, Ejisisinan et al } 2004 \text {, } \\
\text { Handol lel al 2004, Gibson et al } 2004\end{array}$ \\
\hline $\begin{array}{l}\text { Arthrosconic debridement and } \\
\text { revision surgery }\end{array}$ & Noevidence & Grant et al 2004 Lo and Burkhart 2004, \\
\hline $\begin{array}{l}\text { Accurag of diagnostic imaging } \\
\text { techiniques - ultrasonography, } \\
\text { magnetic resonance imaging (NRI) } \\
\text { or magnetic resonance } \\
\text { arthrography (MRM) - in secondany ca }\end{array}$ & Limited evidence & van der Hejeen 1999 , Dinnes et al 2003 \\
\hline
\end{tabular}

General Practitioners (DCGP), issued in 1990, recommended detailed physical examination of shoulder complaints and treatment of injured soft tissues according to the Cyriax method. However, the inter- and intra-observer agreement on signs, diagnostic criteria and classifications for this method was found to be poor (Bamji et al 1996, de Winter et al 1999). Furthermore, evidence on the accuracy of clinical tests to diagnose impingement and rotator cuff tears turned out to be limited (Luime 2004c). In the revised guidelines for shoulder complaints, issued by the DCGP in 1999, the diagnostic classification system based on soft tissue pathology was replaced by a diagnostic system based on functional limitations of the shoulder girdle (Groenier et al 2003, Winters et al 1999b).

Usual care according to this revised guideline consists of information, recommendations and pain-contingent medical or drug therapy. It is the GPs who decide on the specific treatment to be administered. During the first two weeks following the initial consultation, they follow a wait-and-see policy, and give advice and information on the course of the complaints. This policy is supplemented with analgesics or non-steroidal anti-inflammatory drugs (NSAIDs) if GPs consider them necessary. Patients are instructed to re-consult their 
GP if complaints continue for more than two weeks. Up to three corticosteroid injections can then be given, or referral to a physiotlierapist or specialist can be considered.

At present, there is limited evidence that biomedically based interventions speed up recovery in the short term for patients with shoulder complaints, and there is conflicting evidence on long-term effects of conservative treatment (Green 2003, van der Heijden 1999, Kroese 2002, Grin 2004). Referral of patients with shoulder pain to an orthopedic surgeon or a rheumatologist does not seem to be based on clinical signs (pain, function, duration of complaints or initial diagnosis), nor is it associated with greater improvements regarding pain and function (Solomon et al 2001). Table 1 shows the available evidence for the effectiveness of commonly applied treatments for shoulder complaints.

\section{Behavioural treatment}

Reconceptualisation of pain and the development of a new multidimensional biopsychosocial model in which biological, psychological and social factors contribute to persisting pain have led to the development of new treatments addressing psychosocial aspects in chronic pain patients (Fordyce 1976, Nielson and Weir 2001, Turk and Okifuji 1997, Flor 2003, Goucke 2003). Fordyce introduced operant conditioning principles to the management of chronic pain, focussing on the consequences of pain behaviour. Pain behaviour is thought to consolidate when patients experience the consequences of this behaviour as pleasant and to extinguish when they experience the consequences as unpleasant. Positive or negative reinforcement of the preferred behavioural changes is given to increase and maintain the desired behaviour (Fordyce 1976, Fordyce et al 1986, Lindstrom et al 1992, Turk and Okifuji 1999).

The effectiveness of cognitive-behavioural treatment programmes has been documented in several studies (Guzmán et al 2001, Morley et al 1999, Tulder et al 2001, Ostelo et al 2005, Vlaeyen and Linton 2000, Nielson and Weir 2001). However, most studies have involved combined cognitive and behavioural programmes for chronic low back pain patients, in multidisciplinary settings. Table 2 shows the available evidence for the effectiveness of behavioural treatments in musculoskeletal pain patients. It is likely that operant behavioural therapy will be effective in the treatment of patients with chronic shoulder complaints in primary care, although specific evidence on this issue is still lacking (Linton 1995).

Tible 2 Budence for the effectiveness of behavioural treatments in chronie nusculoskeletal pain pattients.

\begin{tabular}{|c|c|c|c|}
\hline Programme & Population & Level of evidence & Reference \\
\hline $\begin{array}{l}\text { Conbined respondent } \\
\text { cognithe treatment }\end{array}$ & Low baskgali & Strong evidence & ostelo et al 2005 \\
\hline Progressive re axation & Low back pain & Moderate evidence & Ostelo et al 2005 \\
\hline Operantboliavioural treatment & Low back pain & Limited evidence & $\begin{array}{l}\text { Staal et al } 2004 \text { ostelo et al } \\
2005 \text { lensen el al } 2005\end{array}$ \\
\hline $\begin{array}{l}\text { Multidisciplinay biopsychosocial } \\
\text { tehabilitation }\end{array}$ & Neck and shoulder pain & Limited evidence & $\begin{array}{l}\text { Karjalainen rehabilitation et } \\
\text { al } 2001\end{array}$ \\
\hline
\end{tabular}




\section{GRADED EXERCISE THERAPY}

We have developed a behavioural Graded Exercise Therapy (GET) programme, based on the principles of graded activity, time contingency and operant learning, to optimise the treatment of patients with chronic shoulder complaints in primary care. This programme is administered by a physiotherapist and attempts to improve the performance of daily activities and to reduce health care costs and indirect costs in these patients. An important aim of GET is to increase levels of daily activity by learning from the consequences of behaviours. Pain behaviour is expected to be consolidated when patients experience the consequences of this behaviour as pleasant and to extinguish when they experience it as unpleasant. Operant learning principles are used to promote and improve healthy behaviour by changing the consequences of behaviour. In graded activity, levels of activity increase in at step-wise time-contingent fashion. This means that the intensity of exercises increases gradually over time, irrespective of pain experience, towards preset goals and with fixed quota agreed upon at the start of the programme. To our knowledge, GET is the first behavioural programme to focus on patients with chronic shoulder complaints. Furthermore, GET is the first behavioural programme to be administered in a mono-disciplinary and primary care setting.

\section{AVAILABLE EVIDENCE AT THE START OF THE STUDY}

At the start of our study, there was no evidence for beneficial clinical effects of behavioural treatments in patients with chronic shoulder complaints in primary care. Nor was any evidence available on the cost-effectiveness of behavioural treatments in these patients. Finally, evidence was lacking on the feasibility of the newly developed behavioural Graded Exercise Therapy programme for patients with chronic shoulder complaints in primary care.

\section{OBJECTIVES OF THIS THESIS}

The main objective of the studies reported in this thesis was to evaluate the clinical effectiveness and cost-effectiveness of our behavioural Graded Exercise Therapy programme in patients with chronic shoulder complaints in a primary care setting. We further aimed to examine the feasibility of the GET programme and the need for improvements to the protocol to facilitate its implementation. This study was part of a research programme of the Netherlands Organisation for Scientific Research (NWO), including a comprehensive prognostic cohort study on shoulder complaints in primary care, with three randomised clinical trials on the clinical effectiveness and cost-effectiveness of three treatment modalities for shoulder complaints in subcohorts. The first trial assessed manipulative therapy of the shoulder girdle additional to usual care, while the second concerned an early education and activation programme in patients with acute shoulder complaints. The third, the present study, examined the behavioural Graded Exercise Therapy programme in patients with chronic shoulder complaints. 


\section{OUTLNE OF THIS THESIS}

The following research questions are answered in the successive chapters of this thesis:

- Chapter 2 discusses the theory and the conceptual model underlying the Graded Exercise Therapy Programme. Furthermore, the development and content of the programme and the design of the study to evaluate the programmes effectiveness and cost-effectiveness are presented.

- Chapter 3 is concerned with the short-term effectiveness of Graded Exercise Therapy in patients with chronic shoulder complaints in primary care.

- Chapter 4 is concerned with the long-term effectiveness of Graded Exercise Therapy in patients with chronic shoulder complaints in primary care.

- Chapter 5 addresses the cost-effectiveness of Graded Exercise Therapy in patients with chronic shoulder complaints in primary care.

- Chapter 6 presents an evaluation of the intervention process and discusses the extent to which the programme is being applied according to protocol, the feasibility of the programme for patients with chronic shoulder complaints in a primary setting and the needs to improve the programme to facilitate implementation.

- Chapter 7 discusses the influence of the two recruitment strategies used on the outcomes in this trial.

The general discussion (Chapter 8) reviews the main results of the studies presented in this thesis, focussing on practical and methodological issues, and considers implications for clinical practice and future research. 


\section{REFERENCES}

Andersen $1 \mathrm{H}$, Kaergaard A, Mikkellsen S, Jensen UE, Frost $P$, Bonde JP, Fallentin N, Thomsen JF Risk factors in the onset of neck/shoulder pain in a prospective study of workers in indtustrial and service companies. Occup Enwiron Med. 2003:60:649-54.

Andersson 111 . The course of non-malignant chronic pain: a 12 year follow-up of a cohort from the general population. Eur J Pain. 2004;8:47-53.

Arroll B, Goodyear-Smith F. Corticosteroid injections for painful shoulder: a meta-analysis. Br / Gen Pract. $2005 ; 55: 224-8$.

Badcock LI, Lewis M. Hay EM, Croft PR. Consultation and the outcome of shoulder-neck pain: a cohort study in the population. J Rheumatol. $2003 ; 30: 2694-9$.

Bemstein RM. Injections and surgical therapy in chronic pain. Clin I Pain. 2001;17(4 Suppl): 594-104.

Bongers. PM, Kremer AM, ter Laak J. Are psychosocial factors, risk factors for symptoms and signs of the shoulder, elbow, or hand/wrist?: A review of the epidemiological literature. Am I Ind Med. 2002;41:315-42.

Buchbinder R, Green S, Youd IM. Conticosteroid injections for shoulder pain. Cochrane Database Syst Rew. 2003;(1):CD004016.

Croft P, Pope D, Silman A. The clinical course of shoulder pain: prospective cohort study in primary carte. BMI. 1996;313:601-2.

Cyriax J. Textbook of Orthopaedic Medicine. London: Bailliere Tindall.1981.

Desmeules $\mathrm{F}$, Cote $\mathrm{CH}$, Fremont $\mathrm{P}$. Therapeutic exercise and orthopedic manual therapy for impingement syndrome: a systematic rewicw. Clin I Sport Med. 2003;13:176-82.

Dinnes J, Loveman E, MoIntyre L, Waugh $N$. The effectiveness of diagnostic tests for the assessment of shoulder pain due to soft tissue disorders: a systematic review. Health Technol Assess. 2003:7:1-166.

Engel GL. The dinical application of the biopsychosocial model. Am I Psychiatry 1980; $137.535-543$.

Ejnisman B, Andreoli CV, Soares BG, Fallopa F, Peccin MS, Abdalla RI, Cohen M. Interventions for tears of the rotator cuff in adults. Cochrane Database Syst Rev. 2004; (1):CD002758.

Flor H. Cortical reorganisation and chronic pain: implications for rehabilitation. J Rehabil Med. 2003:(41 Suppl):66-72.

Fordyce WE. Behavioral methods for chronic pain and ilness. Saint Louis: CV Mosby Company. 1976.

Fordyce WE, Brockway J, Bergman I and Spengler D. A control group comparison of behavioural wersus traditional management methods in acute low back pain. I Behaw Med 1986;2:127-140. 


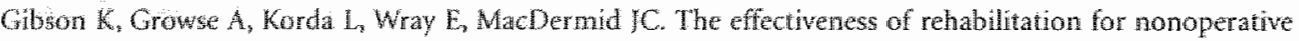
management of shoulder instability: a systematic review. I Hand Ther. 2004;17:229-42.

Gim KA, Cohen WL. Conservative treatment for shoulder pain: prognostic indicators of outcome. Arch Phys Med Rehabil, 2004:85:1231-5.

Goossens MEJB, Evers SMAA. Economic evaluation in back pain interventions. J Occup Rehabil 1997; 7; 15.32

Goucke CR. The management of persistent pain. Med I Aust. 2003;178:444-7.

Grant HJ, Arthur A, Pichora DR. Evaluation of interventions for rotator cuff pathology: a systematic review. I H w wh ther 2004;17:274-99.

Green S, Buchbinder R, Hetrick S. Physiotherapy interventions for shoulder pain. Cochrane Database Syst Rev. 2003;(2):CD004258,

Green $S$, Bucthbinder $R$, Hetrick S. Acupuncture for shoulder pain. Cochrane Database Syst Rev. 2005;18:CD005319.

Groenier $\mathrm{KH}$, Winters $/ \mathrm{C}$, de Jong BM. Classification of shoulder complaints in general practice by means of nonmetric multidimensional scaling. Arch. Phys Med Rehabil. 2003;84:812 7.

Guzmán I, Esmail R, Karjalainen K, Irvin E, Bombadier C. Multidisciplinary rehabilitation for chronic low back pain: systematic review. BMJ 2001322:511-516.

Handoll $\mathrm{HH}$, Amaiyah MA, Rangan A. Surgical versus non-surgical treatment for acute anterior shoulder dislocation. Cochrane Database Syst Rev. 2004;(1):CD004325.

Harkness EF, Macfarlane GI, Nahit ES, Silman Al, McBeth J. Mechanical and psychosocial factors predict new onset shoulder pant a prospective cohort study of newly employed workers. Occup Environ Med. $2003 ; 60: 850-7$.

Heijden G) vann der, van der Windt $D A$, de Winter AF Physiotherapy for patients with solt tissue shoulder disorders at systematic review of randomised clinical trials. BMJ.1997;315:25-30.

Heijden G) van der. Shoulder disorders: a state-of-the-art review. Baillieres Best Pract Res Clin Rheumatol. $1999 ; 13: 287-309$.

Jensen IB, Bergstrom G, Ljungquist T, Bodin L. A 3-year follow-up of a multidisciplinary rehabilitation programme for back and neck pain. Pain. 2005; 15:273-83.

Karjalainen K, Malmivara A, van Tulder M, Roine $\mathbb{R}$, Jauhiainen M, Hurri H, Koes B. Multidisciplinary biopsychosocial rehabilitation for neck and shoulder pain among working age adults: a systematic review within the framework of the Cochrane Collaboration Back Review Group. Spine. 2001;26:174-81. 
Reefe F, Rumble ME, Scipio CD, Gordano LA, Perri LM. Psychological aspects of persistent pain curtent state of the science. I Pain 2004: 5:195-211.

Kroese MEAL. Inventarisatie van effectonderzoek naar regelmatig toegepaste fysiotherapeatische behandelingen bij chronische benigne piin. Nederlands Tijdschrift voot Pysiotherapie 2002;112:42-49.

Kuijpers I, wan der Windt DA, wan der Heijden GI, Bouter LM. Systenatic review of prognostic cohort studies on shoulder disorders. Pain. 2004:109:420-31.

Lindstron I, Ohlund C, Eek C. Wallin L, Peterson LE, Fordyce WE and Nachemson AL. The effect of graded activity on patients with subacute low back pain: A randomised prospective clinical study with an operant conditioning behavioural approach. Phys Ther 1992;72: 279-290.

Linton SI. An overview of psychosocial and behavioral factors in neck-and-shoulder pain. Scand I Rehabil Med. 1995:32:67 77.

Linton SI. Prevention with special reference to chronic musculoskeletal disorders. In Gatchel RJ and 'Turk. DC (Eds): Psychosocial Factors In Pain. New York: Guilford Publications, pp. 374-389. 1999.

Linton ST, Boersma $\mathrm{K}$, Jansson M, Svard L, Botvalde M. The effects of cognitive behavional and physical therapy preventive interventions on pain-related sick leaves a randomized controlled triat. Clin I Pain. 2005;2:109-119.

Lo IK, Burkhart SS. Arthroscopic revision of failed rotator cuff repairs: technique and results. Arthroscopy. $2004 ; 20: 250-67$.

Loeser JD. A definition of pain. Medicine. $1980,7,3$.

Juime IJ, Koes BW, Henriksen IJ, Burdorf A, Verhagen AP, Miedema HS, Verhaar JA. Prevalence and incidence of shoulder pain in the general population; a systematic review. Scand I Rheumatol. 2004a; 33: 73-81.

Luime II. High incidence and recurrence of shoulder and neck pain in a working population during a 2 year follow-up. In Luime I] (fid): Shouder complaints; The occurrence, course and dagnosis. Rotterdant Optima BW, $2004 \mathrm{~b}$; chapter $3,37-57$.

Luime If. Diagnostic evaluation of shoulder pain: a systematic review on the accuracy of signs and symptoms related to rotator cuff disorders. In Luime /f (Ed): Shoulder complaints; The occurrence, course and diagnosis. Rotherdam: Optima BV, 2004c; chapter 6, 1109-132.

Meerding WIL, Bonneux L, Polder IJ, Koopmanschap MA and Maas PJ van der. Demographic and epidemiological determinants of healthoure costs in the Netherlands: a cost of illness study. BMI 1998:31\%:111-115.

Melack R and Wall PD. Pain mechanisms: a new theory. Science 1965:150: 971-979.

Merskey $H$ and Bogduk N. International Association for the Study of Pain. Pain Terminology. In Merskey H and Bogduk $N$ (Eds), Classification of Chronic Pairn. Seattle, LASP Press. pp. 209-214.1994. 


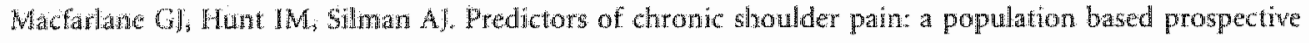
study. I Rheumatol.1998:25:1612-5.

Michener LA, Walsworth MK, Burnet EN. Effectiveness of rehabilitation for patients with subacromial jimpingement syndrome: a systematic review. I Hand Ther. 2004;17:152-64.

Mior S. Excrcise in the treatment of chroric pain. Chin J Pain. 2001a:17(4 Suppl):77-85.

Mior S. Manipulation and mobilization in the treatment of chronic pain. Clin J Pain. 2001b; 17(4 Supp):70-6.

Morley $\$$, Eccleston $C$ and Williams A. Systematic review and meta-analysis of randomized contralled trials of cognitive behaviour therapy and behaviour therapy for chronic pain in adults, excluding headache. 1999; Pain 88: 1-13.

Nielson WR and Weir R. Biopsychosocial approaches to the treatment of chronic pain. Clin I Pain. 2001:17: $114-127$.

Nygren A, Berglund $A_{2}$ von Koch M. Neck and shoulder pain, an increasing problem. Strategies for using insurance material to follow trends. Scand / Rehabil Med Suppl 1995; 32; 107 12.

Ostelo RW, van Tulder MW, Vlaeyen IW, Linton SI, Morley SI, Assendelft WJ. Behavioural treatment for chronic low-back pain. Cochrane Database Syst Rev. 2005; (1):CD002014.

Picavet ASI and Schouten JSAG. Musculoskeletal pain in the Netherlandls: prevalences, consequences and risk groups, the DMC (3) - study. Pain. 2003;102: 167-178.

Prncus T, Burton AK, Vogel $S$, Field AP. A systematic review of psychological factors as predictors of chronicity/disability in prospective cohorts of low back pain. Spine. 2002;27:E109-20.

Pope DP. Croft PR, Pritchard. CM, Silman AI. Macfarlane Gil. Occupational factors related to shoulder pain and disability. Ocop Environ Med. 1997:54:316-21.

Robertson VI, Baker KG. A review of therapeutic ultrasound: effectiveness studies. Phys Ther. 2001;81:1339-50.

Sinidt $N$, de Vet HC, Bouter LM, Dekker J. Effectiveness of exercise therapy: A best-evidence summary of systematic traviews. Aust f Physiother. 2005;51:71-85.

Sobel IS. Winters IC. Arendzen IH, Groenier KH and Meyboom-de Jong B. Kenmerken van schouderklachten in de huisartspraktijk. Huisants en Werenschap 1996;39:169-173.

Solomon DH, Bates DW, Sthaffer IL, Horsky J, Burdick E, Katz JN. Referrals for musculoskeletal disorders: patterns, predictors, and outcomes. I Rheumatol. 2001;28:2090-5.

Staal IB, Hobil H, Twisk JW, Smid T, Koke AJ, van Mechelen W. Graded activity for low back pain in occupational health care: a randomized, controlled trial. Ann Intern Med. 2004;140:77-84. 


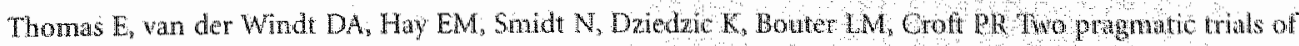
treatment for shoulder disorders in primaty care generalisability, course, and prognosto indicators. 1 : Am Rheum Dis. 2005;64:1056-61.

Tulder MW van, Ostelo RWJG, Vaeyen JWS, Linton SJ, Morley SI and Assendelf WII. Bethavioral treatment for chronic low back pain. A systematic review within the framework of the Cochrane Back Review Group. Spine 2001;26:270-281.

Turk DC and Okifül A. Evaluating the role of physical, operant, cognitive, and affectwe factors in the pain behawiors of chronic pain patients. Behav Modie 1997;21: 259-280.

Turk DC and Okifuin A. A cognitive-behavioural approach to pain management. Textbook of pain. W. P.D. and M. R. Edinburgh: Churchill Livingstone, pp. 1431-1443.1999.

Vlaeyen JWS and Linton SJ. Fear-Avoidance and its consequences in chronic musculaskeletal pain: $A$ state of the art. Pain. 2000;85: 317-332.

Weevers $H J$, van der Beek $A J$, Anema $\int R$, van der Wal $G$, van Mechelen W. Work-related disease in general practice: a systematic review. Fam Pract. 2005;22:197-204.

Windt DA van der, Heijden Gl van der, Scholten RJ, Koes. BW, Bouter LM. The efficacy of non-steroidal antiinflammatory drugs (NSAIDS) for shoulder complaints. A systematic review. ) Clin Epidemiol. 1995;48:691704.

Windt DA van der, Koes BW, Boeke AJ, Deville W, Jong BA de and Bouter LM. Shoulder disorders in general practice: prognostic indicators of outcome. B J Gen Pract. 199646 : 519-523.

Windt DA van der, Heijden GJ wan der, wan den Berg SG, ter Riec $G_{\text {, de }}$ Winter Al; Bouter LM. Ultrasound therapy for musculoskeletal disorders: a systematic review. Pain. $1999 ; 81: 257-71$.

Windt DA van der, Thomas E, Pope DP de Wiater AR, Macfarlane Gf, Bouter LM, Silmatr Al Occupational risk Gactors for shoulder paina a systenatic review, Occup Enwiron Med. 2000;57:433-42.

Winter AF de, Jans MP el al. Diagnostic classification of shoulder disorders: interobserwer aggreement and determinants of disagreement. Ann Rheum Dis. 1999;58:272\%7.

Winters $1 \mathrm{C}$, Sobel 15 , Arendzen $\mathrm{JH}$ et al. The course of pain and the restriction of mobility in patients with shoulder complaints in general practice. Rheumatol lint.1997; 16:219-225

Winters IC, Sobel IS, Groenier KH, Arendzen JH, Meyboom-de Jong B. The long-term course of shoulder complaints: a prospective study in general practice. Rheumatology (Oxford). 1999; 38:160-3.

Winters JC, Iongh AC de, Windt DAWM wan der, Jonquiere $M$, Winter AF de, Heijden GIMG van der, Sobel IS and Goudsward AN. NHG-Standaard Schouderkachten. Huisarts en Wetenschap 19996;42: 222-231. 



\section{CHAPTER 2}

\section{Concepts, development, and study design}

Published as

Geraets JIXR, Goossens EJB, Bruijn GPC de, Koke AJA, Bie RA de, Pel RAGB, Heuvel WJA van den, Heijden GIMG van der A behavioural trea unent for chronic shoulder complaints: concepts, development, and study design. Aust J Physiother. 2004: 50: $33-38$. 


\section{ABSTRACT AND KEY WORDS}

This paper discusses the rationale for and content of a newly developed treatment for shoulder complaints (SC) and the design of a randomised study, which is currently being conducted to test its effectiveness.

Background: In current practice, approximately $50 \%$ of all patients with SC mention limitations in the performance of daily activities and persisting pain after six months. To improve the functional ability of patients with chronic SC, despite their pain, we developed an operant behavioural and time-contingent Graded Exercise Therapy (GET) programme for use in a primary care setting. We present the theory and conceptual model underlying this programme, report on its development and content and describe the design of a randomised clinical trial to evaluate the programme's effectiveness and cost-effectiveness.

Methods: One hundred and thirty-two patients who suffer from SC for at least 3 months are being recruited in general practice. After inclusion in the study, patients are randomly allocated to the GET programme or to usual care.

Measures: Questionnaires will be used to measure factors like severity of the main complaint, functional limitations of daily activities, perceived recovery, global health status, shoulder pain, generic health-related quality of life and costs, assessed at baseline, during treatment ( 6 weeks) and after treatment (12, 26 and 52 weeks).

Key words: Shoulder complaints, behavioural therapy, randomised clinical trial, study design. 


\section{INTRODUCTION}

Shoulder complaints (SC) are a very common problem in Dutch primary health care. The community-based one-year prevalence of chronic shoulder pain lasting more than three months has been estimated at $15 \%$ in 1998 (Picavet et al 2000). The annual incidence of SC registered in general practices in the Netherlands has been reported to be as much an 25 per 1000 patients (Sobel et al 1996). Approximately $50 \%$ of all patients who visit their general practitioner with a new episode endure complaints for up to six months and up to $40 \%$ report complaints after 12 months (Windt et al 1996). Musculoskeletal disorders, of which SC constitute the second largest group after low back disorders, account for the second largest share in healthcare costs (Meerding et al 1998).

To date, there is insufficient information on the aetiology, diagnosis, and prognosis of SC. Biological, psychological and social factors are generally assumed to be involved and to interact in the course of non-specific musculoskeletal pain (Engel 1980, Nielson and Weir 2001, Vlaeyen and Linton 2000). A clear model about pain as a result of interaction between nociceptive stimulation, pain perception, pain experience and pain behaviour has been described by Loeser (Loeser 1980). It is unclear, however, whether and to what extent biological, psychological, and social factors have a causal relation with the initiation of SC or with the transition from acute to chronic SC (van der Heijden 1999). It can be hypothesized, however, that these factors play a role in the course of SC, comparable to other non-specific musculoskeletal pain disorders (Linton 1995).

Over the last decades, cognitive and behavioural principles have been integrated into pain management and have proven to be effective (Guzmán et al 2001. Linton 1999, Morley et al 1999. "Tulder et al 2001, Vlaeyen and Linton 2000). The focus is primarily on pain behaviour, fear-avoidance beliefs and the associated disability. Performance and conditioning of physical activities are important features from a behavioural point of view. Most studies on the effectiveness of cognitive behavioural therapy for musculoskeletal pain have been administered for chronic complaints in multidisciplinary settings (Morley et all 1999).

Given the high prevalence of SC and the tendency for these complaints to become chronic, we have developed a Graded Exercise Therapy (GET) programme for the primary care setting. This programme, which is administered by physiotherapists, is based on behavioural treatment principles. The programme aims to improve functional abilities in patients with SC, largely excluding pain as a primary target. This paper presents the theory and conceptual model underlying this programme, then discusses the development and content of this programme and finally describes the design of a study we are currently undertaking to evaluate its effectiveness and cost-effectiveness.

Several considerations induced us to publish separate articles on the design of the study and the results. The first is that this allows reflection on the study protocol as such, independently of the study results. Secondly, it allows us to identify protocol deviations that might influence study results. Thirdly, it allows publication bias to be avoided.

\section{CONCEPTS OF THE GET PROGRAMME}

\section{Biomedical approach}

Traditionally, the management of $\mathrm{SC}$ has been based on a disease-oriented biomedical model (Cyriax 1981, Uhthoff and Sarkar 1990). This model is based on a one-dimensional causal relationship between tissue pathology and signs of SC, which assumes that pain and disability 
are caused by acute or chronic injury of articular or periarticular soft tissues of the shoulder. Biomedical treatments mainly focus on pain relief and the treatment of disability. There is limited evidence that biomedical based interventions speed up recovery in the short term for patients with SC, and long-term effects have been rather disappointing (Green 2003, van der Heijden 1999, Kroese 2002).

\section{Biopsychosocial approach}

Melzack and Walls gate-control theory of pain has led to a broad discussion and new views on pain (Melzack and Wall 1965). Initially, (chronic) pain was considered to be a result of straightforward somato-sensory stimulation. Nowadays, there is general agreement that pain has sensory, affective and cognitive dimensions. The International Association for the Study of Pain defines pain as "an unpleasant sensory and emotional experience associated with actual or potential tissue damage, or described in terms of such damage" indicating that pain experience is subjective (Merskey and Bogduk 1.994).

This reconceptualization of pain had led to the development of a new multidimensional biopsychosocial model in which biological, psychological, and social factors contribute to produce pain experience and its persistence (Fordyce 1976, Nielson and Weir 2001, Turk and Okifuji 1997).

\section{Operant conditioning approach}

A behaviourally oriented operant conditioning approach focuses on environmental reinforcement contingencies of pain behaviour and pain-related inactivity in the maintenance of pain. According to learning theory principles, pain behaviour is acquired and can be modified through new learning experiences (Skinner 1953), Pain behaviour is considered to be conditional on the consequences of this behaviour. Positive or negative reinforcement may provoke continuation of the performed pain behaviour.

Fordyce et al first described the theoretical concept of operant behavioural treatments (Fordyce 1976). Characteristics of these treatments are reinforcement, rewarding, target setting and activity scheduling. To date, the effectiveness of operant behavioural treatment programmes has been documented in several studies (Morley et al 1999). Moreover, graded activity programmes have been shown to improve the level of daily activities and reduce disability in patients with subacute back pain (Fordyce et al 1986, Lindstrom et al 1992) and those with chronic back pain (Turner and Clancy 1988).

\section{DEVELOPMENT OF THE GET PROGRAMME}

The GET programme has been developed by experts in the field of operant behavioural treatments for chronic pain, together with a steering committee of primary care physiotherapists. Important in the area of behaviour change is to increase levels of daily activity including goal setting, pacing of progress towards goals, and manipulation of cues for and consequences of behaviours to promote change. The main elements of the GET programme are graded activity, time contingency, and operant conditioning (Fordyce et al 1986, Turk and Okifuji 1999).

\section{Graded activity}

In graded activity, levels of activity increase in a step-wise fashion. Graded activity has biomedical and psychosocial aims: improving functional ability, shifting attention from pain 
to activity and provoking healthy behaviour. Behavioural activation is assmed to improve functional ability in patients with chronic musculoskeletal pain (Fordyce 1986).

\section{Time-contingency}

Whereas a disease-oriented pain-contingent approach involves activities that are performed and adjusted according to pain experience, a time-contingent approach involves levels of activity that are structured in time. The intensity of exercises rises gradually over time, irrespective of pain experience, with fixed quota agreed upon at the start of the programme.

\section{Operant conditioning}

By changing the consequences of behaviour, operant learning principles are used to promote and improve healthy behaviour. positive reinforcement of the preferred behavioural changes is given to increase and maintain the frequency of graded activities.

External reinforcement is related to social and environmental factors. Reinforcement on healthy behaviour is given directly by the physiotherapist who acts like a coach. Initially, the emphasis is on external positive reinforcement to provoke behavioural changes. When behaviour has changed in the preferred direction, external reinforcement becomes less intensive and internal reinforcement becomes more important for the maintenance of the healthy behaviour. Internal reinforcement depends on the benefits patients experience as a consequence of healthy behaviour. Patients will become more motivated if they succeed in the performance of preferred activities and experience the progress made as a consequence of their own healthy belaviour.

\section{Characteristics OF THE GET PROGRAMME}

The primary aim of this exercise programme is the patients' ability to perform their own preferred shoulder activities in daily life at home or at work, irrespective of the pain experience. It does not aim to achieve pain relief at all. The programmes activities are related to specific shoulder functions such as reaching, supporting, pushing, pulling, hitting, and stabilizing, with work-related activities receiving special attention.

A total of 18 one hour sessions are held over a period of 12 weeks. The programme is administered in small groups of three to five persons under the supervision of a specially trained physiotherapist. Since not all participants do bave to start the programme at the sane time, some patients in the group may already have made some progress in their rehabilitation plan while others have just joined the group.

\section{Content of the GET programme}

The programme consists of a start-up period and a treatment plus generalization period.

\section{Start-up period}

The programme starts with history taking, physical examination, and identification and assessment of the patient's own preferred activities. Special attention is paid to patients' experiences, beliefs, and behaviour with respect to the complaints and to possible barriers and obstacles towards recovery and increasing activity levels. At this stage, reconceptualization of pain and pain-related disability is important to ensure that patients are convinced they are able to control and influence their pain experience (Turk and Okifuji 1999). The treatment rationale is explained and aims of the treatment programme are set in terms of functional goals. 
During the start-up period, which lasts two weeks, patients are asked to perform and adjust their own preferred activities on the basis of pain-contingency, the assumption being that levels of activity will be high if pain levels are low and vice versa. Levels of activity are registered in graphs that are used to evaluate progress as a consequence of the patients' actual behaviour.

At the end of the start-up period, the baseline for treatment is determined. Because the experience of pain is assumed to lead to limited progress; the level of activity at the start of the treatment period is set slightly below the average of the patient's pain-contingent performance, making it likely that the patient can complete the activities successfully. Positive experiences as a consequence of their initial treatment activities are expected to motivate patients to proceed with further exercises.

Goals, quota, and the precise content of the treatment period are determined and agreed upon for every individual patient. Goals are related to the patient's own preferred daily activities. The patient signs a contract setting out the patient-tailored rehabilitation plan, which defines quota for the treatment period by means of grading, that is, goal setting and time scheduling (figure 1).

Figure 1. Graded Exercise Therapy programme

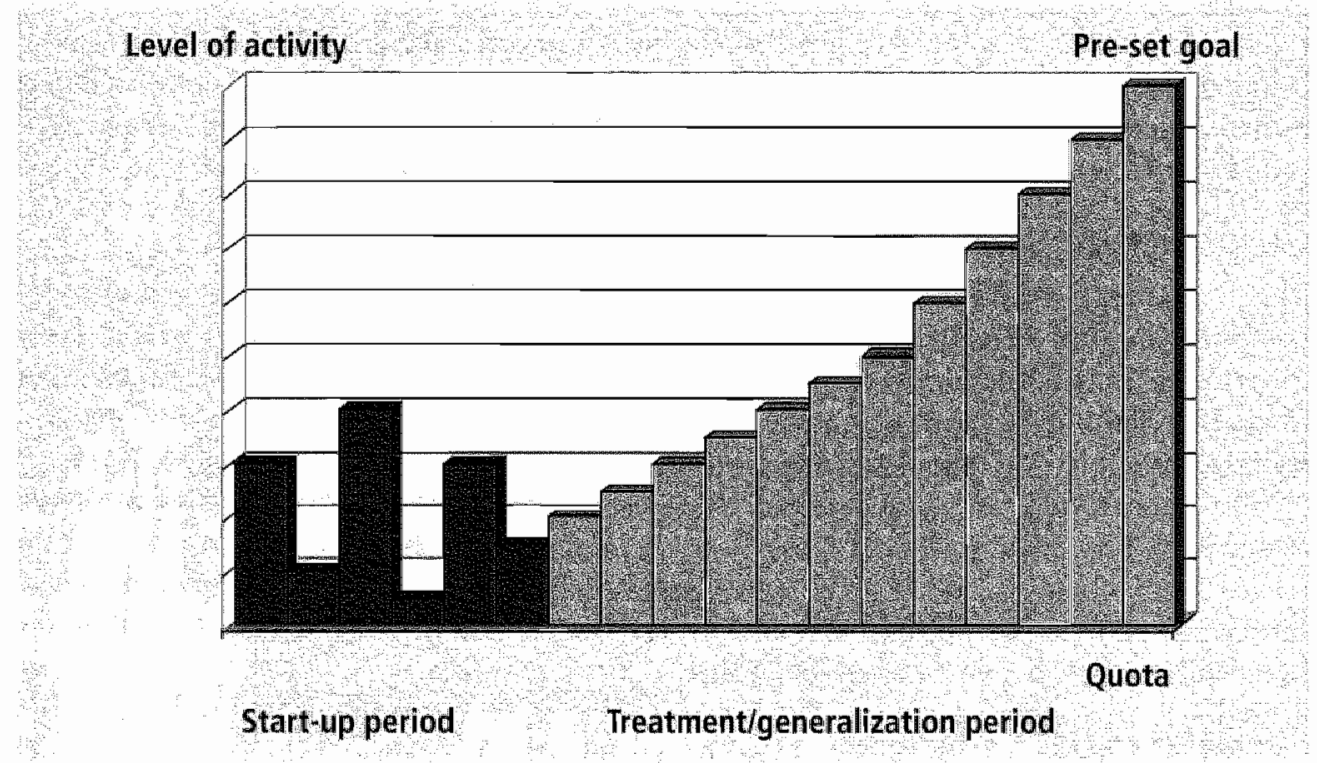

Note

During the start-tup period, lewels of activity are adjusted by pain perception (pain-contingent). During the treatment period, levels of activity are based on prewset quota in time (time-contingent), starting slightly below the level at baseline and increasing in a stepwise fashion to achieve pre-set. goals at the end of the programme.

\section{Treatment plus generalization period}

The second phase, lasting 10 weeks, involves graded activity exercises. Activities are now structured according to a time-contingent approach, and the intensity of the exercises is gradually increased over time. 
At the start of the treatment period, positive reinforcement of healthy behaviour is emphasized. Gradually, reinforcement becomes intermittent and less intense, while graphs are used as an instrument to reinforce patient behaviour and to discuss and evaluate the steps that have been achieved. Progress is attributed to the patient's performance.

Special attention is paid to the application of what has been learned in everyday life, that is, how to deal with new goals and how to manage a relapse or a new episode of complaints. This is called generalization. Generalization already starts at the beginning of the treatment period, but is strongly emphasized at the end of the treatment period.

\section{DESIGN OF THE GET EVALUATION STUDY}

\section{Objectives}

The GET trial is designed to study whether GET is a clinically effective and cost-effective treatment of patients with chronic SC after 6 and 12 months (figure 2). GET is compared with usual care (UC) according to the guideline for SC issued by the Dutch College of General Practitioners (DCGP) 1999 version. The following research questions will be addressed in this study:

1 Is GET clinically more effective than UC on performance of daily activities, perceived recovery, global health status, shoulder pain, and generic health-related quality of life after 6 and 12 months in patients with chronic SC

2 Is GET more cost-effective than UC after 1.2 months in patients with chronic SC

\section{Recruitment and allocation of patients}

Thirty-two general practitioners (GPs) in the province of Limburg, the Netherlands, are currently recruiting patients who suffer from SC. The period of enrolment runs from lanuary 2002 until July 2003. Patients who visit their GP and meet the selection criteria are asked to participate in the study. A research assistant visits potential participants at home within two weeks after they have visited the GP. Patients are eligible for inclusion if they are at least 18 years of age and have suffered from shoulder pain or complaints in the shaded area shown in figure 3 for at least three months.

Furthermore, patients have to suffer from $\mathrm{SC}$ at the time of intake. Exclusion criteria are: treatment for their SC during the three months prior to the initial GP consultation; complete rotator cuff tears; serious prior traumata, i.e. fractures or dislocations, or prior surgery of the shoulder, upper limb, neck or thorax; osteoporosis, rheumatoid or bacterial arthritis, a tumour, referred pain from internal organs, a cervical radicular syndrome, gross shoulder hypermobility, stroke, polyneuropathy, multiple sclerosis, polymyalgia or ankylosing spondylitis; treatment for serious psychiatric disorders or unable to complete questionnaires in Dutch.

\section{Sample size}

Sample size calculations are based on perceived recovery rates since rates of performance of daily activities are not available. Recent studies of shoulder treatment in general practice show that six months after the first consultation, about $50 \%$ of all patients report full recovery or that their complaints are much improved. Since only patients with complaints lasting at least three months participate in the study, we estimate that only $25 \%$ of these patients feel fully recovered or much improved at six months after randomisation. Since we 
Higure 2. How-chart of study design

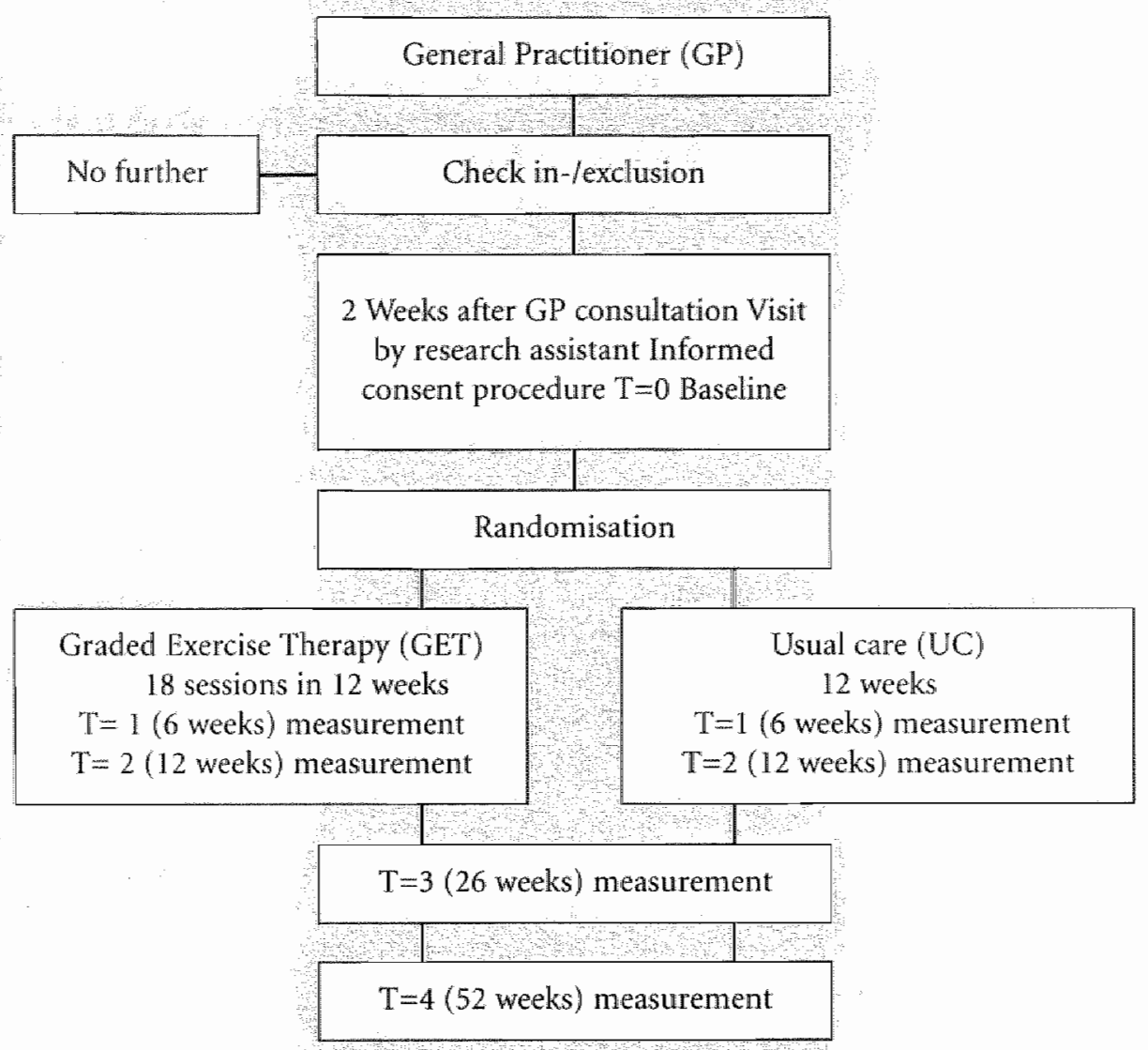

Figure 3. Area of shoulder complaints
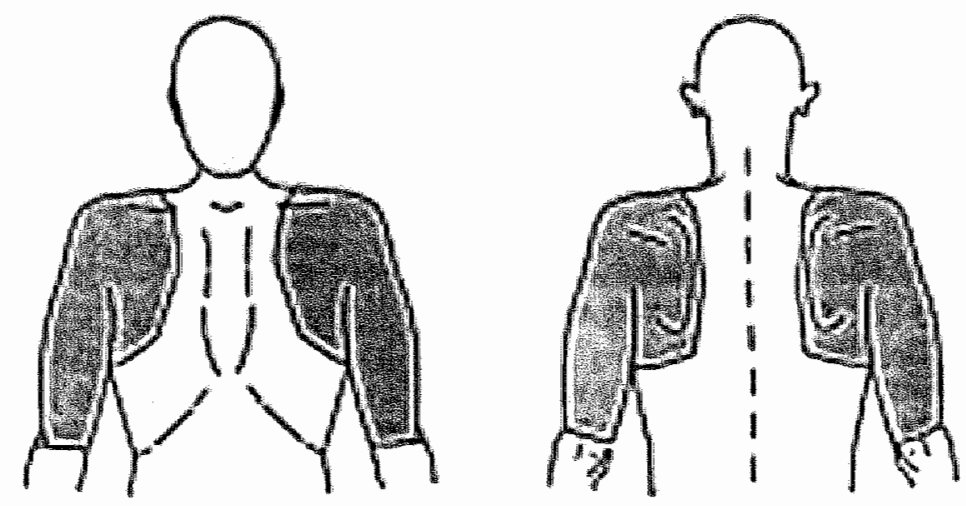
aim at a 1 -sided alpha of 5\%, a statistical power (1-beta) of 0.90, and a 10\% dropout rate, we need 66 persons per treatment group to increase the recovery rate from $25 \%$ to $50 \%$. The number needed to treat is calculated to be four.

\section{Informed consent and randomisation}

After giving their informed consent to participate in the study patients are ramdomised to receive either GET or UC. A random number list generated by a researcher who is not involved in the conduct of the study is used to allocate patients.

\section{Intervention}

\section{GET}

GET is protocollized and carried out as described above. At the start of the intervention, patients are given a short brochure about the rationale behind the therapy, as well as a booklet containing graphs to evaluate progress and a treatment agreement to promote compliance with the programme.

\section{UC}

Usual care is standardized according to the 1999 version of the guidelines for SC issued by the DCGP (Winters et al 1999) and consists of information, recommendations and medical or drug therapy. This usual care of SC is pain-contingent. The GP makes the specific choice of treatment.

\section{Physiotherapists and general practitioners}

Prior to the start of the study, physiotherapists participating in the GET group took part in a one-day workshop and two booster sessions under the supervision of experts in the field of cognitive-behavioural treatments (A.K. and $\mathbb{R} . P_{.}$). General practitioners participating in the UC group have been given a refresher course on using the 1999 guideline for SC of the DCGP.

\section{Baseline and follow-up measurements}

Patients are seen for collection of baseline data before randomisation, during the intervention at 6 and 12 weeks after randomisation, and after completion of the treatment at 26 and 52 weeks after randomisation. At all these moments, the variables shown in table 1 are assessed.

In addition, demographic variables, disease characteristics, co-morbidity, physical activity, workload and treatment credibility and preferences are documented at baseline. Function of the shoulder girdle and cervicothoracic spine, severity of the main complaint, and psychosocial variables (anxiety, depression, somatization, distress and job content) are regarded as prognostic variables.

\section{Clinical effectiveness}

Performance of daily activities as outcome variable of clinical effectiveness is measured by the severity of the main complaint and functional limitations of daily activities. Perceived recovery as outcome variable of clinical effectiveness is measured on a seven-point ordinal scale. Patients are regarded as recovered if they feel either fully recovered or much improved. Global health status, shoulder pain, and generic health-related quality of life are also assessed as outcome variables of clinical effectiveness. Process measures include kinesiophobia, fear avoidance beliefs and fear of re-injury, catastrophizing, coping with pain, and internal and external locus of control. 


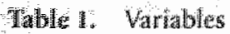

\begin{tabular}{|c|c|c|c|c|c|c|}
\hline \multirow[t]{2}{*}{ Variable } & \multirow[b]{2}{*}{$T=0$} & \multirow[b]{2}{*}{$T=1$} & \multicolumn{4}{|r|}{ Measure } \\
\hline & & & $T=2$ & $T=3$ & $T=4$ & \\
\hline \multicolumn{7}{|l|}{ Baseline status } \\
\hline Demographic variables & $x$ & & & & & \\
\hline Spectic disease characteristics & $x$ & & & & & \\
\hline Comorbidity & $x$ & & & & & \\
\hline Plysical activity & $x$ & & & & & \\
\hline Workload & $x$ & & & & & \\
\hline Treatment credbilly and preference & $x$ & & & & & \\
\hline \multicolumn{7}{|l|}{ Prognostic variables } \\
\hline Function of shoulder girdle & $x$ & & & & & Physical examination \\
\hline Function of cervicothoracic spine & $x$ & & & & & Physical examination \\
\hline Severity of main complaint & $x$ & & & & & 8-dimension inventory \\
\hline Psychosocial wariables & $x$ & & & & & 4050 \\
\hline Job content & $x$ & & & & & \\
\hline \multicolumn{7}{|l|}{ Outcome variables } \\
\hline \multicolumn{7}{|l|}{ Performance of daily activities } \\
\hline I Severity of main complaint & $x$ & $x$ & $x$ & $x$ & $x$ & 11-point Likert scale \\
\hline $\begin{array}{l}2 \text { Functional lirmitations of } \\
\text { dailly activities }\end{array}$ & $x$ & $x$ & $x$ & $x$ & $x$ & Shoulder Disability Questionnaire \\
\hline Perceived recovery of complaints & & $x$ & $x$ & $x$ & $x$ & 8-point scale \\
\hline Glabal health status & & $x$ & $x$ & $x$ & $x$ & \\
\hline Shoulder pain & $x$ & $x$ & $x$ & $x$ & $x$ & Shoulder Pain Score \\
\hline Quality of life & $x$ & $x$ & $x$ & $x$ & $x^{x}$ & $E Q 5 D$ \\
\hline Costs & \multicolumn{5}{|c|}{ Continuous } & Cost diary \\
\hline \multicolumn{7}{|l|}{ Process variables } \\
\hline Kineslophobia & $x$ & $x$ & $x$ & $x$ & $x$ & Tampa Scale for Kinesiophobia \\
\hline Fear-awoidance beliefs & $x$ & $x$ & $x$ & $x$ & $x$ & Fear-Avoidance Beliefs Questionnaire \\
\hline Catastrophizing & $x$ & $x$ & $x$ & $x$ & $x$ & Pain Coping and Cognition List \\
\hline Coping with pain & $x$ & $x$ & $x$ & $x$ & $x$ & Pain Coping and Cognition List \\
\hline Intemál locus of control & $x$ & $x$ & $x$ & $x$ & $x$ & Pain Coping and Cognition List \\
\hline Extemal locus of control & $x$ & $x$ & $x$ & $x$ & $x$ & Pain Coping and Cognition List \\
\hline
\end{tabular}

\section{Noteders:}

$\mathrm{T}=0$ (baseline), $\mathrm{T}=1$ ( 6 weeks), $\mathrm{T}=2$ (12 weelks), $\mathrm{T}=3$ (26 weaks) and $\mathrm{T}=4$ (52 weeks)

$4 D S Q$ Four Dimensions of psychological Symptomatology Questionnare (Terlutin 1998)

SOQ Showder Disability Questionmane (van der Hejden et al 2000)

SPS Shoutder Pain Score (Winters al 1996)

LOS1) Quality of life (Brooks 1996)

TSK-DV Tampa Scalo lor Kinesiophobia (Vareyen et all 1995)

BABQ-DV Fea-Awoidance Bellefs Questionna he (Vendrige al 1998 )

PCCL. Pan Coping and Cognition List (Berg et al 2001)

\section{Cost-effectiveness}

To evaluate the short-term and long-term cost-effectiveness of GET, the following socioeconomic endpoints are collected: programme costs, direct health care costs, direct non- 
medical costs and indirect costs. Costs are measured by means of patient cost diaries (Goossens et al 2000). The effects are measured in terms of generic health-related quality of life descriptions measured with the EQ5D (Brooks 1996).

\section{Blinding}

Two research assistants who are not involved in the randomisation procedure carry out the data collection of baseline characteristics, process- and outcome measurements. Blinding of patients and health care providers (e.g., physiotherapists and general practitioners) is not possible. Data entry, intention to treat analysis, and cost analysis will be carried out independently and blinded for treatment allocation.

\section{Data presentation and statistical analysis}

Baseline data, which are relevant for comparability of groups, will be presented. Dropouts and losses-to-follow up will be described.

Analyses will be performed on the primary outcome measures, i.e., severity of the main complaint and functional limitations of daily activities, and on other clinical outcome measures, i.e., perceived recovery, global. health status, shoulder pain, and generic healthrelated quality of life. $\mathrm{T}$ or $\mathrm{F}$ tests will be used to compare groups for outcome variables measured on continuous scales and Gaussian data distribution, while Mann"Whitney tests will be used for non-Gaussian distributions and chi-square tests for ordinal and dichotomous outcome variables.

The primary endpoint, i.e. the change in performance of daily activities at 6 and 12 months will be compared using the average change over time of both groups. The difference between those averages and its $95 \%$ confidence interval will be calculated. Effect measurements, point estimates and $95 \%$ confidence intervals will be presented.

Baseline characteristics that a priori are considered to be possible prognostic factors for performance of daily activities, with post randomisation differences between the groups, will be handled as potential confounders. Their influence will be evaluated by means of multivariable regression analyses. In case of confounding, adjusted effect estimates will also be reported. In the analyses of the difference in change for the primary end point at 6 and 12 months we will account for the repeated measures character of the data.

All patients will primarily be analysed according to the intension-to-treat principle. In order to study the influence of protocol violations on the study outcomes, an on-treatmentanalysis will be performed. Patients with documented deviations from the study protocol will be excluded from this on-treatment analysis.

\section{Qualitative evaluation of content and feasibility}

A qualitative evaluation of the trial progress is being performed concomitantly. Treatment reports and questionnaires completed by the patients allocated to GET and the physiotherapists involved are used to evaluate the content of GET at the end of each treatment period. Interviews with patients allocated to UC and their UC providers are used to evaluate the content of the control treatment.

Feasibility and applicability of the GET programme will be evaluated at the end of the study. Experiences with and beliefs about the content of the programme, among both patients and physiotherapists, will be evaluated in focus group discussions. 


\section{Discussion}

Since it is as yet unclear whether and which patients will benefit from the GET programme, we only exclude patients on the basis of systematic diseases, referred pain or severe biomedical or psychiatric disorders. We consider the programme most suitable for patients with discrepant pain behaviour and pain beliefs. They might either postpone activities because they believe activity may cause damage or re-injury, or ignore the pain and consequently exceed suitable levels of activity. We hope this study will contribute to further insights into the applicability of behavioural treatments in musculoskeletal pain.

The present study is characterized by randomised allocation, cost-effectiveness evaluation and qualitative process evaluation. However, since blinding patients is not possible in this pragmatic study, information bias has to be taken into account. GET's contribution towards total effects cannot be evaluated in absolute terms because the study does not have an addon design. There is some uncertainty as to required sample size, because calculations are based on rates of recovery and not on rates of performance of daily activities.

Although the GET programme could be embedded in a multidisciplinary approach to $\mathrm{SC}$, it was developed to be administered in a primary care physiotherapy setting. It is obvious that professional capacities and attitudes towards SC among health care providers are extremely important. Physiotherapists do have capacities in terms of coaching patients in their physical activities, but special training in the treatment of psychological factors of pain and disability appears to be necessary.

\section{Approval}

T.he design of the study presented here has been approved by iRw/SRL's nationally recognized Medical Ethics Committee. 


\section{REFERENCES}

Berg SCM van den, Vlaeyen WS, Kuil MM ter, Spunhoven Ph, Bitenkelen $G$ van and Kole-Snijders AM]: Meetinstrumenten chronische pijn deel 2. Pij Coping en Cognitie Lijst. Mastricht: Pin Kemis Centrum. 2001.

Brooks R. EuroQol: The current state of play. Health Policy 1996;37:53-72.

Cyriax 1. Textbook of Orthopaedic Medicine. London: Bailliere Tindatl.1981.

Engel GL. The clinical application of the biopsychosocial model. An I Psychatry. 1980; 137; 535-543.

Fordyce WE. Behavioral methods for chronic pain and ilness. Saint Lotis. CV Mosby Company. 1976.

Fordyce WE, Brockway I, Bergman I and Spengler D. A control group comparison of behavioural versus traditional management methods in acute low back pain. I Behav Med.1986; 2:127-140.

Goossens ME, Rutten wan Molken MP, Waeyen IW, Linden van der SI (2000): The cost diary: a method to measure direct and indirect costs in cost-effectiveness research. J Clin Epidemiol, 2000: 53:688-695.

Green S, Buchbinder R, and Hetrick S. Physiotherapy interventions for shoulder pain (Cochrane Revicw). In: The Cochrane Library, Issue 42003.

Guzmán J, Bsmail R, Karjalainen K, Irvin E, Bombadier C. Multidisciplinairy rehabilitation for chronic low back pain: systematic review. Br Med 1. 2001:322:511-516.

Heijden GIMG van der. Shoulder disorders: A state-of-the-art teview. Bailliere's Clin Rhenmatol. 1999;13: $287-309$.

Heijden GIMG van der, Leffers $P$ and Bouter $I M$. Shoulder Disability Questionnaite design and responsiveness of a functional status measure. J Clin Epidemiol 2000;53: 29-38.

Kroese MEAL. Inventarisatie wan effectonderzock nat regehmatig toegepaste fysiotherapeatische behandelingen bij chronische benigne pijn. Nederlands Tijdschrift woor Fysiotherapie 2002;112:42,49.

Lindstron $\mathbb{1}_{\text {, Ohlund }} \mathrm{C}$ Eek $\mathrm{C}$, Wallin $\mathrm{L}$, Peterson $\mathrm{LE}$, Fordyce WE and Nachemson AL. The effect of graded actiwity on patients with subacute لlow back pain: A randomised prospective climical study with int operant conditioning behavioural approach. Phys Ther 1992;72: 279-290.

Linton S. An overview of psychosocial and behawioral factors in meck-and-shoulder pain. Scand I Rehabil Med 1995;32: 67-77.

Linton SI. Prevention with special reference to chronic musculoskeletal disorders. In Gatchel R/ and Turk DC (Eds): Psychosocial Factors In Pain. New York: Guilford Publications, pp. 374-389.1999.

Loeser JD. A definition of pain. Medicine, 1980;7. 3. 
Meerdmg Wy, Bonneux 1 , Polder J). Koopmanthap MA and Maas PJ van der. Demographic and epidemiological determinans of healthare costs in the Netherlands: a cost of illness study. Br Med $1998 ; 317: 1111115$.

Melack R and Wall PD. Pain mechanisms: a new theory. Science 150: 971-979.1965.

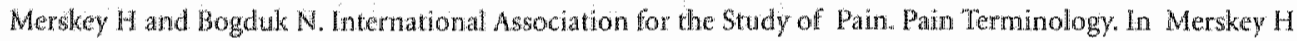
and Bogduk N (Eds). Classification of Chronic Pain. Seattle, LASP Press: pp. 209-214.1994.

Mortey 5 , Eccleston $\mathrm{C}$ and Williams. A. Systematic review and meta-analysis of randomized controlled trials: of cognitive behaviour therapy and behaviour therapy for chronic pain in adults, excluding headache. Pain $11999 ; 88: 1-13$.

Nielson WR and Weir R. Biopsychosocial approaches to the treatment of chronic pain. Chin J Pain 2001;17: $114-127$.

Ostelo RWIG, Stomp-wan de Berg SGM, Vlaeyen IWS, Wolters PMIC and Vet HCW de. Health care provider"s attitudes and beliefs regardling low back pain. Department of Epidemiology. Maastricht University. Maastricht pp. 131-144, 2002

Picavet HSI, Gils HWV van and Schoteen ISAG. Klachten van het bewegingsapparat in de Nederlandse bevolking. Bithoven: National Institute of Public Health and the Environment. 2000.

Skinner B. Science and Human Behavior. New York: Macmillan.1953.

Sobel IS, Winters JC. Arendzen IH, Groenier KH and Meyboom-de Jong B. Kenmerken wan schouderklachten in de huisartspraknijk. Fuisarts en Wetenschap. 1996; 39:169-173.

Terluin B. De Vierdimensionale Klachtenlijst (4.DKL) in de huisairtspraktijk. De Psycholoog: 1998; 18-24.

Tulder MW Wan, Ostelo RWJG, Vlacyen IWS, Linton SJ, Morley SIand Assendelf WII. Behavioral treatment for chronic low back pain. A systematic rewiew within the framework of the Cochrane Back Review Group. Spine 2001:26: 270-281.

Turk DC and Okifuji A (1997): Evaluating the role of physical, operant, cognitive, and affective factors in the pain behaviors of chronic pain patients. Behav Modif 1997; 21: 259-280.

Turk DC and Okifuji A. A cognitive-behavioural approach to pain management. Textbook of pain. W. P.D. and M. R. Bdinburgh: Chutchill Livingstone, pp. 1431-1443.1999.

Turner A and Clancy 5 . Companison of operant behavioural and cognitive-behavioural group treatment for chronic low-back pain. I Consult Clin Psychol. 1988; 56:261-266.

Uhthoff $\mathrm{H}$ and Sarkar $K$. An algorithm for shoulder pain caused by soft-tissue disorders. Clin Orthop Relat Res 1990:254:121-127. 


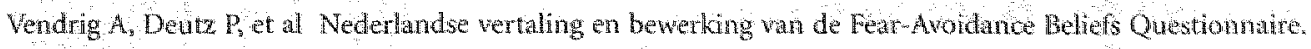
Nederlands Tujdschift woor Pijn en Pinbestrijding 1998;18: 11-14.

Vlaeyen WWS, Kole-Snijders AMJ, et al. Fear of movement/re) injury in chronic low back pain and its relaton to behavioral performance. Pain $1995 ; 62: 363-372$.

Vlaeyen WWS and Linton SI. Fear-Avoidance and its consequences in duronic musculoskeletal pain A state of the art. Pain $2000 ; 85: 317-332$.

Windt DA van der, Koes BW, Boeke A., Deville W, Iong BA de and Bouter LM. Shoulder disorders in general practice: prognostic indicators of outcome. Br f Gen Pract 1996;46:519-523.

Winters JC, Sobel IS, Groenier KH, Arendzen IH and Meyboom-de long B. A Shoulder Pain Score: A comprehensive questionnaire for assessing pain in patients with shoulder complaints. Scand If Rehabil Med $1996 ; 28: 163-167$.

Winters JC, longh AC de, Windt DAWM vatn der, fonquiere $\mathrm{M}$, Winter AF de, Heijden GMG van der, Sobel IS and Goudswaard AN. NHG-Standaard Schouderklachten. Huisarts en Wetenschap 1999;42: 222-231. 



\section{ChAPTER 3}

\section{Short-term effectiveness}

Published as

Geraets JJXR, Goossens EJB, Groot IM de, Bruijn CPC de, Bie RA de, Dinant GJ, Heijden GMG van der, Heuvel WAA van den. Effectiveness of a graded exercise therapy programme for patients with chronic shoulder complaints. Austr 1 Physiother $2005,51.8794$. 


\section{ABSTRACT}

An operant behavioural and time-contingent Graded Exercise Therapy (GET) programme to improve functional ability irrespective of pain experience in patients with chronic shoulder complaints (SC) was developed. The clinical effectiveness of GET compared to usual care (UC) was evaluated in a randomized clinical trial.

Assessments were carried out before and after 12 weeks of treatment. Performance of daily activities was measured by two outcome measures: the main complaints instrument and the Shoulder Disability Questionnaire (SDQ). Patients were eligible for participation if they had suffered from SC for at least three months. Patients suffering from systemic diseases, referred pain or severe biomedical or psychiatric disorders were excluded.

Patients $(N=176)$ were randomized and allocated either to GET $(N=87)$ or UC $(N=89)$. GET led to larger improvement in the performance of daily activities than UC. However, only mean differences between groups in performance of actuvities related to the main complaints reached statistical significance $(\mathrm{P}=0.049,95 \%$ CI: $0.0,15.0)$. The observed beneficial effects were considered to be small to moderate (calculated effect sizes: 0.30 for the main complaints instrument and 0.07 for the SDQ). Subgroup analysis showed larger improvements on the mean complaints instrument in patients not reporting pain reduction over time. GET seems to be less effective in restoring performance of daily activities as assesses by the SDQ in patients showing a painful are during physical examination.

Results showed that GET is more effective in restoring performance of daily activities in patients with chronic SC than UC, although beneficial effects are small.

Key words: Shoulder complaints, behavioral therapy, randomized clinical trial. 


\section{INTRODUCTION}

Shoulder complaints (SC) are a major topic in primary health care: the 1998 point prevalence of self-reported shoulder pain in the general Dutch population was estimated at $210 \%$, while $41 \%$ of all patients with SC in the past 12 months visited a general practitioner (GP) (Picavet and Schouten 2003). A majority of SC last for relatively long periods of time or recur: approximately $50 \%$ of all patients who visit their GP with a new episode endure complaints for up to 6 months (Kuipers et al 2004, Windt van der et al 1996, Winters et al 1997 and 1999) and up to $40 \%$ still have complaints after 12 months. Moreover, $46 \%$ of all patients with at new episode of complaints recall a previous history of SC (Windt van der et al 1996). Eightyfive percent of patients with initial chronic shoulder pain in the general Swedish population still reported pain after 12 years (Andersson 2004).

Patients with SC suffer from pain (27\%) and disability (29\%) (Heijden van der 1999, Picavet and Schouten 2003). Because SC can have considerable impact on daily life and often develop into a chronic disorder, it is important to optimize the treatment. It has been hypothesized that the course of SC involves biological, psychological, and social factors, as is also the case in other non-specific musculoskeletal pain disorders (Linton 1995). We therefore developed an operant behavioural and time-contingent Graded Exercise Therapy (GET) programme to improve functional ability in patients with chronic SC despite their pain. We chose this approach in view of the proven effectiveness of this type of treatment in patients with low back pain (Fordyce et al 1986, Guzmán et al 2001, Lindstrom et al 1992, Linton 1999, Morley et al 1999, Tulder et al 2001, Vlaeyen and Linton 2000). We have previously described the theory and conceptual model underlying this programme, reported on the programme's development and content, and presented the design of our study (Geraets et al 2004). The present paper describes the clinical effectiveness of GET in patients with chronic SC. GET is compared to usulal care (UC) as described in the 1999 guidelines for SC issued by the Dutch College of General Practitioners (DCGP) (Winters et al 1999: see also http:/nhg.artsennet.nl/upload/104/guidelines2/E08.htm). The objective of the study was to assess whether GET is more effective than UC after 12 weeks of treatment in terms of restoring the performance of daily activities irrespective of pain experience in patients with chronic $S C$.

\section{METHODS}

\section{Design}

The short-term climical effectiveness of Graded Exercise Therapy (GET) compared to usual care (UC) was assessed in a randomized clinical trial. Short term was defined as the end of the 12 -week treatment period. GET was administered by 20 physiotherapists (PTs), whereas UC was administered by 32 general practitioners (GPs). The study was approved by iRv/SRL's Medical Ethics Committee.

\section{Recruitment and allocation of patients}

Patients with chronic SC (lasting for at least three months) living in the Province of Limburg, the Netherlands, were invited to participate in the study in the period from January 2002 until July 2003 . With $25 \%$ and $50 \%$ recovered patients in respectively the usual care and GET group at 26 weeks follow-up, we aimed at 132 patients to participate in the study (66 in each intervention group) based on a 1 -sided alpha of 0.05 , a statistical power (1-beta) of 0.90 , and 
a 10\% non-differential dropout rate. Patients were recruited either by the GPs during consultation for $\mathrm{SC}$, or by advertisement in local newspapers. All potential participants received written information and visited the $\mathrm{GP}$ to check eligibility according to the criteriat listed below. A research assistant visited the patients at home for the intake procedure, within two weeks after the consultation with the GP. Eligible patients were asked to give written informed consent. Patients were included if they were at least 18 years of age and had suffered

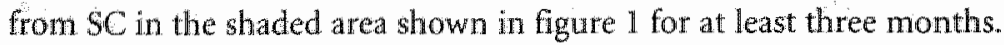

Figure 1. Atea of shoulder complaints
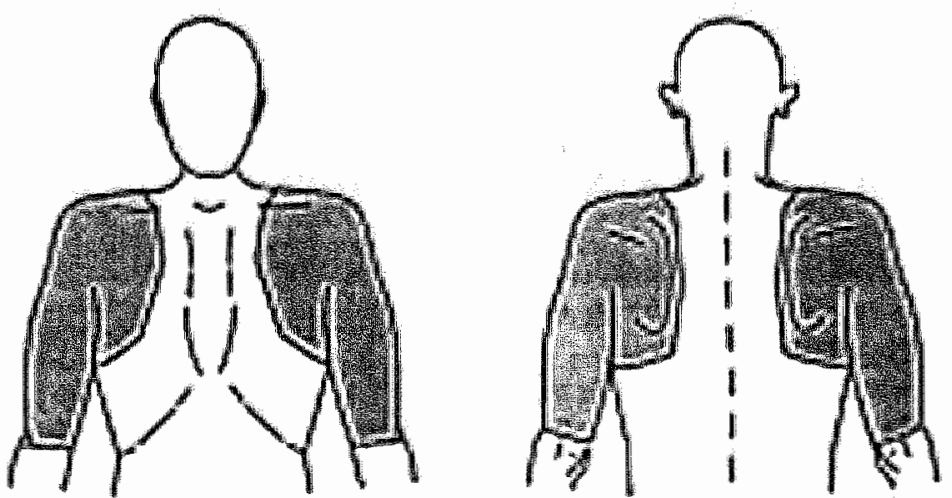

Exclusion criteria were: medical treatment for SC during the previous three months; complete rotator cuff tears; serious prior traumata, i.e., fractures or dislocations; prior surgery of the shoulder, upper limb, neck or thorax; osteoporosis; rheumatoid or bacterial arthritis; a tumour; referred pain from internal organs; a cervical radicular syndrome; gross shoulder hypermobility; stroke; polyneuropathy; multiple sclerosis; polymyalgia; ankylosing spondylitis; treatment for serious psychiatric disorders or inability to complete questionnaires in Dutch.

\section{Randomization and allocation}

Patients were pre-stratified at PT practice level. We used block randomization, with blocks of 10 patients, to allocate patients either to GET or to UC in each stratum. Concealed randomization. was based on a random number list generated by an experienced researcher who was not involved in the conduct of the study. Patients received prepared opaque sealed and coded randomization envelopes after the baseline measurements.

\section{Interventions}

Graded Exercise Therapy

GE $\mathrm{T}$ is a behavioural treatment programme characterized by graded activity, time contingency and operant conditioning. The primary aim of this exercise programme is to increase the patients ${ }^{*}$ ability to perform their own preferred shoulder activities in daily life at home or at work, irrespective of the pain experience. It does not aim to achieve pain relief at all. The programme's activities are related to specific shoulder functions such as reaching, supporting, pushing, pulling, hitting, and stabilizing, with work-related activities receiving special attention. 
The content of the GET programme has been described in detail elsewhere (Geraets et al 2004).

An important aim of GET is to increase levels of daily activity by learning from the consequences of behaviours, the so-called operant learning principle (Fordyce 1976, Skimner 1953). Pain behaviour is expected to be consolidated when patients experience the consequences of this behaviour as pleasant and to be extinguished when they experience the consequences as unpleasant. Positive reinforcement of the preferred behavioural changes is given to increase and maintain the desired behaviour. In graded activity, levels of activity increase in a step-wise time-contingent fashion, irrespective of pain experience. Goals are preset and agreed upon at the start of the programme. The GET programme consists of a maximum of 18 group sessions each lasting approximately 60 minutes, over a period of 12 weeks, administered. in groups of three to five persons. During the 'start-up period', the rationale is explained, and pain and pain-related disability are discussed. The "treatment plus generalization" period inwolves the performance of operant conditioning and time-contingent graded exercises. At the start of the programme, the frequency of sessions is three times a week, after which it giadually decreases to one session every two weeks. Generalization to everyday life is strongly emphasized at the end of this phase.

Prior to the start of the study, physiotherapists (PTs) participating in the GET group (two in each of the ten local practices) took part in a one-day workshop and two booster sessions under the supervision of experts in the field of cognitive-behavioural treatment.

\section{Usual Care}

Usual care was standardized according to the 1999 version of the guidelines for SC issued by the Dutch College of General Practitioners (DCGP)(Winters et al 1999). UC consisted of information, recommendations and pain-contingent medical or drug therapy. During the first two weeks following the initial GP consultation, a wait-and-see policy was followed. This policy was supplemented with analgesics or NSA.TDs if the GP thought this was necessary. The patient was instructed to re-consult the GP if complaints continued for more than two weeks. The GPS made the specific choice of treatment, like corticosteroid injections or referral to a PT or or thopedic surgeon. GPs participating in the UC group attended a refresher conrse on the application of the guidelines.

\section{Blinding}

Two research assistants who were not involved in the randomization procedure carried out the data collection of baseline characteristics and outcome measurements. Blinding of patients and health care providers (PTs and GPs) was not possible. Data entry and statistical analysis were carried out according to a pre-specified analysis plan and blinded for treatment allocation.

\section{Baseline and outcome assessment}

At baseline demographic variables, disease characteristics, and treatment preferences were documented (Table i). Before randomization and after 12 weeks of treatment continuous outcome variables were documented.

The primary outcome variable, the performance of the level of daily activities, was assessed using two different assessment instruments: the main complaints instrument (a measure for the performance of activities related to patient-specific complaints) and the Shoulder Disability Questionnaire (SDQ) (Heijden wan der et al 2000). In the first instrument, patients selected at baseline three daily activities they regarded as most important in relation 
to their $\mathrm{SC}$, but not necessarily related specifically to pain. They rated their ability to perform these activities during the past week on an ordinal (11-point) scale at baseline and during follow-up. The second instrument, the SDQ, is a functional status measure consisting of 16 statements regarding pain and limitations while performing common daily activities during the past 24 hours.

The secondary outcome measures we assessed were perceilved recovery, shoulder pain, generic health-related quality of life, catastrophizing, coping with pain, kinesiophobia and fear-avoidance beliefs. Perceived recovery was measured on an eight-point ordinal scale ( 0 fully recovered -7 very much deteriorated). Patients were regarded as recovered if they felt either fully recovered (0) or very much improved (1). Shoulder pain was scored on the Shoulder Pain Score (SPS) and pain intensity was measured on an 11-point ordinal scale (Winters et al 1996). Generic health-related quality of life was rated on the EQ5D (Brooks 1996). Catastrophizing and coping with pain were scored on subscales of the Pain Coping and Cognition List (PCCL) (Berg et al 2001). Kinesiophobia was assessed by two items (items 1 and 9) of the Tampa Scale for Kinesiophobia (TSK-DV))(Vlaeyen et al 1995). Fearavoidance beliefs were scored on the subscale of fear-avoidance beliefs about physical activity, adjusted for SC, of the Fear-Avoidance Beliefs Questionnaire (FABQ-DV) (Vendrig et al 1998).

\section{Statistical analyses}

All data were analysed according to the intention-to-treat principle. Analyses were carried out with SPSS statistical software (11.5 version). A p-value of $<0.05$ was considered to be statistically significant (two-tailed) for all comparisons.

The primary endpoints, i.e., the change in the performance of daily activities at 12 weeks as assessed by the main complaints instrument and the SDQ, were compared using the average change over time in both groups. For all cases, we calculated the highest score of three selected main complaints at baseline and differences at follow-up. If two or three of the main complaints were rated equally high at baseline, we calculated mean differences over time.

Differences between groups were calculated and analysed by means of Student's 'T-tests for all outcome variables measured on continuous scales and having a Gaussian data distribution, and by Mann-Whitney tests for non-Gaussian distributions. Average change for groups, mean differences between groups, and $95 \%$ confidence intervals of the differences were calculated. Chi-square tests were performed for ordinal and dichotomous outcome variables. Risk differences were calculated and presented for dichotomous outcome measures. Effect-sizes were calculated by taking the mean differences between groups and dividing it by the standard deviation of the average change of the total population. We considered effect-sizes of $0.2,0.5$, and 0.8 as small, medium and large beneficial effects respectively (Cohen 1977).

We used imputation of the overall mean for missing data if patients of whom data were missing and patients eligible for analyses were comparable at baseline, that is if all baseline means of missing cases were no more than half of a standard deviation away from the overall means for continuous outcome measures and no more than 5 percent for dichotomous outcome measures.

We considered the following variables as putative prognostic factors: function of the shoulder girdle as assessed by physical examination (passive range of external rotation, active range of abduction/elevation, and presence of painful arc), psychosocial variables (anxiety, depression, somatization, distress) (Four Dimensions of psychological Symptomatology Questionnaire (4DSQ)) (Terluin 1998), and treatment preferences. Using a stepwise forward 
procedure $(p<0.10)$ and the main complaint instrument and SDQ as outcome measures, the influence of these putative prognostic factors and post randomization differences between groups was evaluated by means of multiple linear regression analyses.

A change in shoulder pain intensity was considered a priori to be a modifier. We assumed that pain reduction over time might naturally result in increased performance of daily activities. Since the aim of GET is to increase performance of daily activities, irrespective of pain experience, we assumed that the programme might be more effective in patients not reporting pain reduction over time. Therefore, the influence of changes in pain intensity on performance of daily activities as a modifying factor was analysed. We defined subgroups based on pain reduction by more than one standard deviation away from baseline. We studied the effect of GET in these subgroups using multivariate linear regression for the main complaint instrument and for the SDQ. We also evaluated the interaction with treatment. Crude and adjusted regression coefficients and $95 \%$ confidence intervals are presented.

\section{RESULTS}

The GPs regarded 192 patients as eligible to participate in the study. Sixteen patients were excluded before randomisation (for reasons see figure 2), so 176 patients were randomized and allocated to either Graded Exercise Therapy (GET) (N=87) or usual care (UC) (N=89) (figure 2). Eighteen patients withdrew from the study during the treatment period. Six withdrawals had been allocated to GET (for reasons see figure 2), while 12 had been allocated to UC (for reasons see figure 2). Data for eight patients were missing at 1.2 weeks (2 GET and 6 UC).

Table 1 shows that at baseline, treatment groups were comparable on all continuous outcome measures. Patterns of treatment preferences were similar for both groups, although patients allocated to UC more frequently favored behavioural therapy and less frequently favoured manual therapy and drugs therapy (analgesics and NSAIDs). Patients allocated to UC scored slightly lower on the distress subscale of the 4DSQ and reported less frequent concomitant neck problems as well as more often a quick onset of their current complaints. Otherwise, prognostic status at baseline was comparable for both groups.

Patients who withdrew from the study during the treatment period $(N=18)$ or had missing data at 12 weeks $(\mathrm{N}=8)$ were more likely to report a quick onset and a shorter duration of complaints, and had fewer prior episodes of SC during the past year. In terms of treatment preferences, they less frequently favored manual therapy and more frequently favoured drug therapy and injection therapy. Patients who withdrew scored slightly higher on the somatization subscale of the 4DSQ. No difference on the baseline values of outcome measures was found.

Table 2 shows that patients allocated to GET improved more than patients allocated to UC as measured on both primary outcome measures. Differences between groups for improvement of the main complaints reached statistical significance $(p=0.049)$. Effect sizes for the main complaints instrument and the SDQ were calculated to be 0.30 and 0.07 respectively. Improvements on all secondary outcome measures favor GET, but only differences between groups for improvement of catastrophizing thoughts, reached statistical significance. Imputation did not alter these results.

Crude and adjusted analyses are presented in table 3. The between group difference for reduction of severity of the main complaint at 12 weeks post randomisation for patients receiving GET, was on average 7.5 points larger and statistically significant than for those 
Figure 2. How-chant

Excluded $\mathbb{N}=16$

- Referred pain 4

- Difficulties reading measurement scales 2

- Trauma 1

- Travelling problems 1

- Treatment preferences 2

- Not willing 4

- Private reasons 2
Eligible to participate according to $G P$ $N=192$

Two weeks after GP consultation:

Visit by research assistant Informed consent procedure

Baseline measurement

Prestratification / Randomization

$$
\mathrm{N}=176
$$

Graded Exercise Therapy

$$
\mathbb{N}=87
$$

Dropouts $N=6$

- Neck problems 1

- Private reasons 1.

- Frequency of sessions 1

- Treatment preterence 1

- No more time 1

- Not willing to participate 1

Post treatment ( 12 weeks) $\mathrm{N}=81$

$$
\text { Missing } \mathrm{N}=2
$$

Eligible for analysis $\mathrm{N}=79$
Usual Care

$N=89$

Dropouts $\mathrm{N}=12$

- Other medical reasons 1

- Moved to other region 1

- Treatment preference 3

- Not willing to participate 4

- Unknown 3

Post treatment (12 weeks) $N=77$

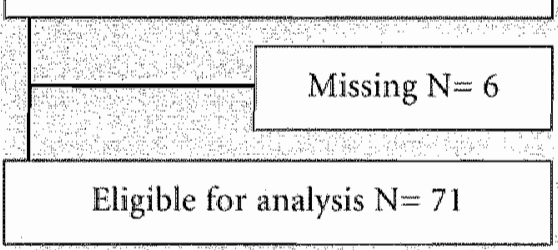

receiving UC (model 1.1). The between group difference for reduction in SDQ score at 12 weeks post randomisation, favored GET, but failed to reach statistically significance (model 2.1).

Pain intensity was unchanged in 132 patients, while pain reduction was seen in 44 patients. There was a significant relationship between reduction of the severity of the main complaint at 12 weeks on the one hand and pain reduction and depression scores at baseline on the other hand (model 1.2). After adjustments for pain reduction and depression score at baseline, the difference in reduction of severity of the main complaint between treatment groups was retained at the conventional level (7.5 versus 7.6). When analyzed according to strata, mean differences between treatment groups for reduction of severity of the main complaint were larger in patients reporting no change in pain over time (7.6) than in patient reporting pain reduction (1.6\%. 
Table 1. Basaline charactenistics

\begin{tabular}{|c|c|c|c|c|}
\hline 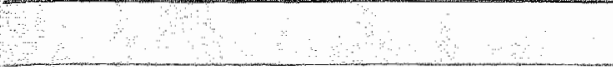 & $\mathrm{GET}$ & $\mathrm{TC}$ & $\begin{array}{l}\text { Eligible for } \\
\text { analysis }\end{array}$ & Mssing \\
\hline Number & 87 & 89 & 150 & 26 \\
\hline \multicolumn{5}{|l|}{ Demographic wartables } \\
\hline Ane (years) (sd) & $51.2(13.2)$ & $53.3(11.7)$ & $53.1(12.6)$ & $47.4(10)$ \\
\hline Female $1 \%$ & 51 & 58 & 34 & 58 \\
\hline \multicolumn{5}{|l|}{ Specific disease variables } \\
\hline Duration of shoulder pain $1>6$ months $)(0 \%)$ & 79 & 77 & 79 & 73 \\
\hline Sick leatwe (if paid employment in past 8 weeks ( 1 week $1 \%$ ) & 4 & 12 & 7 & 13 \\
\hline Quick onset $(\%)$ & 17 & 27 & 21 & 31 \\
\hline Concomitant neck problems (\%) & 54 & 40 & 47 & 50 \\
\hline \multicolumn{5}{|l|}{ Cause of complaints } \\
\hline - Sudden movement $(\%)$ & 6 & 7 & 6 & 8 \\
\hline - Overuse $(\%)$ & 25 & 26 & 25 & 27 \\
\hline - Slight trauma $(\%)$ & 3 & 5 & 3 & 9 \\
\hline - others $(\%)$ & 12 & 12 & 13 & 8 \\
\hline - Unknown $(\%)$ & 40 & 35 & 37 & 39 \\
\hline \multicolumn{5}{|l|}{ Prior episodes of $5 \mathrm{C}$} \\
\hline Episodies of at leas 1 week in past year $1>511 \%$ & 68 & 69 & 70 & 61 \\
\hline \multicolumn{5}{|l|}{ Treatment preferences (no, unclear, yes) $(\%)$ : } \\
\hline - Birhavioural therapy & $6 / 88 / 6$ & $12 / 73 / 15$ & $9 / 8: 110$ & $12 / 8018$ \\
\hline - Physiotherapy & $6: 38 / 56$ & $15 / 34 / 51$ & $11 / 36 / 53$ & $8 / 35 / 57$ \\
\hline - Manual Therapy & $7180 / 13$ & $21 / 59 / 20$ & $12 / 70 / 18$ & $25 / 63 / 12$ \\
\hline - Analgesics & $67 / 29 / 4$ & $79: 14 / 7$ & $76 / 19 / 5$ & $56 / 32 / 12$ \\
\hline - NSAIDS & $57 / 36 / 7$ & $74 / 20 / 6$ & $69 / 25 / 6$ & $46 / 42 / 12$ \\
\hline - Conticosteroid injection & $71126 \cdot 3$ & $75 / 21 / 3$ & $76 / 21 / 3$ & $58 / 38 / 4$ \\
\hline - Surgery & $76 / 22+2$ & $84 / 14 / 2$ & $81 / 17 / 2$ & $73 / 23 / 4$ \\
\hline \multicolumn{5}{|l|}{ Prognositic variables } \\
\hline - Passive range of motion exoratation $(<6,00)(\%)$ & 38 & 36 & 33 & 37 \\
\hline - Actiwe range of motion abductionielevation $(<1500)(\%)$ & 17 & 15 & 17 & 24 \\
\hline - Presence of painful arc $(\%)$ & 74 & 72 & 76 & 70 \\
\hline \multicolumn{5}{|l|}{ Psychosocial (4050) $(\%)$} \\
\hline - Distress (medium/high) & 32 & 18 & 26 & 19 \\
\hline - Anxiety (medium/highi² & 2 & 4 & 4 & 0 \\
\hline 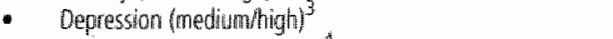 & 10 & 9 & 10 & 8 \\
\hline - Somatisation (mediumbigh) & 43 & 33 & 34 & 54 \\
\hline \multicolumn{5}{|l|}{ Outcome variables Mean (sd) } \\
\hline \multicolumn{5}{|l|}{ Peformance of daily activities: } \\
\hline - Severty of main complaints (0-100) & $76.2(19.2)$ & $71.9(19.6)$ & $74,3(19.2)$ & $72,3(212)$ \\
\hline - Functiondl limutations in daly activites $(500)(0-100)$ & $660(118.1)$ & $65.6(19.9)$ & $55.7(17.9)$ & $65.3(24.4)$ \\
\hline Shoutder parin (SPS) $(7-28)$ & $179(4,4)$ & $17.1(3.8)$ & $17.4(4.1)$ & $17.8(3.7)$ \\
\hline Pain intensity $(11$-point scale $)(0-10)$ & $5.6(2.2)$ & $5.4(1.8)$ & 5.42 .09 & $6.3(1.8)$ \\
\hline Quality of life $[\mathrm{EOSO}](-1$ to 1$)$ & $0.66(0.23)$ & $0.69(0.20)$ & $0.68(0.21)$ & $0.64(0.23)$ \\
\hline \multicolumn{5}{|l|}{ Process variables Mean (sd) } \\
\hline Kinesiophobla 2 items TSK $(1-7)$ & $2.8(1.9)$ & $2.8(2.0)$ & $29(1.9)$ & $2.2(1.8)$ \\
\hline Fear-Avoidance Beilets (5 items subscale FABQ) (1-7) & $4.3(1.3)$ & $4.5(1.3)$ & $4.5(1.3)$ & $4.2(1.4)$ \\
\hline Catastrophizing (12 items subscale $\mathrm{P}(\mathrm{CL})(1-6) 5$ & $2.4(0.8)$ & $2.3(0.8)$ & $2.4(0.8)$ & $23(0.9)$ \\
\hline Coping with Pain (11) items subscale PCCL)(1-6i)s & 3.01101 & $3.2(0.9)$ & 3.10 .99 & $3.2(0.9)$ \\
\hline Interna locus of contro (11 ittems subscale PCC) $(1-6) 5$ & $3.3(0.9)$ & $3.7(0.8)$ & $3.5(0.9)$ & $3.5(0.8)$ \\
\hline External locus of control 17 items subscale PCCL $(1-6) 5$ & $29(0.8)$ & $3.0(0.8)$ & 2.910 .90 & $2.9(0.8)$ \\
\hline
\end{tabular}

1 Distess: low $(0-10)$, medum $(11-20)$, high $(21-32)$

2 Anxiety: low $(0-7)$, medium $(8-12)$, high $(13-24)$

3 Depression: low $(0-2)$, medium $(3-5)$, high $(6-12)$

4 Somatisation: low $(0-90)$, medum $(11-20)$, high $(21-32)$

5 PCCL subscale scotes: very low $(1.0-1.9)$, low $(2.0-3.4)$, high $(3.5-5.0$, wery high $(5.1-6.0)$ 


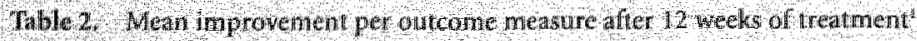

Primary outcome measures

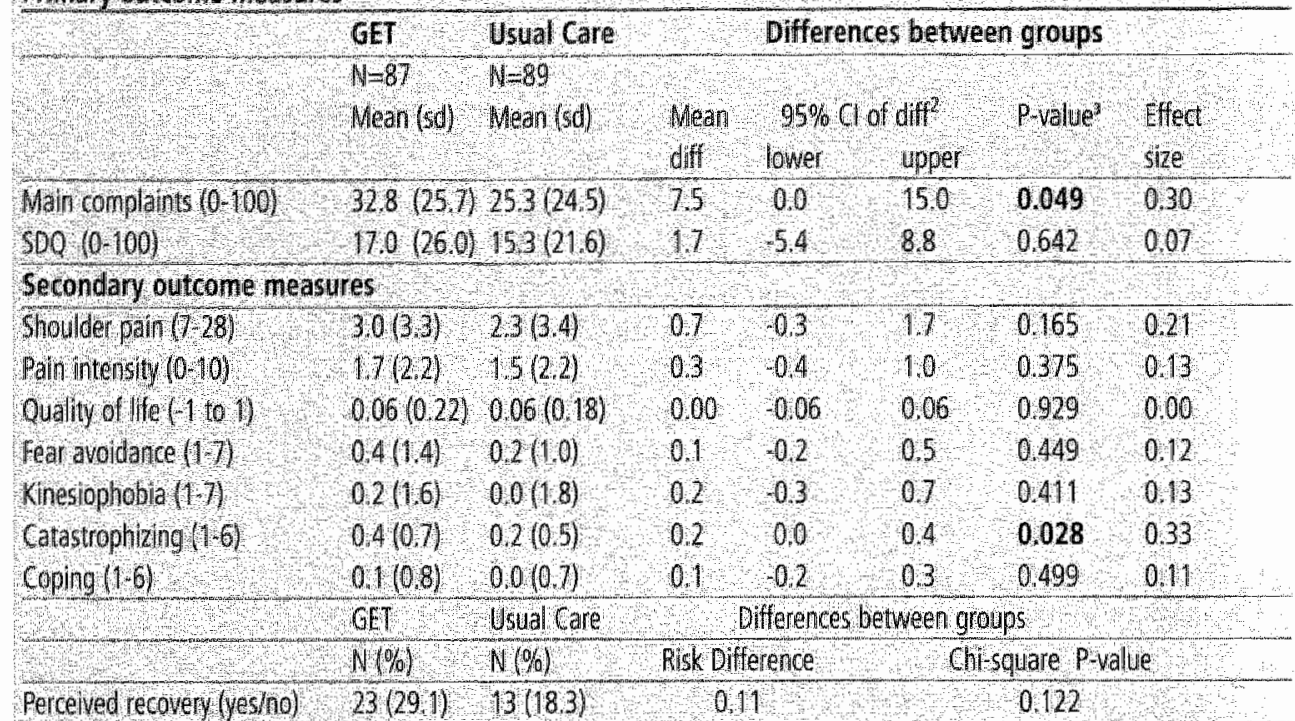

Atter impistation of the overall mean

$395 \%$ conidence interval of difference

Statisically signiticant $P<0.05$

There was a significant relationship between reduction in SDQ scores at 12 weeks on the one hand and pain reduction and presence of a painful arc at baseline on the other hand (model 2.2), and in addition for the interaction between GET * Painful arc (model 2.3). After adjustment for pain reduction, for presence of painful arc at baseline, and for the interaction between GET * Painful arc, the difference in reduction of severity of disability (SDQ) between treatment groups changed substantially (from 1.7 to 10.8). When analysed according to strata, mean differences between treatment groups for reduction of severity disability (SDQ) were smaller and favored UC in patients with a painful arc (-0.2) as compared with patients with no painful arc (7.3). These findings suggest that in terms of improvement of the SDQ scores GET was less effective in patients showing a painful arc at baseline.

\section{Discussron}

Our findings suggest that the operant behavioural Graded Exercise Therapy (GET) programme is more effective than usual care (UC) in restoring daily activities in patients with chronic shoulder complaints. However, only differences between groups for the main complaint instrument reached statistical significance and we consider the observed beneficial effects to be small.

Performance of daily activities was measured by two outcome measures (main complaints instrument and SDQ). Patients allocated to GET improved more on both measures than those allocated to $U C_{x}$ although differences between the groups were only statistically significant for 
Table 3. Crude and adjusted analysis of primary outome measures

\begin{tabular}{|c|c|c|c|c|c|c|c|}
\hline & Variables & $\mathrm{B}^{\mathrm{Z}}$ & $\mathrm{B}^{3}$ & $B^{4}$ & $95 \% \mathrm{Cl}$ & ference & P-value \\
\hline 8 & & & & & lower & upper & \\
\hline Main comp & laints," mean differences betwe & en gro & $100)$ & & $\mathrm{a}$ & & \\
\hline Model 1.1 & GET & 7.5 & & & 0.0 & 15.0 & 0.049 \\
\hline & $(G E T=1 ; U C=0)$ & & & & & & \\
\hline Model 1.2 & $\mathrm{GET}$ & & 7.6 & & 0.9 & 14.3 & 0.026 \\
\hline & $(G E T=1 ; U C=0)$ & & & & & & \\
\hline & $\begin{array}{l}\text { Change in pain intensity } \\
\text { (changed }=1 \text {; unchanged }=0 \text { ) }\end{array}$ & & 26.8 & & 19.3 & 34.4 & 0.000 \\
\hline & $\begin{array}{l}\text { Depression } \\
\text { (medium/imigh =1; low = o) }\end{array}$ & & 8.3 & & 0.1 & 16.6 & 0.048 \\
\hline SDQ: mean & differences between groups to & $100)$ & & & & ? & \\
\hline Model 2.1 & $\begin{array}{l}\text { GET } \\
(\mathrm{GET}=1 ; U C=0)\end{array}$ & 1.7 & & & -5.4 & 8.8 & 0.642 \\
\hline Model 2.2 & $\begin{array}{l}G E T \\
\left(G E T=\eta_{;} U C=0\right)\end{array}$ & & 0.6 & & -5.6 & 6.9 & 0.840 \\
\hline & $\begin{array}{l}\text { Change in pain intensity } \\
\text { (changed =1; unchanged }=0 \text { ) }\end{array}$ & & 23.6 & & 16.3 & 30.8 & 0.000 \\
\hline & $\begin{array}{l}\text { Painful arc } \\
\text { (present=1; absent }=0)\end{array}$ & & 10.3 & & -174 & -3.3 & 0.004 \\
\hline Madel 2.3 & $\begin{array}{l}\text { GET } \\
(G E T=1 ; U C=0)\end{array}$ & & & 10.8 & -1.2 & 22.7 & 0.077 \\
\hline & $\begin{array}{l}\text { Change in pain intensity } \\
\text { (changed }=1 ; \text { unchanged }=0 \text { ) }\end{array}$ & & & 24.6 & 17.3 & 31.8 & 0.000 \\
\hline & $\begin{array}{l}\text { Painful arc } \\
\text { (present=1; absent }=0 \text { ) }\end{array}$ & & & -3.5 & .133 & 63 & 0.486 \\
\hline & $\begin{array}{l}\text { GET * Painful arc } \\
(\text { GET }=1 ; U C=0) \\
\text { (present }=1 ; \text { absent }=0)\end{array}$ & & & $-14,0$ & .28 .1 & 0.1 & 0.05 \\
\hline
\end{tabular}

After imputation of the overall mean

"Regression coefficient model adjusted only for GET

${ }^{3}$ Regression coefficient model adjusted for depression and presence of painful arc at baseline and for change in pain infensity.

- Regression coefficient model adjusted for presence of painful arc at baseline, interaction between GET and presence of painful arc at baseline and for change in pain intensity.

changes in performance of activities related to patients' main complaints. 'The SDQ is an instrument to assess activities in terms of functional limitations related to pain. Given the aim of the GET programme, which is not primarily to reduce pain intensity, SDQ changes might be expected to be less obvious. Nevertheless, patients allocated to GET showed greater changes in shoulder pain than those allocated to UC. Shoulder pain reduction was considered a priori to be a modifying factor. Mean differences between groups as assessed by the main complaints instrument were higher in patients not reporting pain reduction. GET was more effective in restoring 
performance of daily activities as assesses by the SDQ in patients not reporting a painful arc. For clinical practitioners like GPs and PTs, these results mean that GET seems to be particularly effective in improving the performance of daily activities among patients who eventually show little reduction of pain intensity. GET seems less effective in patients who report a painful arc during physical examination. However, since only 44 participants (26\%) reported pain reduction post treatment, and since a painful arc was absent in only 48 patients ( $28 \%$ ), these outcomes need to be interpreted with caution. We suggest that these factors should be evaluated in greater detail in further studies.

GET is a behavioural treatment and not a cognitive behavioural treatment. Nevertheless, data show that GET had positive effects on all psychological outcome measures. The positive effect on catastrophizing thoughts was even statistically significant ( $\mathrm{p}=0.028$ ).

Thirty-six patients (23 GET versus 13 UC) reported recovery post treatment (full recovery or very much improved). Differences between groups in perceived recovery rates were $11 \%$ and not statistically significant $(\mathrm{p}=0.122)$. But even though patients did not perceive themselves as recovered, performance of daily activities improved. These results implicate that patients allocated to GET consider their ability to perform daily activities at home or at work less frequently dependent of perceived recovery or pain experience.

As patients were only excluded from the trial on the basis of systemic diseases, referred pain or severe biomedical or psychiatric disorders, we regard our study population as fairly representative of persons with SC in the general practice population.

Treatment groups were comparable with respect to outcome measures at baseline. Blinding of patients and health care providers (PTs and GPs) for the nature of allocated treatment was not possible. However, although treatment preferences could therefore introduce bias these were found to have no influence on outcome measures after 12 weeks of treatment. Blinding could explain the differential rates for dropouts and loss to follow-up. Eighteen patients $(10.2 \%)$ withdrew from the study, and data for eight patients ( $4.5 \%$ ) were missing for post-treatment analysis. Although more withdrawals had been allocated to UC (12 UC versus $6 \mathrm{GET})$, the numbers of patients who withdrew because of the content of the interventions (frequency of treatment sessions and treatment preferences) were small and similar for both groups ( 3 UC versus 2 GET).

Since patients who withdrew from the study during treatment period $(N=18)$ or had missing data at 12 weeks $(\mathrm{N}=8)$, had a shorter duration of complaints and had fewer prior episodes of $\mathrm{SC}$ during the past year, the prognostic status at baseline of these patients was probably slightly better compared to patients available for analysis (Windt van der et al 1996). Because the numbers of withdrawals per group were not equally balanced, we applied imputation of the overall mean for missing data. However, imputation of missing outcome data did not alter the results of this study.

This study confirms the hypothesis that behavioural factors play a role in the course of SC, which is comparable to that in other non-specific musculoskeletal pain disorders (Linton 1995, Vlaeyen and Linton 2000). Further evaluation of long-term effectiveness and costeffectiveness is needed before implementation of GET can be recommended.

Our overall conclusion is that GET seems to be more effective than UC in restoring the performance of daily activities in patients with chronic $\mathrm{SC}$, although beneficial effects are small. Mean improvements for the mean complaints instrument were larger in patients not reporting pain reduction. GET has a favourable effect on catastrophizing thoughts among patients with chronic SC. GET seems to be less effective in patients showing a painful arc during physical examination. 


\section{REFERENCES}

Andersson HI. The course of non-malignant chronic pain: 12 year follow-up of a cohor from the genetal population. Eur I Pain. 2004;8: 47-53.

Berg SGM van den, Vlaeven WWS, Kuil MM ter, Spinhoven Ph, Breukelen $G$ van and Kole-snijders AMJ. Meetinstrumenten chronische pijn deel 2. Pijn Coping en Cognitie Lijst. Maastricht Pijn Kenmis Centrum. 2001.

Brooks R. EuroQol: The current state of play. Health Policy. 1996;37:53-72.

Cohen 1. Statistical power analysis for the behaworal sciences. London: Academic press Inc.1977.

Fordyce WE. Behaviorat methods for chronic pain and ilness. Saint Louis: CV Mosby Company. 1976.

Fordyce WE, Brockway J, Bergman J and Spengler D. A control group comparison of behawioural versus traditional management methods in acute low back pain. I Behav Med. 1986; 2:127-140.

Geraets JXXR, Goossens EIB, Bruign CPC de, Köke AJA, Bie RA de, Pelt RAGB, Heuvel W/A van den, Heijden GIMG van der. A behivioural treatment for chronic shoulder complaints: concepts, development, and study design. Aust I Physiother. 2004;50:33-38.

Guzmán J, Esmail R, Karjalainen K, Irvin E, Bombadier C. Multidisciplinary rehabilitation for chronic low back pain: systematic review. Br Med ] 2001:322:511-516.

Heijden GIMG wan der. Shoulder disorders: A state-of-the-art review. Bailliere's Clin Rheumatol. 1999;13: $287-309$.

Heijden GMG van der, Leffers $P$ and Bouter LM. Shoulder Disability Questionnaire design and responsiveness of a functional status measure. I Clin Epidemiol. 2000;53: 29-38.

Kuipers T, Windt van der DA, Heijden GMG van det, Bouter LM. Systenatic review of prognastic cohort studies on shoulder disonders. Pain. 2004:109:420-431

Lindstrom I, Oblund $\mathrm{C}$. Eek $\mathrm{C}$, Wallin L, Peterson LE, Fordyce WE and Nachemson AL. The effect of graded activity on patients with subacute low back pain: A randomised prospective clinical study with an operant conditioning behavioural approach. Phys Ther. 1992,72: 279-290.

Linton S. An overview of psychosocial and behavional factors in neck-and-shouder pain. Scand / Rehabil Med. 1995;32:67,77.

Linton SI. Prevention with special reference to chronic musculosketetal disorders. In Gatchel RI and Turk DC (Eds): Psychosocial Factors In Pain. New York: Guilford Publications, pp. 374-389.1999.

Morley S, Ecleston C and Williams A. Systematic review and meta-andysis of randomized controlled trials of cognitive behawiour therapy and behaviour therapy for chronic pain in adults, excluding headache. Pain. $1999 ; 88: 1-13$. 
Picuver HSJ and Schouten ISAG (2003): Musculoskeletal pain in the Netherlands: prevalences, consequences and risk yroups, the DMC (3) - study. Pain. 2003;102: 167-178.

Skinner B. Science and Human Behavior. New York: Macnollan. 1953.

Tequin S. De Vicrdimensionale Klachtenliyst (4DKL) in de buisartspraktijk. De Psycholoog.1998;18-24.

Tulder MW van, Ostelo RWJG, Vlaeyen JWS, Linton SI, Morley SI and Assendelfe WIJ (2001): Behavioral treatment for chronic low back pain. A systematic review within the framework of the Cochrane Back Review Group. Spine. 2001:26:270-281.

Vendrig $A$, Deutz $P$, et all. Nederlandse vertaling en bewerking van de Fear-Avoidance Beliefs Questionnaire. Nederlands Tijdschrift voor Pijn en Pijnbestrijding. 1998;18: 11-14.

Vlaeyen JWS and Linton SI. Fear Avoidance and its conseguences in chronic musculoskeletal pain: A state of the art Pain. 2000:85: 317-332.

Windt DA yan der, Koes BW, Boeke AI, Deville W, Jong BA de and Bouter LM. Shoulder disorders in general practice: prognostic indicators of outcome. Br J Gen Pract 1996* 46:519-523.

Winters IC, Sobel IS, Groenier KKH, Arendzen JH and Meyboom-de Jong B. A Shoulder Pain Score: A comprehensive questionnaire for assessing pain in patients with shoulder complaints. Scand I Rehabil Med.1.996;28:163-167.

Winters JC, Jongh AC de, Windt DAWM van der, Jonquiere M, Winter AF de, Heijden GIMG van der, Sobel IS and Gotidswaard AN. NHG-Standaard Schouderklachten. Huisarts en Wetenschap 1999;42:222-231. 



\section{ChAPTER 4}

\section{Long-term effectiveness}

Submitted (revised version) as

Long-term effectiveness of a graded exercise therapy programme for patients with chronic shoulder complaints. Geraets JJXR, Goossens MEJB, de Groot JJM, de Bruijn CPC, de Bie RA, Dinant GJ, van den Heuvel WJA, van der Heijden GIMG. 


\section{ABSTRACT}

Objective: The long-term effectiveness of a behavioural Graded Exercise Therapy (GET) programme in restoring performance of daily activities, compared with usual care (UC), in patients with chronic shoulder complaints in a primary care setting was assessed in a randomised clinical trial.

Methods: Primary outcome measures (main complaint, shoulder disability) and secondary outcome measures (perceived recovery, shoulder pain, generic health-related quality of life, catastrophising, coping with pain, internal locus of control, external locus of control, kinesophobia and fear-avoidance beliefs) were assessed before and directly after 12 weeks of treatment and during follow-up at 26 and 52 weeks.

Results: GET patients $(\mathrm{N}=87)$ showed statistically significantly greater improvement than UC patients ( $\mathrm{N}=89$ ) on the main complaint instrument directly after 12 weeks of treatment $(\mathrm{P}=0.049$, $95 \% \mathrm{Cl}: 0.0,15.0)$ and these improvements lasted for at least 52 weeks $(\mathrm{P}=0.025,95 \% \mathrm{Cl}: 1.2$, 17.3). GET was equally effective as UC in patients with a painful arc during physical examination and more effective in patients with no pain reduction during the treatment period. Significantly greater improvements with GET were found for catastrophising at 12 weeks ( $\mathrm{P}=0.028,95 \% \mathrm{CI}$ : $0.0,0.4)$ and for fear avoidance beliefs $(\mathrm{P}=0.043,95 \% \mathrm{Cl}: 0.0,0.8)$ and kinesophobia ( $\mathrm{P}=0.003$, $95 \% \mathrm{Cl}: 0.3,1.3$ ) at 52 weeks. Calculated effect sizes were rather modest (up to 0.45 ).

Conclusions: The effectiveness of GET compared with UC in restoring daily activities in patients with chronic SC, as assessed directly after treatment, persists in the long term (at least 52 weeks), although clinical benefits are rather modest.

Key words: Shoulder complaints, behavioural therapy, randomised clinical trial. 


\section{INTRODUCTION}

Shoulder complaints (SC) have a tendency to last for prolonged periods of time or to recur (Luime et all 2004a). Earlier studies on the long-term course of SC in primary care in the Netherlands have shown that approximately $50 \%$ of all patients who visit their general practitioner (GP) with a new episode have complaints lasting up to 6 months (Windt van der et al 1996, Winters et al 1997, Kuipers et al 2004) and about $40 \%$ still have complaints after 12 months (Winters et al 1999a). Forty-six percent of all patients with a new episode of conplaints recall a previous history of SC (Windt van der et al 1996). Recurrence rates for SC subsequent to complaints during the preceding year in a Dutch population of employed persons were estimated at $31 \%$ and $66 \%$ after 12 and 24 months respectively (Luime et al $2004 \mathrm{~b}$ ). Thus, chronic and recurrent SC are a major health problem. Nor is this problem unique to the Netherlands. Fifty-four percent of patients with SC in an open British population still reported shoulder pain after three years of follow-up (Macfarlane et al 1998) and $85 \%$ of patients with initial chronic shoulder pain in the general Swedish population still reported pain after 12 years (Andersson 2004).

Because SC can have considerable impact on daily life and often develop into a chronic disorder, it is important to optimise treatment in primary care. We hypothesised that - just as with other non-specific musculoskeletal pain disorders - biological, psychological and social factors would affect the course of SC (Linton 1995). The effectiveness of behavioural treatment in patients with chronic musculoskeletal pain has been documented in several studies (Fordyce et al 1986, Lindstrom et al 1992, Linton 1999, Morley et al 1999, Vlaeyen and Linton 2000, Guzmán et al 2001, Tulder et al 2001). However, most of these studies involved patients with chronic low back pain, and were conducted in secondary or multidisciplinary settings. There is limited evidence for operant-behavioural treatment (graded activity) on return to work and reduced sick-leave in low back pain patients (Stal et al 2004, Ostelo et al 2005, Jensen et al 2005). There is also limited evidence that there is no difference between behavioural treatments and exercise therapy in low back pain patients (Ostelo et al 2005). We have developed a behavioural Graded Exercise Therapy (GET) programme, to be administered by physiotherapists, which aims to improve functional ability and promote healthy behaviour and the long-term course in patients with chronic SC in a primary care setting. We have previously described the theory and conceptual model underlying this GET programme and presented the design of our study (Geraets et al 2004). We have also reported on the shortterm clinical effectiveness of GET after 12 weeks of treatment (Geraets et al 2005): GET seemed to be more effective in restoring the performance of daily activities in patients with chronic SC after 12 weeks of treatment than usual care (UC). The question that remained was whether this favourable effect of GET would last. We therefore studied the long-term effectiveness of GET after 26 and 52 weeks in patients with chronic SC.

\section{Methods}

\section{Design}

The objective of this randomised study was to see whether GET was more effective than UC in terms of restoring the performance of daily activities in patients with chronic SC in the long term (26 and 52 weeks after the start of the treatment). GET was administered by 20 physiotherapists (PTs), whereas UC was administered by 32 general practitioners (GPS). With 
$25 \%$ and $50 \%$ recovered patients in the usual care and GET groups, respectively, at 26 weeks follow-up, we would need 132 patients ( 66 in each intervention group) to reach statistical significance ( 2 -sided alpha of 0.05 , statistical power ( 1 -beta) of 0.90 , and $10 \%$ non-differential dropout rate). The study was approved by the iRv/SRL's Medical Ethics Committee.

\section{Recruitment and allocation of patients}

Patients who were at least 18 years of age, had suffered from SC for at least three months and were living in the Province of Limburg, the Netherlands, were invited to participate in the study between January 2002 and July 2003. Patients were recruited either by their GP during consultation for $\mathrm{SC}$, or via advertisements in local papers. All potential participants received written information and consulted their GP, who checked their eligibility according to the criteria listed below. Within two weeks after the consultation with the GP, a research assistant visited the patients at home for intake and baseline assessment. Eligible patients were asked to give written informed consent.

Exclusion criteria were: medical treatment for SC during the previous three months; complete rotator cuff tears; serious prior traumata of the shoulder girdle, e.g. fractures or dislocations; prior surgery of the shoulder, upper limb, neck or thorax; osteoporosis; rheumatoid or bacterial arthritis; a tumour; referred pain from internal organs; a cervical radicular syndrome; gross shoulder hypermobility; stroke; polyneuropathy; multiple sclerosis; polymyalgia; ankylosing spondylitis; treatment for serious psychiatric disorders; and inability to complete questionnaires in Dutch.

\section{Physiotherapists and general practitioners}

Prior to the start of the study, physiotherapists (PTs) participating in the GET group (two in each of the 10 local practices) took part in a one-day workshop and two booster sessions under the supervision of experts in the field of cognitive-behavioural treatment. GPs participating in the UC group followed a refresher course on using the 1.999 guidelines for $5 \mathrm{C}$ of the Dutch College of General Practitioners (DCGP).

\section{Randomisation and allocation}

We used blocked randomisation, with blocks of 10 patients, to allocate patients either to GET or to UC. Concealed randomisation was based on a random number list generated by a researcher who was not involved in the conduct of the study. Patients received prepared opaque sealed and coded randomisation envelopes after the baseline measurements.

\section{Interventions}

Graded Exercise Therapy

GET is a behavioural treatment programme based on the principles of graded activity, operant conditioning and time-contingency. The programme attempts to improve the performance of daily activities, irrespective of pain experience, and to promote healthy behavtour e.g. to reduce utilisation of health care services and relevant non-health care services, in patients with chronic shoulder complaints. In graded activity, levels of activity increase in a step-wise time-contingent fashion. An important aim of GET is to increase levels of daily activity by learning from the consequences of pain behaviours, the so-called operant learning principles (Skinmer 1953, Fordyce 1976). Pain and pain behaviour are assumed dependent on consequence-controlled learning. Pain behaviour is expected on the 
one hand to consolidate when patients experience the consequences of this behaviour as pleasant and on the other hand to extinguish when they experience these as unpleasant. To promote and maintain the desired behaviour, PTs used graphs as an instrument to reinforce patient's behaviour and to discuss and evaluate the steps that have been achieved.

Table 1. Man elements of the Graded Exercise Therapy programme

\section{Start-up period (approximately 6 sessions over a 2 week period)}

- Rationale: Prior to the start of the programnie patients receive a shont brochure explaining the rationale behind it

- Reconceptualisation: Pain and pain-related disability are revewed to ensure that patlents are convinced hey are able to control and influence their pain experience and improve levels of activity

- Goal-setting, Treatinent goals are set, gelated to the patient's own preferred daily activities:

\section{Treatment plus generalisation period (approximately 12 sessions over a 10 week period)}

- Graded Activity Levels of activity are increased in a step-wise fashion.

- Time contingency Levels of activity are structured in time and not according to pain experience

- Operant conditioning, Environmental reinforcement is used to promote and improve healthy behaviour.

- Generalisation: What has been leamed is applied to everyday life:

The main elements of the GET programme are listed in table 1. GET consists of a maximum of 18 group sessions of approximately 60 minutes over a period of 12 weeks, administered in small groups of three to five persons. At the start of the programme, the rationale is explained, pain and pain-related disability are discussed and goals are set and agreed upon. The 'treatment plus generalisation' period involves the performance of operant conditioning and time-contingent graded exercises. Initially, the frequency of sessions is fixed at three times a week, after which it gradually decreases to one session every two weeks. During the last phase of the treatment, generalisation to everyday life is strongly emphasised. The GET programme has been described in detail elsewhere (Geraets et al 2004).

\section{Usual Care}

Usual care was standardised according to the 1999 version of the guidelines for SC issued by the Dutch College of General Practitioners and consists of information, recommendations and pain-contingent medical or drug therapy (Winters et al 1999b; see also http://nhg.artsennet.n]/upload/104/guidelines2/E08.htm). During the first two weeks following the initial consultation with the G., a wait-and-see policy is followed, supplemented with analgesics or NSAIDs if the GP thinks this necessary. Patients are instructed to re-consult their GP if complaints continue for more than two weeks. The GP makes the specific choice of treatment, like corticosteroid injections or referral to the PT or orthopaedic surgeon.

\section{Blinding}

Two research assistants who were not involved in the randomisation procedure collected data on baseline characteristics and outcome measurements. Patients and health care providers (PTs and GPs) could not be blinded. Data entry and statistical analysis were carried out according to a pre-specified analysis plan and blinded for treatment allocation. 
Palde 2* Waseline doracteristics

\begin{tabular}{|c|c|c|}
\hline to & GET. & Usuall Care \\
\hline $8-3-3-3-3$ & 87 & 89 \\
\hline \multicolumn{3}{|l|}{ Demographic variables } \\
\hline Ane yerars) (sd) & $512(13.15)$ & $53.3(11.69)$ \\
\hline herrelg $(\%)$ & 506 & 584 \\
\hline \multicolumn{3}{|l|}{ Sperific disease variables } \\
\hline \multicolumn{3}{|l|}{ Present episode of $5 \mathrm{c}$} \\
\hline Duration of shoulder felln $(36$ monihs $)(\%)$ & 79 & 77 \\
\hline Dufalon of linitation of daily actunt as in past year ( $>1$ month) (of) & 15 & 24 \\
\hline 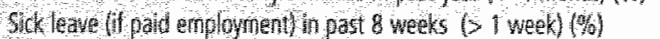 & 4 & 12 \\
\hline Guldonet (o) & 17 & $2 ?$ \\
\hline concomtant reck protalems $(\%)$ & 54 & 40 \\
\hline \multicolumn{3}{|l|}{ Cause of complants } \\
\hline 4 sudden movement $(\%)$ & 6 & 7 \\
\hline - oweruse $(\%)$ & 25 & 26 \\
\hline - Hatuma $(\%)$ & 3 & 5 \\
\hline * others $1 \%)$ & 12 & 12 \\
\hline - unknown $(\%)$ & 40 & 35 \\
\hline \multicolumn{3}{|l|}{ Pion episodes of $\mathrm{SC}$} \\
\hline - Episodes of at least I week un past year (p.5) (\%) & 68 & 69 \\
\hline \multicolumn{3}{|l|}{ Treatment preferences (na, unclear; yes) (\%): } \\
\hline - Behawoural therapy & $6 / 88: 6$ & $12 / 73 / 15$ \\
\hline * Ploysiotherapy & $6 / 38 / 56$ & $15 / 34 / 51$ \\
\hline - Manual Therapy & $7 / 80 / 13$ & $21 / 59 / 20$ \\
\hline - Analgesics & $67 / 29 / 4$ & $79 / 14 / 7$ \\
\hline$\because$ NSAIDS & $57 / 36 / 7$ & $74 / 20 / 6$ \\
\hline - Corticosteroid injection & $71 / 26 / 3$ & $75 / 21 / 3$ \\
\hline : Surgery & $76 / 22 / 2$ & $84 / 14 / 2$ \\
\hline \multicolumn{3}{|l|}{ Prognostic variables } \\
\hline \multicolumn{3}{|l|}{ function of shoulder girdle } \\
\hline - Passve range of motion exoretation $(<600)(\%)$ & 38 & 36 \\
\hline - Active range of motion abduction/elevation $(<1500)(\%)$ & 17 & 15 \\
\hline - Presence of painful arc $(\%)$ & 74 & 72 \\
\hline \multicolumn{3}{|l|}{ Psichosociall $(4050)(\%)$} \\
\hline - Distress (mediun/hightit & 32 & 18 \\
\hline - Anxiety (mediumhigh) & 2 & $4:$ \\
\hline - Depression (mediundighte & 10 & 9 \\
\hline - Somatisation (mediunthigh) & 43 & 33 \\
\hline \multicolumn{3}{|l|}{ Outcome variables Mean (sd) } \\
\hline \multicolumn{3}{|l|}{ Pertorimance of daily arthwites: } \\
\hline - Severity of main condalants $(0-100)$ & $76.2(19.18)$ & $71.9(196)$ \\
\hline - Functónal linitutons in daily activities $(500)(0-100)$ & $06,0(18.06)$ & $65.6(49.86)$ \\
\hline Stuculder pain $(S P S)(7-28)$ & $17.9(4.43)$ & $17.13 .77)$ \\
\hline P唃intersity $(11$-joint scale) $(0-10)$ & $5.6(2.19)$ & $5.4(1.77)$ \\
\hline Qualuy of life $(\mathrm{EQSO})(-1$ to 1$)$ & $0.66(0.234)$ & $0.69(0.198)$ \\
\hline \multicolumn{3}{|l|}{ Process variables Mean (sod) } \\
\hline Kinesiopholia (2 Iems TSK $)(1-7)$ & $2.8(1.91)$ & $2.8(1.95)$ \\
\hline 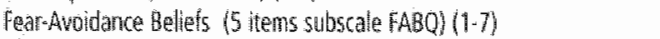 & $4.3(1.25)$ & $4.5(1.32)$ \\
\hline Catastrophising $(12$ irems rubsale $\mathrm{PCC})(1-6)^{\mathrm{e}}$ & $2.4(0.84)$ & $2.3(0.79)$ \\
\hline Coping whth Pain (11 items subsale PCCL) (1.6) & $3.0(0.96)$ & $3.2(0.89)$ \\
\hline In hemal locus of control 111 inems subscale PCCY $(1-6)^{\mathrm{e}}$ & $3.3(0.94)$ & $3.7(0.83)$ \\
\hline Frtena locus of conirol ( 7 tems subscale $P(C)(1-6)^{e}$ & $29(0.84)$ & $3.0(0.84)$ \\
\hline
\end{tabular}

\footnotetext{
* Distiess: low $(0-10)$, nedion $411-20)$, high $(21-32)$

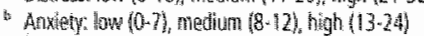

* Depressioni: lowi $(0-2)$, mediun $(3-5)$, high $(6-12)$

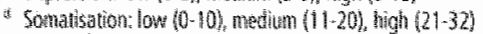

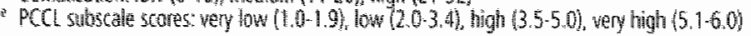




\section{Baseline and outcome assessment}

Demographic variables, disease characteristics and treatment preferences were recorded at baseline (Table 2). Continuous outcome variables were recorded before randomisation, after 12 weeks of treatment and at 26 and 52 weeks of follow-up.

The primary outcome variable, i.e. the level of daily activities, was assessed using 2 different instruments: the 'main complaints' instrument, which is a clinically relevant and responsive measure for the performance of activities related to patient-specific complaints, and the Shoulder Disability Questionnaire (SDQ), which is a disease specific measure considered reliable and responsive (Beurskens et al 1999, Windt van der et al 1998, Heijden van der et al 2000). In the 'main complaints' instrument, patients selected at baseline the three most important daily activities that were affected by their SC, which were not necessarily related specifically to pain. They rated their ability to perform these activities during the past week on an ordinal (eleven-point) scale at baseline and during follow-up. The SDQ is a functional status measure consisting of 16 dichotomous items on pain and limitations experienced while performing daily activities during the past 24 hours (e.g. My shoulder is painful when I lie on it).

Secondary outcome measures were perceived recovery, shoulder pain, generic healthrelated quality of life, catastrophising, coping with pain, internal locus of control, external locus of control, kinesiophobia and fear-avoidance beliefs. Perceived recovery was measured on an eight-point ordinal scale $(0=$ fully recovered; $7=$ very much deteriorated $)$. Patients were regarded as recovered if they felt either fully recovered $(0)$ or very much improved (1). Shoulder pain was scored on the Shoulder Pain Score list (SPS) which is considered valid and pain intensity was measured on an eleven-point ordinal scale (Winters et al 1996). Generic healthrelated quality of life was rated on the EQ5D which appeared to be sufficiently valid, reliable and responsive to change (Brooks 1996, Hurst et al 1997). Catastrophising, coping with pain, internal locus of control and external locus of control were scored on subscales of the Pain Coping and Cognition List reported to be sufficiently valid and reliable (PCCL) (Berg et al 2001). Kinesiophobia was assessed by two items (items 1 and 9) of the Tampa Scale for Kinesiophobia (TSK-DV)) (Vlaeyen et al 1995). Fear-avoidance beliefs were scored on the subscale of fear-avoidance beliefs about physical activity of the Fear-Avoidance Beliefs Questionnaire (FABQ-DV), adjusted for SC (Vendrig et al 1998). The test-retest reproducibility and internal consistency of the FABQ have appeared to be satisfactory (Waddell et al 1993).

Furthermore, utilisation of direct health care services and relevant non-health care services during the 52 weeks follow-up period (GET and UC during the 12 weeks treatment period excluded) was documented. Utilisation of direct health care services included the number of visits to general practitioners, physiotherapists, manual therapists, Cesar/ Mensendieck exercise therapists, physicians and/or alternative therapists and the number of prescriptions for medication after the treatment period. Utilisation of non-health care services included the number of hours of professional home care, of paid housekeeping, and of unpaid help from relatives or friends and the number of expenses for health-related activities (e.g. fitness training) and other out-of-pocket expenses (e.g. non-prescribed medication).

\section{Statistical analyses}

Data were analysed with SPSS statistical software, version 12.0.1 (SPSS, Inc. Houston, Texas), according to the intention-to-treat principle. A p-value of $<0.05$ was considered to be statistically significant (two-tailed) for all comparisons. 
The primary endpoints, i.e, change in the performance of daily activities at 12,26 and 52 weeks as assessed by the main complaint and the SDQ, were compared using the mean change over time in both groups. For all cases, we calculated the highest score of the three selected main complaints at baseline and the differences between baseline and follow-up. If two or three main complaints had been rated equally high at baseline we calculated mean differences over time.

Differences between groups were calculated and analysed by means of Student's t-tests for all outcome variables measured on continuous scales and having a Gaussian data distribution, and by Mann-Whitney tests for non-Gaussian distributions. Average change for groups, mean differences between groups and $95 \%$ confidence intervals of the differences were calculated. Chi-square tests were used for ordinal and dichotomous outcome variables. Risk differences and $95 \%$ confidence intervals were calculated and presented for dichotomous outcome measures. Effect sizes were calculated by taking the mean differences between groups and dividing them by the standard deviation of the average change for the total population. We regarded effect sizes of $0.2,0.5$ and 0.8 as small, medium and large beneficial effects, respectively (Cohen 1977).

We used unconditional imputation of the overall mean for missing data if patients whose data were missing and patients eligible for analysis were comparable at baseline, that is, if differences were no more than half of a standard deviation removed from the overall means for continuous outcome measures and no more than 5 percent for dichotomous outcome measures.

We regarded the following variables as putative prognostic factors: function of the shoulder girdle as assessed by physical examination (passive range of external rotation, active range of abduction/elevation and presence of painful arc), psychosocial variables (anxiety, depression, somatisation, and distress, assessed by the Four Dimensions of psychological Symptomatology Questionnaire (4DSQ)) (Terluin 1998), treatment preferences and recruitment strategy (either by GP or by advertisement). Using a stepwise forward procedure $(\mathrm{p}<0.10)$ and taking the main complaint and SDQ as the outcome measures, we evaluated the influence of these putative prognostic factors and post-randomisation differences between groups by means of multiple linear regression analyses.

A change in shoulder pain intensity was considered a priori to be a modifying factor. We assumed that pain reduction over time might result in improved performance of daily activities as a natural course. Since the aim of GET is to improve the performance of daily activities, irrespective of pain experience, we considered the possibility that the programme might be more effective in patients without pain reduction over time. Therefore, the influence of changes in pain intensity on the performance of daily activities was explored and analysed as a modifying factor. We defined subgroups on the basis of pain reduction by more than one standard deviation of the overall mean of the pain intensity at baseline, and studied the effect of GET in these subgroups using multivariate linear regression for the main complaint instrument and for the SDQ.

\section{RESULTS}

The flow-chart of the recruitment process is presented in figure 1. The GPs regarded 192 patients as eligible to participate in the study. Sixteen patients were excluded before randomisation (for reasons see figure 1), 176 patients were randomised and allocated to either Graded Exercise Therapy (GET) (N=87) or usual care (UC) (N=89). Eighteen patients 
Figure 1. Flow-chart

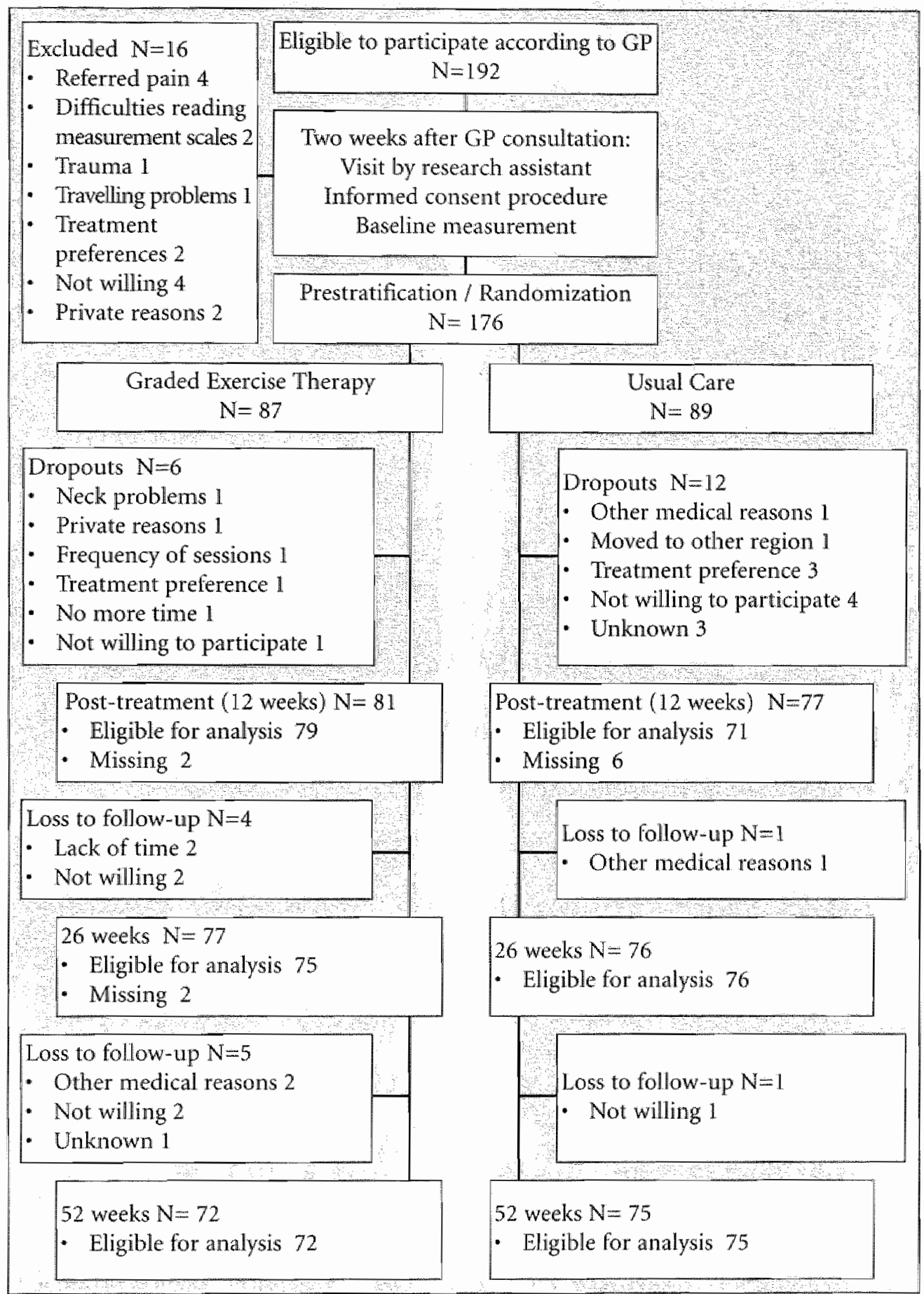


Table 3. Mean improvement on primary outcome measures ather 12,26 and 52 weetes Oucrall and subgroup analystes

\begin{tabular}{|c|c|c|c|c|c|c|c|c|}
\hline & & GET & Usual Care & & Differenk & ces beth & leen group & \\
\hline 3 & & Mean (sd) & Mean (sd) & $\begin{array}{l}\text { Mean } \\
\text { diff }\end{array}$ & $\begin{array}{l}95 \% \mathrm{Cl} \\
\text { lower }\end{array}$ & $\begin{array}{l}\text { of diff } \\
\text { upper }\end{array}$ & P-yalue & $\begin{array}{c}\text { Effect } \\
\text { size }\end{array}$ \\
\hline Main com & aints $(0-100)$ & & & & & & & \\
\hline Qverall and & (GETUC) & & & & & & & \\
\hline 12 weeks & $N=176(87.89)$ & $32.8(25.7)$ & $25.3(24.5)$ & 7.5 & 0.0 & 15.0 & 0.049 & 0.30 \\
\hline 26 weeks & $N=176(87-89)$ & $38.4(26.7)$ & $31.2(28.0)$ & 7.1 & -1.0 & 15.3 & 0.086 & 0.26 \\
\hline 52 weeks & $N=176(87.89)$ & $41.1(26.7)$ & $31.8(27.4)$ & 9.2 & 1.2 & 17.3 & 0.025 & 0.34 \\
\hline Pain intens & reduced & & & & & & & \\
\hline 12 weeks & $N=44(24 \cdot 20)$ & $50.7(23.5)$ & $49.1(24.7)$ & 1.6 & -13.1 & 6.3 & 0.826 & 0.06 \\
\hline 26 weeks & $N=110(54-56)$ & $49.1(24.3)$ & $43.1(24.4)$ & 6.0 & -3.2 & 15.2 & 0.202 & 0.25 \\
\hline 52 weeks & $N=114(58-56)$ & $49.9(23.9)$ & $43.3(24.2)$ & 6.6 & -2.3 & 15.5 & 0.147 & 0.27 \\
\hline Pain intens & unchanged & & & & & & & \\
\hline 12 weeks & $N=132(63.69)$ & $25.9(23.1)$ & $18.4(19.8)$ & 7.6 & 0.2 & 15.0 & 0.045 & 0.35 \\
\hline 26 weeks & $N=66(33-33)$ & $20.8(20.8)$ & $11.1(21.8)$ & 9.8 & -0.7 & 20.2 & 0.068 & 0.46 \\
\hline 52 weeks & $N=62(29-33)$ & $23.5(23.3)$ & $12.4(21.1)$ & 111.1 & -0.2 & 22.4 & 0.054 & 0.50 \\
\hline SDQ $10-1$ & & & & & & & & \\
\hline Overall and & & & & & & & & \\
\hline 12 weeks & $N=176(87-89)$ & $17.0(26.0)$ & $15.3(21.6)$ & 1.7 & -5.4 & 8.8 & 0.542 & 0.07 \\
\hline 26 weeks & $N=176(87-89)$ & $22.6(29.0)$ & $20.2(27.8)$ & 2.3 & -10.8 & 6.1 & 0.587 & 0.08 \\
\hline 52 weeks & $\mathbb{N}=176(87-89)$ & $22.5(26.2)$ & $20.4(31.2)$ & 2.1 & -6.5 & 10.7 & 0.633 & 0.07 \\
\hline Painful arc & esent at baseline & & & & & & & \\
\hline 12 weeks & $N=128(64-64)$ & $12.9(25.7)$ & $13.1(20.9)$ & 0.2 & 8.4 & 8.1 & 0.971 & -0.011 \\
\hline Painful arc & sent at baseline & & & & & & & \\
\hline 12 weeks & $N=48(23-25)$ & $28.4(23.6)$ & $21.2(22.5)$ & 7.3 & -6.1 & 20.7 & 0.280 & 0.32 \\
\hline Pain intens & reduced & & & & & & & \\
\hline 12 woeks & $N=44(24 \cdot 20)$ & $34.5(26.3)$ & $34.2(25.3)$ & 0.4 & -15.4 & 16.2 & 0.964 & 0.02 \\
\hline 26 weeks & $N=110(54-56)$ & $26.6(26.9)$ & $27.3(27.5)$ & 0.8 & -11.0 & 9.5 & 0.885 & -0.03 \\
\hline 52 weeks & $N=114(58-56)$ & $30,0(26.1)$ & $30.7(27.5)$ & -0.7 & -10.7 & 92 & 0.886 & .0 .09 \\
\hline Pain intens & unchanged & & & & & & & \\
\hline 12 weeks & $N=132(63-69)$ & $10.4(22.8)$ & $9.9(16.9)$ & 0.5 & -6.4 & 7.3 & 0.894 & 0.03 \\
\hline 26 weeks & $N=66(33-33)$ & $16.1(31.5)$ & $8.3(24.2)$ & 7.8 & -6.0 & 21.6 & 0.264 & 0.28 \\
\hline 52 weeks & $N=62(29-33)$ & $7.3(19.4)$ & $2.8(29.7)$ & 4.6 & -8.2 & 17.4 & 0.481 & 0.19 \\
\hline
\end{tabular}

withdrew from the study during the treatment period. Five and six withdrawals were registered during follow-up at 26 weeks and 52 weeks respectively (for reasons see figure 1). Data were missing for eight patients at 12 weeks and for two patients at 26 weeks.

Table 2 shows that at baseline, treatment groups were comparable on all continuous outcome 
Table 4 Mean improvement on secondary outcome measures affer 12,26 and 52 week $\mathrm{s}^{\mathrm{a}}$

\begin{tabular}{|c|c|c|c|c|c|c|c|}
\hline & GET & Usual Care & \multicolumn{5}{|c|}{ Differences between groups } \\
\hline & $N(\%)$ & $\begin{array}{c}N(\%) \\
\text { diff }\end{array}$ & $\begin{array}{l}\text { Rigk } \\
\text { lowter }\end{array}$ & \multicolumn{2}{|c|}{$\begin{array}{l}95 \% \text { c o o diff } \\
\text { upper }\end{array}$} & P-value & NNT \\
\hline \multicolumn{8}{|c|}{ Perceived recovery (yes/no) } \\
\hline 12 weeks & $23(29.1)$ & $13(18.3)$ & 0.11 & .0 .01 & 0.24 & 0.122 & 9 \\
\hline 26 weeks & $20(26.7)$ & $18(23.7)$ & 0.03 & -0.07 & 0.18 & 0.673 & 33 \\
\hline \multirow[t]{3}{*}{52 weeks } & $25(34.7)$ & $18(24.0)$ & 0.11 & 0.02 & 0.25 & 0.153 & 9 \\
\hline & GET & Usual Care & \multicolumn{5}{|c|}{ Differences between groups } \\
\hline & $\operatorname{Mean}(s d)$ & Mean (sd) & $\begin{array}{l}\text { Mean } \\
\text { diff }\end{array}$ & \multicolumn{2}{|c|}{$95 \%$ Cl of diff } & P-value & Effect-size \\
\hline \multicolumn{8}{|c|}{ Shoulder pain $(7-28)$} \\
\hline 12 weeks & $3.0(3.3)$ & $23(3.4)$ & 0.7 & 0.3 & 9.7 & 0.165 & 0.21 \\
\hline 26 weeks & $3.3(3.7)$ & $2.4(4.0)$ & 1.0 & -0.2 & 2.1 & 0.096 & 0.25 \\
\hline 52 weeks & $7.2(3.2)$ & $6.6(3.8)$ & 0.6 & .0 .4 & 1.7 & 0.230 & 0.18 \\
\hline \multicolumn{8}{|c|}{ Pain intensity $(0-10)$} \\
\hline 12 weeks & $1.7(2.2)$ & $1.5(2.2)$ & 0.3 & -0.3 & 0.9 & 0.375 & 0.13 \\
\hline 26 weeks & $22(2.7)$ & $1.9(2.2)$ & 0.2 & -0.5 & 1.0 & 0.375 & 0.10 \\
\hline 52 weeks & $2.5(2.2)$ & $1.9(2.5)$ & 0.6 & -0.2 & 1.3 & 0.125 & 0.23 \\
\hline \multicolumn{8}{|c|}{ Quality of life $(-1$ to 1$)$} \\
\hline 12 weeks & $0.06(0.22)$ & $0.06(0.18)$ & 0.00 & 0.06 & -0.06 & 0,929 & 0.00 \\
\hline 26 weeks & $0.10(0.23)$ & $0.08(0.16)$ & 0.03 & 0.09 & -004 & 0.409 & 0.15 \\
\hline 52 weeks & $0.10(0.22)$ & $0.07(0.18)$ & 0.03 & 0.09 & .0 .03 & 0.345 & 0.15 \\
\hline \multicolumn{8}{|c|}{ Fear avoidance $(1-7)$} \\
\hline 12 weeks & $0.4(1.4)$ & $0.2(1.0)$ & 0.1 & -0.2 & 0.5 & 0.449 & 0.12 \\
\hline 26 weeks & $0.7(1.5)$ & $0.3(1.5)$ & 0.4 & -0.0 & 0.8 & 0.082 & 0.26 \\
\hline 52 weeks & $0.7(1.4)$ & $0.3(1.0)$ & 0.4 & 0.0 & 0.8 & 0.043 & 0.33 \\
\hline \multicolumn{8}{|c|}{ Kinesiophobia (1-7) } \\
\hline 12 weeks & $0.2(1.6)$ & $0.0(1.8)$ & 0.2 & -0.3 & 0.7 & 0.411 & 0.13 \\
\hline 26 weeks & $0.4(1.6)$ & $0.1(1.8)$ & 0.4 & .0 .2 & 0.9 & 0.201 & 0.21 \\
\hline 52 weelss & $0.6(1.6)$ & $.0 .2(1.8)$ & 0.8 & 0.3 & 1.3 & 0,003 & 0.45 \\
\hline \multicolumn{8}{|c|}{ Catastrophising (1-6) } \\
\hline 12 weelss & $0.4(0.7)$ & $0.2(0.5)$ & 0.2 & 0.0 & 0.4 & 0.028 & 0.33 \\
\hline 26 weeks & $0.4(0.7)$ & $0.2(0.8)$ & 0.1 & -0.1 & 0.4 & 0.190 & 0.20 \\
\hline 52 weeks & $0.4(0.7)$ & $0.2(0.7)$ & 0.2 & -0.0 & 0.4 & 0.053 & 0.29 \\
\hline \multicolumn{8}{|c|}{ Coping (1-6) } \\
\hline 12 weeks & $0.1(0.8)$ & $-0.0(0.7)$ & 0.1 & 0.2 & 0.3 & 0.499 & 0.11 \\
\hline 26 weeks & $0.0(0.9)$ & $0.1(1.0)$ & .00 & -0.2 & 0.3 & 0.777 & 0.04 \\
\hline 52 weeks & $0.1(0.9)$ & $0.0(0.8)$ & 0.1 & -0.1 & 0.4 & 0.366 & 0.13 \\
\hline \multicolumn{8}{|c|}{ Internal locus of controll (1-6) } \\
\hline 26 weeks & $0.2(0.6)$ & $-0.0(0.6)$ & 0.2 & -0.0 & 0.4 & 0.097 & 0.25 \\
\hline 52 weeks & $0.4(1.0)$ & $0.2(0.9)$ & 0.3 & -0.0 & 0.9 & 0.058 & 0.29 \\
\hline \multicolumn{8}{|c|}{ External locus of control $(1-6)$} \\
\hline 26 weeks & $0.3(0.7)$ & $0.2(0.9)$ & 0.0 & 0.2 & 0.3 & 0.797 & 0.04 \\
\hline 52 weeks & $0.2(0.9)$ & $0.1(0.9)$ & 0.1 & -0.2 & 0.4 & 0.405 & 0.13 \\
\hline
\end{tabular}

after unconditional mean imputation

b $95 \%$ confidence interwal of difference

c statistically significant $P<0,05$

"Number Needed to Treat 
measures. Patterns of treatment preferences were similar for both groups, although patients allocated to UC more frequently favoured behavioural therapy and less frequently favoured manual therapy and drugs therapy (analgesics and NSAID). Patients allocated to usual care had lower scores on the distress subscalle of the $4 \mathrm{DSQ}$. These patients were less likely to report concomitant neck problems, and were more likely to report a quick onset of their current complaints. Otherwise, prognostic status at baseline was comparable for both groups. Patients eligible for analysis and patients who withdrew from the study during the treatment or follow-up period or had missing data at 1.2 or 26 weeks were comparable on all outcomes measures at baseline.

Overall and subgroup analyses of primary outcome measures are presented in table 3. Overall analyses show that although GET patients improved more than UC patients on both of the primary outcome measures, the differences were only statistically significant for the main complaint directly after treatment (i.e. at 12 weeks after baseline) and during follow-up at 52 weeks. Imputation did not alter these results.

Multiple regression analyses of primary outcome measures at 12,26 and 52 weeks showed that, when adjusted for a-priori putative modifying factors (i.e. shoulder function,

Table 5. Mean utilisation of Health Care Services' and telexant non-health care services per patient during a one-yeat follow up

\begin{tabular}{|c|c|c|c|}
\hline Type of utilisation & $\begin{array}{l}\text { GET } \mathrm{N}=87 \\
\text { Mean (sd) }\end{array}$ & $\begin{array}{c}\text { Usual Care } \mathrm{N}=89 \\
\text { Mean (sd) }\end{array}$ & $\begin{array}{c}\text { P-value }{ }^{2} \\
\text { non-parametric }\end{array}$ \\
\hline \multicolumn{4}{|l|}{ Direct health care services } \\
\hline General practitioner (no of visits) & $0.4(0.86)$ & $0.8(1.15)$ & 0.005 \\
\hline Physiotherapist (no of visits) & $0.8(2,99)$ & $39(7.04)$ & 0.000 \\
\hline Manual therapist (no of visits) & $0.1(0.48)$ & $0.4(1: 44)$ & 0.012 \\
\hline Cesar/Mensendieck exeróse therapist (no. of visits) & $0.0(0.21)$ & $0.2(1.27)$ & 0.040 \\
\hline Physician (no, of visits) & $0.2(1.00)$ & $0.4(1.08)$ & 0.034 \\
\hline Alternative therapist (no. of visits) & $0.4(1.26)$ & $10(3.62)$ & 0.016 \\
\hline Prescribed drugs (no of prescriptions)- & $0.5(1.19)$ & $0.8(1.82)$ & 0.023 \\
\hline \multicolumn{4}{|l|}{ Relevant non-health care services } \\
\hline Proftessional home care (no, of hours) & $0.0(0,00)$ & $0.7(3.81)$ & 0.000 \\
\hline Paid housekeeping (no, of hours) & $3.4(17.84)$ & $7.2(27.72)$ & 0.086 \\
\hline Unpaid help from family/friends (no of hours) & $9.7(79: 43)$ & $1.2(5.39)$ & 0.144 \\
\hline Unpaid help from familyffrends adjusted (no, of hours) & $0.8(5.63)$ & $1.2(5: 39)$ & 0.046 \\
\hline Expenses for health activities (no. of expenses) & $13,0(30,03)$ & $17.2(51,72)$ & 0.553 \\
\hline other out-of-pocket expenses (no of expenses) & $0.50 .25)$ & $11(2,27)$ & 0.004 \\
\hline
\end{tabular}

1 excluding interventions ( $6 \mathrm{G}$ and $\cup \mathrm{C}$ )

3 tatistically signifcant $\mathrm{B}<0.05$

3 non parametric Mann Whitmey test

7 adjusted for one patient reporting extremely high utilisation of unpaid help from familyffriends by imputation of the group mean for utilisation of unpaid help. 
anxiety, depression, somatisation and distress), baseline differences (i.e. duration of complaints, quick onset of complaints, concomitant neck problems, prior episodes of $\$ \mathrm{C}$, treatment preferences) and recruitment strategy, the results were scarcely influenced by these variables, except for the presence of a painful arc during physical examination. Presence of a painful arc turned out to be an effect modifier. Table 3 shows that the presence of a painful arc markedly reduced the effect of GET as assessed by the SDQ after 12 weeks of treatment. GET was associated with decreases in pain intensity over time. Subgroup analyses presented in table 3 show that pain reduction was experienced by 44,110 and 114 patients at 12,26 and 52 weeks, respectively. GET was more effective in patients without pain reduction during the treatment.

Table 4 shows that statistically significant differences between groups as to improvement on the secondary outcome measures were only found for catastrophising (12 weeks) and for fear avoidance beliefs and kinesiophobia ( 52 weeks).

Table 5 shows the mean volumes of health care utilisation per patient during the oneyear follow-up period. The overall utilisation of all direct health care services and relevant non-health care services during the follow-up period was lower for patients allocated to GET than for those allocated to UC (except for unpaid help from family/friends) and the difference reached statistical significance (except for paid housekeeping and expenses for health activities).

\section{Discussion}

Effectiveness of GET seems to last for at least 52 weeks. The clinical differences between the GET and UC groups were rather modest, and the calculated effect sizes in this study were small (up to 0.45).

At present, there is no consensus on the outcome that is the most appropriate for shoulder complaints (Green et al 2000). Furthermore, one might argue whether or not patient centred outcomes are appropriate to evaluate effectiveness of treatments at the group level in clinical evaluation studies (Jolles et al 2005). In the 'main complaints' instrument, patients were asked at baseline to select three daily activities they regarded as most important in relation to their shoulder complaints, but not necessarily related specifically to pain. Since activities, and their relevance or importance in daily life, can vary widely between patients with shoulder complaints, and the GET programme is tailored to the patient's goals and needs, this measure is considered to be appropriate to assess the performance of daily activities in this trial. The SDQ is an instrument to assess activities in terms of functional limitations related to pain. Given the aim of the GET programme, which is not primarily to reduce pain intensity, SDQ changes might be expected to be less obvious.

Several sources of bias may have influenced the results of this study. First, since patients and health care providers could not be blinded in this study, treatment preferences of patients could have introduced bias. However, multiple regression analyses showed that treatment preferences did not influence the outcomes. Lack of blinding could also have introduced bias through differential drop-out and loss-to-follow-up rates. However, patients eligible for analyses and withdrawals were comparable at baseline and the numbers of patients that withdrew from both intervention groups were very similar. Treatment groups were comparable 
with respect to outcome mieasures at baseline. Putative modifying factors and post-randomisation differences between groups showed no influence on primary outcome measures except for the presence of a painful arc.

One possible explanation for the modest beneficial effects found in our study may be an inadequate match between the GET programme and patient characteristics. The study population in this trial was rather heterogeneous, since only patients suffering from systemic diseases or severe medical or psychological pathology were excluded. Vlaeyen and Morley presumed that modest effect sizes in trials of behavioural treatments could be explained by a lack of knowledge about the specific biobehavioural mechanisms for the transition from acute pain to chronic pain and pain disability (Vlaeyen and Morley 2005). They suggest that the effectiveness of these treatments could be improved by a better matching between treatment and patient characteristics. Another explanation for the modest effect sizes could be the way the GET programme was administered in this trial. An earlier evaluation of the GET intervention process in this trial, using treatment registration forms filled in by the physiotherapists during treatment, evaluation forms filled in independently by physiotherapists and patients 26 weeks after the start of the treatment period, and information gathered during the focus group interview at the end of the study, showed that the process of goalsetting left some room for improvement (Geraets et al 2006). Furthermore, it showed that implementation of the programme could be facilitated when embedding the programme in a multidisciplinary primary care approach. However, the overall clinical effectiveness of GET was not influenced by flaws in the application of the programme or by lack of patient adherence. Finally, the modest effect sizes in our study could be explained by a lack of contrast between treatment groups. Firstly, one might argue whether or not the brief training courses for GPs and PTs were effective, although the supervisors (experts in the field of behavioural treatment) confirmed physiotherapists" eligibility to administer the program prior to the start of the study. Secondly, since the principles of the biopsychosocial model are nowadays more commonly applied in usual care physiotherapy, one might argue that the differences between treatments have become less distinct than intended, although none of the patients allocated to usual care was treated with behavioural therapy as such.

To our knowledge, this is the first trial on the effectiveness of a behavioural exercise programme for chronic shoulder complaints in a primary care setting administered by a PT. Earlier studies mainly focused on the effectiveness of these treatments for other chronic pain patients, viz. those with chronic low back pain. Moreover, the behavioural exercise programmes evaluated in earlier studies were mostly embedded in multidisciplinary cognitive-behavioural programmes and in secondary settings (Morley et al 1999, Tulder et al 2001). The content and the effectiveness of the GET programme cannot be compared with more comprehensive multidisciplinary programmes or operant treatment packages administered by the psychologist.

The GET programme is based on the principles of graded activity, operant conditioning and time contingency, and aims at restoring patients' own preferred daily activities, rather than primarily at pain reduction. Therefore, we firstly assumed that pain behaviour and painrelated inactivity would be modified in accordance with learning theory principles during the treatment period, i.e., through new learning experiences, reinforcement, rewarding, goal setting and levels of activity gradually increasing over time (Skinner. 1953, Fordyce 1976). This assumption was confirmed by our short-term results on primary outcome measures after 12 weeks of treatment, although the differences between the groups were only 
statistically significant for main complaints. Secondly, we assumed these behavioural changes to be consolidated after the treatment period. We assume that once behaviour has changed in the preferred direction and patients experience the progress made as a consequence of their own healthy behaviour, they will become more motivated to succeed in performing and maintaining the preferred activities. Furthermore, we expected that the special attention paid to the application of what has been learned in everyday life, would lead to improvements in the performance of daily activities after the treatment period. Our present findings confirm that differences between the treatment groups on the primary outcome measures remain significant after 52 weeks of follow-up. Furthermore, utilisation of health care services and mon health care services during 52 weeks of follow-up was lower for patients allocated to GET. Patients allocated to GET had significantly higher scores for improvement on paincatastrophising and pain-related fear in the long term. We assume that, even though GET is a behavioural treatment (and not a cognitive treatment), positive experiences in performing daily activities during treatment may not only have contributed to improvements in the performance of daily activities, but also to reduction of pain-catastrophising and pain-related fear in the long term. These findings are in line with earlier studies on chronic low back pain patients in which catastrophising thoughts and fear of movement were associated with the performance of activities (Vlaeyen 1999).

Patients allocated to GET showed greater improvement in the performance of daily activities, irrespective of perceived recovery after 12,26 and 52 weeks. These results imply that patients allocated to GET were less likely to consider their ability to perform daily activities at home or at work to be dependent on perceived recovery or pain experience, which is in line with the concepts of the GET programme.

A question that remains is which patients might benefit most from GET. The present trial included a broad range of patients with shoulder complaints. Analysis showed that the presence of a painful arc during physical examination at baseline minimised the effectiveness of GET. Painful arc is a well-known sign associated with sub-acromial impingement, as the initial stage of rotator cuff injuries (characterised by inflammation of the tendon), with rotator cuff tears as the final stage (Neer and Welsh 1977). Numerous causes, contributing factors and possible therapeutic options for shoulder impingement have been reported (Pyne 2004). Furthermore, GET seemed to be more effective in patients not reporting pain reduction during the treatment period. We expected that pain reduction over time would lead to improvements in the performance of daily activities as a natural course. Since the aim of GET is not primarily to reduce pain intensity, we assumed that GET would be more effective in patients not reporting pain reduction over time. Explorative subgroup analyses on pain reduction in patients confirmed this assumption. A recent study on shoulder complaints in primary care showed that high pain intensity scores at baseline predict a poorer long-term outcome (Kuipers et al 2004). More generally, chronic pain research has shown that pain-catastrophising, pain anxiety and pain-related fear seem to be associated with overpredicting actual pain and under-predicting abilities to perform physical tasks and to adjust pain behaviour (Keefe et al 2004).

Based on our study we recommend that GET should not be used for patients with a painful arc. More research on the phenomenon of a painful arc is needed to elucidate the value of exercise programmes in general for patients with shoulder impingement. Predicting which patients are at risk for persistent shoulder pain in the long term is of great interest to achieve a better match between the GET programme and patient characteristics. We suggest 
that nore research is needed on the cognitive and behavioural aspects of pain-predicting in patients with chronic shoulder pain, as it could provide new insights into the prognosis and course of complaints.

\section{ACKNOWLEDGEMENTS}

This study was funded by the Netherlands Organisation for Scientific Research (NWO-MW, grant number 904-65-901) and by the "De Drie Lichten" Foundation, Hilversum, the Netherlands. 


\section{REFERENCES}

Andersson HL. The course of non-malignant chronic pain: a 12 -year follow-up of a cohont from the gemeral population. Furopean fournal of Pain $2004: 8: 47-53$.

Berg SGM van den, Vhaeyen WWS, Kuil MM ter, Spinhoven Ph, Breukelen G van and Kole-Smijders AMJ. Meetinstrumenten chronische pinn deel 2. Pijn Coping en Cognitie Lijst. Masstricht: Pijn Kennis Centrum 2001.

Beurskens AJHM, Vet HCW de, Köke AJA, Lindeman E, Heijden GMG wan der, Regtop W, Knipschild PG. A patient-specific approach for measuring functional status in low back pain. I Matnipulative Physiol Ther 1999; $22: 1.4 .4-8$

Brooks R. EuroQol: The current state of play. Health Policy 1996; 37:53-72.

Cohen). Statistical power analysis for the behavioral sciences. London: Academic press Inc. 1977.

Fordyce WE. Behavioral methods for chronic pain and illness. Saint Louis: CV Mosby Company. 1976.

Fordyce WE, Brockway ], Bergman I and Spengler D. A control group comparison of behavioural versus traditional management methods in acute low back pain. Journal of Behavioral Medicine. 1986; 2:127-140.

Geraets JJXR, Goossens EIS, Bruinn CPC de, Köke AIA, Bie RA de, Pelt RAGB,

Heuvel WJA wan den, Heijden GJMG van der. A behavioural treatment for chronic shoulder complaints: concepts, development, and study design. Australian Journal of Physiotherapy. 2004; 50: 33-38.

Geraets IJXR, Goossens EJB, Groot IJM de, Bruijn CPC de, Bie RA de, Dinant GI, Heijden GIMG van der, Heuvel WIA van den. Effectiveness of a graded exercise therapy programme for patients with chronic shoulder complaints. Australian Journal of Physiotherapy. 2005; 51 : 87-94.

Geraets JIXR, Goossens EJB, Hastregt J van, Groot IJM de, Bruijn CPC de, Bie RA de, Köke AlA, Henvel WIA van de. Jmplications of process evaluation for clinical effectiveness and clinical practice in a trial on chronic shoulder complaints. Pat Educ Couns 2006 (in press)

Green $\$$, Buchbinder R, Glazier $\mathbb{R}$, Forbes A. Interwentions for shoulder complaints. Cochrane Databuse Syst Rev. 2000; (2):CD001156.

Guzmän I, Esmail R, Karjalainen K, Irvin E, Bombadier C. Multidisciplinary rehabilitation for dnonic low back pain: systematic review. British Medical Jotrnal. 2001:322:511-516.

Heijden GIMG van der, Leffers $P$ and Bouter LM. Shoulder Disability Questionnaire design and responsiveness of a functional status measure. Journal of Clinical Epidemiology 2000; $53: 29-38$.

Hurst NP, Kind P, Ruta D, Hunter M, Stubbings A. Measuring health-related quality of life in rheumatoid arthritis: validity, responsiveness and reliability of the Euroqol (EQ-5D). Br) Rheumatol. 1997:36551-9.

Jensen IB, Bergstrom $G$, Lingquist $T$, Bodin L. A 3-year follow-up of a multidisciplinary rehabilitation programme for back and neck pain. Pain. 2005;115:273-83. 
IoHles BM. Buchbinder R, Beaton DE. A study compared nine patient-specific indices for musculosketetal disorders. I Clin Epidemiol. 2005:58:791-801

Keefe $\mathbb{V}$, Rumble ME, Scipio CD, Giordano LA, Perri LM. Psychological aspects of persistent pain current state of the science. I Pain $2004 ; 5: 195 \times 211$.

King $M$, Dawidson $O$, Taylor $F$, Haines $A_{\text {, }}$ Sharp $D$, Turner $\mathbb{R}$. Effectiweness of teaching general practitioners skills in bref cognitiwe behaviour therapy to treat patients with depression: randomised controlled trial.BMI. 2002 Apr $20,324(7343): 9477-50$.

Kuipers $\mathrm{T}$, Windt wan der DA, Heilden GMG van der, Bouter LM. Systematic review of prognostic cohort studies on shoulder disorders. Pain. $2004 ; 109: 420-431$

Lindstrom $I_{2}$ Ohlund $C_{s}$ Eek $C_{\text {, Wallin }}$, Peterson LE, Fordyce WE and Nachemson AL. The effect of graded activity on patients with subacute low back pain: $A$ randomised prospective climical study with an operant conditioning behawioural approach. Physical Therapy. 1992; 72: 279-290.

Linton SI. An owerview of psychosocial and behavioral factors in neck-and-shoulder pain. Scandinavian Journal of Rehabilitation Medicine. 1995; 32:67-77.

Linton SI. Prewention with special reference to chronic musculoskeletal disonders. In Gatchel RJ and Turk DC (Feds): Psychosocial Factors In Pain. New York: Guiltord Publications. 1999, pp. 374-389.

Luime II, Koes BW, Henriksen I], Burdorf A, Verhagen AP, Miedema HS, Verhar IA. Prevalence and incidence of shoulder pain in the general population; a systematic review. Scand I Rheunatol. 2004a; 33:73-81.

Luime IJ, Kuiper II, Koes BW, Verhaar JA, Miedema HS, Burdorf A. Work-related risk factors for the incidence and recurrence of shoulder and neck complaints among nursing-home and elderly-care workers. Scand $I$ Work Environ Health. 2004b; 30: 279-86.

Macfarlane GJ. Hunt IM, Silman AJ. Predictors of chronic shoulder paina a population based prospective study. I Rheurvatol. 1998; 25:1612-5.

Morley $\$$, Eoweston $C$ and Willans A. Systematic revicw and meta-analysis of randomized controlled trals of cognitive behaviour therapy and behawiour therapy for chronic pain in adults, exduding headache. Pain. 1999; 88: 1-13.

Neer Cs and Wesh RP. The shoulder in sports. Orthop Clin North Am 1977; $8: 583-591$.

Ostelo RW, de vet HC, Vlacyen JW, Kerckhoffs MR, Befelo WM, Wotters PM, van den Brandt PA. Bedrawioral graded anctivity after first-time lumbar disc surgery: One-year results of a randomized controlled trial. Spine. 2003;28:1757-65

Ostelo RW, wan Tulder MW, Vlaeyen MW. Linton S), Morley SI, Assendelft Wh. Behravioural treatment for chronic low-back pain. Cochrane Database Syst Rev. 2005;(1);CD002014.

Byne SW. Diagnosis and current treatment options of shoulder impingement. Curr Sports Med Rep. 2004; 5: $251-5$. Skimner B. Science and Human Behavior. New York: Macmillan. 1953 
Staal IB, Hobil H, Twisk JW, Smid T, Koke AJ, wan Mechelen W. Graded activity for low badk pain in accupational health care: a randomized, controlled trial. Ann Intern Med. $2004,14077-84$ :

Terluin B. De Vierdimensionale klachtenlijst (4DKL) in de huisartspraktilk. De Psycholoog: 1998; 18-24.

Tulder MW van, Ostelo RWJG, Vlaeyen JWS, Linton S1, Morley SI and Assendelf WIJ. Behavioral treatment for chronic low back pain. A systematic review within the framework of the Cochrane Back Review Group. Spine. 2001; 26: 270-28:.

Vendrig A, Deutz P, et al Nederlandse vertaling en bewerking van de Fear-Avoidance Beliets Questioninare. Nederlands Tijdschrift voor Pijn en Pijnbestrijding. $1998 ; 18: 11-14$.

Vlaeyen IWS, Kole-Snijders AMJ, Boeren $R G_{n}$ Eek H van. Fear of movement/(re)injury in chronic low back pain and its relation to behavioral performance. Pain.1995; 62: 363-372.

Vlaeyen JWS and Linton SJ. Fear-Avoidance and its consequences in chronic musculoskeletal pain: A state of the art. Pain. 2000;85:317-332.

Vlaeyen NWS and Morley. Cognitive-behavioral treatments for chronic pain: What works for whom? Clin I Pain. 2005; 21:1-8.

Waddell $G$, Newton M, Henderson L., Somerville D, Main CJ. A Fear-Avoidance Beliefs Questionmaire (FABQ) and the role of fear-avoidance beliefs in chronic fow back pain and disability. Pain. 1993:52: 157-1.68

Windt DA van der, Koes BW, Boeke AJ, Deville W, Jong BA de and Bouter LM. Shoulder disorders in general practice: prognostic indicators of outcome. British Journal of General Practice. 1996; 46: 519-523.

Windt DA van der, Heijden van der GJ, Winter de AE, Koes BW, Deville W, Bouter LM. The responsiveness of the Shoulder Disability Questionnaire. Ann Rheum Dis. 1998;57:82-7

Winters JC, Sobel IS, Groenier KH, Arendzen IH and Meyboomade long B. A Shoulder Pain Score: $A$ comprehensive questionnaire for assessing pain in patients with shoulder complaints. Scandinavian fournal of Rehabilication Medicine. 1996; 28: 163-167.

Winters $/ C_{\mathrm{s}}$ Sobel 15 , Arendzen $\mathrm{JH}$ et al. The course of pain and the restriction of mobility in patients with shoulder complaints in general practice. Rheumatology International. 1997; 16, 219-225.

Winters JC, Sobel IS, Groenier KH, Arendzen JH, Meyboom-de Jong B. The long-term course of shoulder complaints: a prospective study in general practice. Rheumatology (Oxford). 1999; 38:160-3.

Winters JC, Jongh AC de, Wirudt DAWM van der, Jonquiere M, Winter AF de, Heijden GIMG van der, Sobel IS and Goudsward AN. NHG.Standaard Schouderklachten. Huisarts en Wetenschap. 19996; 42:222-231. 



\section{Chapter 5}

\section{Cost-effectiveness}

Accepted for publication as Cost-effectiveness of a graded exercise therapy programme for patients with chronic shoulder complaints. Geraets JJXR, Goossens MEJB, de Bruijn CPC, de Groot IM, Köke AJA, Pelt RAGB, wan der Heijden GIMG, Dinant GI, van den Heuvel WJA. Int I Techioology Assess Health Care 2006 . 


\section{ABSTRACT}

Objectives: The present study evaluated the cost-effectiveness of a behavioural Graded Exercise Therapy (GET) programme compared to usual care (UC) in terms of the performance of daily activities by patients with chronic shoulder complaints in primary care. Methods: One-hundred-and-seventy-six patients were randomly assigned either to GET $(\mathrm{N}=87)$ or to $U C(N=89)$. Clinical outcomes (main complaints, shoulder disability ( $S D Q$ ) and generic health-related quality of life (EQ5D)) and costs (intervention costs, direct health care costs, direct non-health related costs and indirect costs) were assessed during the 12week treatment period and 52 weeks of follow-up.

Results: Results showed that GET was more effective than UC in restoring daily activities as assessed by the main complaints instrument after the 12-week treatment period ( $p=0.049$; mean difference $7.5 ; \mathrm{Cl} 0.0-15.0)$. These effects lasted for at least 52 weeks ( $\mathrm{p}=0.025$; mean difference 9.2; $\mathrm{CI} 1.2-17.3)$. No statistically significant differences were found on the SDQ or EQ5D. GET significantly reduced direct health care costs $(p=0.000)$ and direct non-health care costs $(p=0.029)$. Nevertheless, total costs during the one-year follow-up period were significantly higher ( $\mathrm{p}=0.001$; GET 530 versus $\mathrm{UC} € 377$ ) due to the higher costs of the intervention. Incremental cost-effectiveness ratios for the main complaints $(0-100)$, SDQ $(0-$ $100)$ and EQ5D $(-1.0-1.0)$ were $€ 17, € 74$, and $€ 5278$ per unit of improvement respectively.

Conclusion: GET proved to be more effective in the short and long term and reduces direct

health care costs and direct non-health care costs, but is associated with higher costs of the intervention itself.

Key words: cost-benefit analysis, shoulder, behavior therapy, randomized controlled trials. 


\section{INTRODUCTION}

Shoulder complaints (SC) are serious musculoskeletal problems because of their occurrence, course, and persistence (Luime 2004). Patients with shoulder complaints suffer from pain and limitations in the performance of daily activities (Picavet et al 2003). Besides personal suffering, chronic shoulder complaints entail a huge social and economic burden due to patients' inability to carry out household tasks, loss of productivity, sick leave and/or utilisation of health care services. Musculoskeletal disorders, of which SC constitute the second largest group after low back disorders, account for the second largest share in healthcare costs in the Netherlands (Meerding et al 1998). In Sweden, 18\% of disability payments made for musculoskeletal disorders relate to shoulder complaints (Nygren et al 1995).

In the past decade, increasing attention has been focused on economic evaluations regarding patients with musculoskeletal disorders, alongside clinical effectiveness studies. Remarkably, costs for low back pain patients are not normally distributed: most expenses (more than $80 \%$ ) are incurred for a minority of patients (less than $25 \%$ ) in whom low back pain develops into a chronic disorder (Goossens et al 1997, Waddell 1998). Hence, preventing chronic musculloskeletal disorders and improving abilities and healthy behaviours in pain patients at an earlier stage should be able to reduce costs to health care and society.

Behavioural treatments have proved to be effective in the treatment of chronic pain patients in multidisciplinary secondary and tertiary settings (Morley et al 1999, Guzman et al 2001, Tulder et al 2001).

We have developed a behavioural Graded Exercise Therapy (GET) programme to improve the performance of daily activities irrespective of pain experiences in patients with chronic shoulder complaints in primary care settings. The clinical effectiveness of this programme was proved in an earlier study (Geraets et al 2005). We assumed that improved abilities and behavioural changes would also contribute to a reduction in costs of health care services and in costs due to loss of productivity or sick leave. This study was done for three reasons: first, to evaluate the clinical effectiveness of the GET programme compared to usual care; second, to evaluate the costs (intervention costs, direct health care costs, direct nonhealth related costs, and indirect costs) for both treatment groups; third, to evaluate the costeffectiveness from a societal perspective for both treatment groups. To our knowledge, this is the first study on the cost-effectiveness of behavioural treatment in patients with chronic shoulder complaints in primary care.

\section{METHODS}

\section{Study population}

Patients with chronic SC living in the Province of Limburg (the Netherlands) were invited to participate in the study either during consultation with their general practitioner (GP) for chronic shoulder complaints or by advertisement in a local newspaper between January 2002 and July 2003. Patients were included if they were at least 18 years old and had been suffering from SC for at least three months. Patients suffering from systemic diseases, referred pain or severe biomedical or psychiatric disorders were excluded. The study design was approved by the iRv/SRL's Medical Research Ethics Committee. 


\section{Interventions}

Eligible patients were randomised and allocated either to Graded Exercise Therapy (GET) or to usual care (UC). GET is a behavioural treatment programme characterised by graded activity, time-contingency and operant conditioning, which was administered by 20 physiotherapists (PTs). The programme consists of a maximum of 18 group sessions of approximately 60 minutes ower a period of 12 weeks. The content of the GET programme has been described in detail elsewhere (Geraets et al 2004). Usual care was standardised according to the 1999 wersion of the guidehines for $\mathrm{SC}$ issued by the Dutch College of General Practitioners (DCGP) (Winters et al 1999b; see also htp://nhg artsennethlupload/104/gudelines2/E08.htm). UC consists of information, recommendations and pain-contingent medical or drug therapy. UC was administered by 32 practitioners. In UC, it was the general practitioners who decided on the specific treatment.

\section{Clinical outcome measures}

Primary outcome measures to assess the performance of daily activities were the "main complaints' instrument and the Shoulder Disability Questionnaire (SDQ) (Beurskens et al 1999, Heijden van der et al 2000). In the 'main complaints' instrument, patients selected, at baseline, the three most important daily activities that were affected by their SC. They rated their ability to perform these activities during the past week on an ordinal (eleven-point) scale at baseline and during follow-up. The SDQ is a functional status measure consisting of 16 statements regarding pain and limitations to daily activities during the past 24 hours. Generic health-related quality of life was assessed and rated on the EuroQol-5D (EQ5D) (Brooks 1996). The EQ5D consists of a descriptive system for health status, related to five dimensions of health (mobility, self-care, usual activities, pain/discomfort and anxiety/ depression) and a visual analogue scale. Measurements took place at baseline, directly after the 12-week treatment period and after 52 weeks of follow-up.

\section{Costs}

Intervention costs, direct health care costs, direct non-health related costs, and indirect costs were assessed during the 12-week treatment period and the 52-week follow-up period. The intervention costs of the GET programme included the costs of visits to physiotherapists for group treatment during the 12 -week treatment period. The intervention costs for UC included the costs of visits to general practitioners, to physiotherapists for usual care or to manual therapists or Cesar/Mensendieck exercise therapists during the 12 -week intervention period. Other direct health related costs for both treatment groups during the 12-week treatment period included the costs of prescribed medication, of hospitalisation and of visits to physicians or alternative therapists. Direct health related costs after the treatment period included the costs of visits to general practitioners, physiotherapists, manual therapists, Cesar/Mensendieck exercise therapists, physicians and/or alternative therapists, costs of hospitalisation and costs of prescribed medication during the 52 -week follow-up period. Direct non-heath related. costs included costs of professional home care, of paid housekeeping, of unpaid help from relatives or friends, of health-related activities (e.g. fitness training) and other out-ofpocket expenses (e.g. non-prescribed medication). Indirect costs included the costs of production losses due to sick leave from paid or unpaid work. 
Physiotherapists documented the number of visits by patients allocated to GET on a registration form (Geraets et al 2006). Cost diaries filled in by the patients were used to assess direct health care costs, direct non-health related costs and indirect costs (Goossens et al 2000). The cost diaries were sent to the patients by post. Two strategies were used to collect the cost data. Patients were allocated at random to a group recording their weekly expenses continuously in ten diary booklets covering the 52-week period or to a group recording them intermittently in seven diary booklets, covering two weeks out of each eight-wweek period (fourteen weeks in total during the 52-week follow-up period). We did this to answer an addition methodological question, viz., whether keeping a diary for an intermittent period would yield different results than keeping one for the total follow-up period of one year. We found no significant difference between the two assessment strategies $(p=0.890)$, which means that both could be used to calculate the final cost data. Patients returned the diaries immediately after each booklet had been completed.

Prices of visits to health care providers, hospitalisation, professional home care and paid housekeeping were obtained from the guidelines for economic evaluation in health care by the Dutch Health Care Insurance Counsel (Oostenbrink et al 2004). Prices of visits to alternative therapists were obtained from professional organisations or from the cost diary. Prices of prescribed or non-prescribed medication were obtained from the Royal Dutch Society for Pharmacy or from the cost diaries. Prices of unpaid help from family/friends and sick leave from unpaid work were based on shadow prices for unpaid work (Oostenbrink et al 2004). The Human Capital Approach was used to calculate the costs of sick leave from paid work (Oostenbrink et al 2004).

\section{Statistical analysis}

Analyses were performed according to the intention-to-treat principle, using SPSS statistical software (12.0.1 version). A p-value of $<0.05$ was considered to be statistically significant (two-tailed) for all comparisons.

Change scores on clinical outcome measures were calculated (follow-up scores minus baseline scores), as well as mean differences between treatment groups and 95\% confidence intervals. Paired-sample Student's t-tests were used to test for significant differences between groups on continuous scales having a Gaussian distribution. If data were missing, unconditional imputation of the overall mean was applied.

Differences between groups in utilisation of health care services were calculated for both intervention groups. Mean costs per treatment group and mean differences between groups were analysed. As cost data are usually highly skewed, non-parametric Mann-Whitney tests for non-Gaussian distributions were used to test for significant differences between groups. If data were missing, individual mean imputation was applied. If no cost data were available, we used unconditional imputation of the group mean.

Incremental cost-effectiveness ratios (the ratio between the difference in costs and the difference in clinical effects) were calculated by bias-corrected bootstrapping (using 1000 replications) (O'Brien and Briggs 2002, Campbell and Torgerson 1999). Cost-effectiveness ratios for both of the primary outcome measures (main complaints and SDQ) and for health-related quality of life (EQ5D) were plotted on a cost-effectiveness plane.

Alternative cost analyses were performed to evaluate the influence of outliers for the utilisation of health care services on outcomes. 


\section{Results}

\section{Study population}

A total of 176 patients were randomised and allocated to either Graded Exercise Therapy (GET) $(\mathrm{N}=87)$ or usual care (UC) $(N=89)$. Eighteen patients ( $10 \%)$ withdrew from the study during the treatment period, while $11(6 \%)$ withdrawals were registered during the 52-week follow-up period. Eighty-nine patients ( $\mathrm{GET}=41 ; \mathrm{UC}=48$ ) filled in the diaries continuously, while 87 patients ( $\mathrm{GET}=46, \mathrm{UC}=41$ ) filled in the diaries intermittently. One hundred and two patients $(58 \%)$ completed and returned all cost diaries. No cost data were available for the 15 withdrawals $(9 \%)$. Overall, 1213 out of a total of $1499(81 \%)$ cost diaries were returned during the 52 -week follow-up period.

\section{Baseline}

Treatment groups were comparable at baseline in terms of patient characteristics and clinical outcome measures (table 1). The numbers of patients who reported having paid work were similar for both treatment groups (GET 57\%; UC 59\%). Sick leave from paid work at baseline (if applicable) extending a one-week period during the past eight weeks was reported by $4 \%$ of the patients allocated to GET and by $12 \%$ of the patients allocated to

Table I. Voluation of health care wolumes (in E)

\begin{tabular}{|c|c|}
\hline Direct Health Care Costs & $m$ \\
\hline General practitioner (per visit) & $2020^{\prime}$ \\
\hline Physiotherapist (per visit) & $22,75^{1}$ \\
\hline Manual therapist foer visity & $3220^{\prime}$ \\
\hline Cesarmensendleck exercise therapist (per contact) & $23.00^{1}$ \\
\hline Physiclan (per visit) & $56.00^{1}$ \\
\hline Alternative therapist (per visit) & Variable $^{2}$ \\
\hline Hospitalisation (per day) & $337: 00^{9}$ \\
\hline Preseribed drugs (eng analgetics and nsaids) & Variable $e^{3}$ \\
\hline \multicolumn{2}{|l|}{ Direct Non-Health Care Costs } \\
\hline Profosslonal hone tare lper hour') & $26.70^{1}$ \\
\hline Puld housekeeping (per hour) & $12.70^{1}$ \\
\hline Sinpaid heip from familyffriends (per hour) & $830^{4}$ \\
\hline Expenses for hea th activities (e.g. fitness) & Variable $^{2}$ \\
\hline Other out of pocket expenses (e.g. non-prescribed drugs) & Variable \\
\hline Indirect Costs & 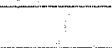 \\
\hline Sick:leave fron paid work (per day) & $H C A^{5}$ \\
\hline Sick leave from unpaid work (per hour) & $830^{4}$ \\
\hline
\end{tabular}

1 prices obtained from the Health Care insurance Board (Oostenbrink et all 2004)

2. prices as indicated by patients in the cost diaries

3 prices obtained from the Royal Dutch Sociely for Phamacy

4 based on shadow prices for unpaid work (Oostenbrink et al 2004)

${ }^{5}$ Human Capital Approach (Oostenbrink et al 2004) 
UC. Furthermore, patients eligible for analysis and patients who withdrew from the study or had missing data during the treatment or follow-up periods were comparable on all outcomes measures at baseline.

\section{Clinical effectiveness}

Table 1 shows that GET patients had improved more than UC patients on both primary" outcome measures (main complaint and SDQ) inmediately after the 12 week treatment and after 52 weeks of follow-up, although the differences were only statistically significant for the main complaint. No statistically significant differences between groups were found as regards improvement in quality of life (EQ5D). Imputation did not alter these results.

\section{Health care utilisation and sick leave}

Table 2 shows the mean volumes of health care utilisation per patient during the one-year follow-up period (excluding GET and UC). The overall utilisation of all direct health care services and relevant non-health care services during the follow-up period was lower for patients allocated to GET than for those allocated to UC (except for unpaid help from family/friends) and the difference reached statistical significance (except for paid housekeeping and expenses for health activities). There was also a statistically significant difference in sick leave from unpaid work during follow-up in favour of GET. No statistically significant differences between the treatment groups were found in sick leave from paid work.

Table 2. Baseline characteristics

\begin{tabular}{|c|c|c|}
\hline 18 & $\begin{array}{l}\mathrm{GET} \\
\mathrm{N}=87\end{array}$ & $\begin{array}{c}\text { Usual Care } \\
N=89\end{array}$ \\
\hline \multicolumn{3}{|l|}{ Demographic variables } \\
\hline Meanage (years) (sd) & $51(3)$ & $53(117)$ \\
\hline Female $(\%)$ & 51 & 58 \\
\hline Paid work $(\%)$ & 56 & 57 \\
\hline Sick leave (ff paid work) in past 8 weeks (s 1 week $(0 \%)$ & 4 & 12 \\
\hline \multicolumn{3}{|l|}{ Outcome variables Mean (sd) } \\
\hline Severity of main complaints $(0-100)$ & $762(1918)$ & $719(196$ \\
\hline Functional limitat ons n daily activities (SDQ) (0 100) & $66,0(18,06)$ & $65,6(19.86)$ \\
\hline Quality of life $(\operatorname{COSD})(1 \mathrm{to})$ & $0.66(0,234)$ & $069(0198)$ \\
\hline
\end{tabular}

\section{Costs}

The mean costs per treatment group are presented in table 3 . The intervention costs for the GET programme were based on an average of 17.2 sessions per patient. The intervention costs for GET ( $€ 261)$ were significantly higher than those for UC ( $€ 61$ ). Patients allocated to GET had significantly higher total costs during the 12 week treatment period and significantly lower costs during the follow-up period (weeks 12-52) than patients allocated to UC. Totall mean costs over the entire 52 -week period of treatment plus follow-up were $E 153$ higher for patients allocated to GET. 
Tabe 3. Mean mpromement per ovrcome neasure after 12 and 52 weeks

\begin{tabular}{|c|c|c|c|c|c|c|}
\hline \multirow{2}{*}{$\frac{}{4}$} & \multirow{2}{*}{$\begin{array}{c}\text { GET } \\
N=87\end{array}$} & \multirow{2}{*}{$\begin{array}{c}\text { Usual Care } \\
N=89\end{array}$} & \multicolumn{4}{|c|}{ Differences between groups } \\
\hline & & & $\begin{array}{l}\text { Mean } \\
\text { diff }\end{array}$ & \multicolumn{2}{|c|}{$95 \%$ Cl of diff } & $\begin{array}{c}\text { Pualue } \\
\text { Parmetric }\end{array}$ \\
\hline \multicolumn{7}{|c|}{ Main complaints $(0-100)$. } \\
\hline 12 weeks & $32.8(25.7)$ & $25.3(24.5)$ & 7.5 & 0.0 & 15.0 & $0.049^{4}$ \\
\hline 52 weeks & $41.1(26.7)$ & $31.8(27.4)$ & 9.2 & 12 & 17.3 & $0.025^{4}$ \\
\hline \multicolumn{7}{|c|}{ SDQ $(0-100)$} \\
\hline 12 weeks & $17.0(26.0)$ & $15.3(21.6)$ & 1.7 & -5.4 & 8.8 & 0.642 \\
\hline 52 weeks & $22.5(26.2)$ & $20.4(31.2)$ & 2.1 & -6.5 & 10.7 & 0.633 \\
\hline \multicolumn{7}{|c|}{ Quality of life $(-1$ to 1$)$} \\
\hline 12 weeks & $0.0610 .22)$ & $0.05(0.18)$ & 0.00 & -0.06 & 0.06 & 0.929 \\
\hline 52 weeks & $0.10(0.22)$ & $0.07(0.18)$ & 0.03 & .0 .03 & 0.09 & 0.345 \\
\hline
\end{tabular}

after unconditional mean imputation

$295 \%$ confidence interval of difference

3 parametric Student's t-test

statistically significant $P<0.05$

\section{Cost-effectiveness analysis}

The incremental cost-effectiveness ratios (CER) for the severity of the main complaints ( 0 $100)$, SDQ $(0-100)$ and EQ5D $(-1.00-1.00)$ after 52 weeks indicate that the incremental costs for GET per unit improvement on these outcome measures were $€ 17(\mathrm{Cl}-4-129), € 74(\mathrm{Cl}$ -2-101) and $€ 5278(\mathrm{Cl}-11.808-51.407)$, respectively.

Figure 1. Cost-effectiveness plane for the main complaints after 52 weeks

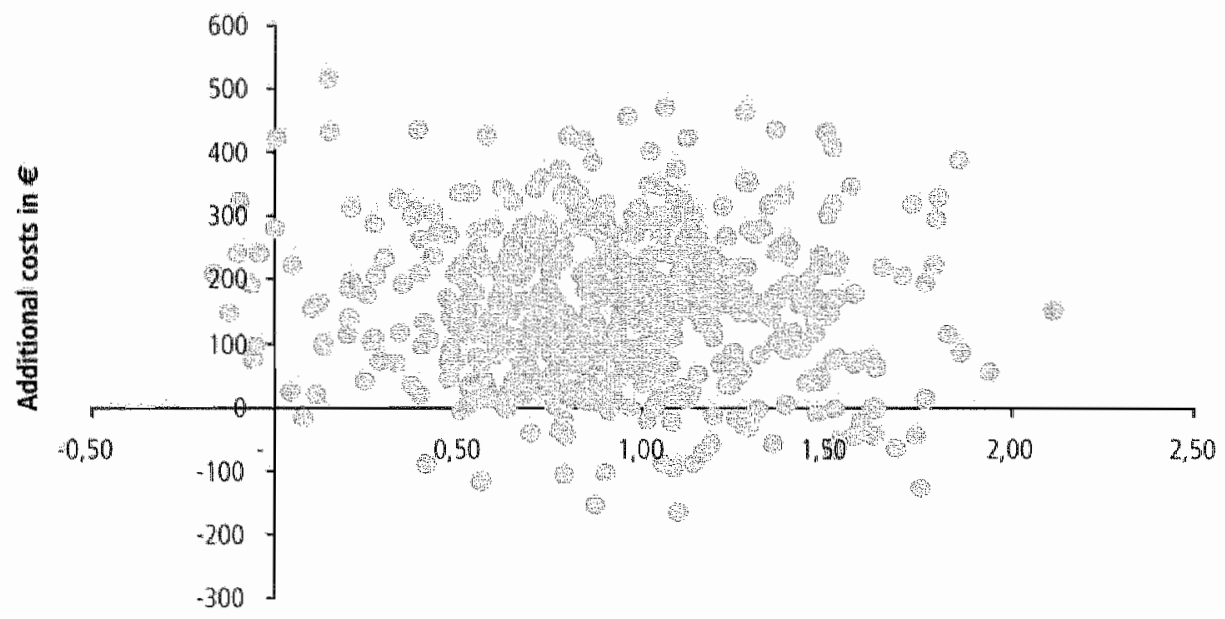

Additional effects per 10 units improvement 
The cost-effectiveness plane for the main complaints instrument after 52 weeks of follow-up is shown in figure 1. This plane shows that most cost-effect pairs (91\%) are in the upper-right quadrant, indicating positive effects at higher costs. Cost-effectiveness planes for the SDQ and EQ5D showed similar patterns, although more cost-effect pairs were located near the vertical axis, indicating smaller clinical effects at higher costs (no data presented).

\section{Sensitivity analysis}

Alternative analyses were performed after imputation of the group mean for one patient who reported extremely high utilisation of unpaid help from relatives/friends. After adjustment for this outlier, utilisation of all direct non-health care services was lower for patients allocated to GET than for those allocated to UC (table 2). Adjusted total mean costs were 79 higher for patients allocated to GET (table 3). The adjusted incremental cost-effectiveness ratios for the severity of the main complaints, SDQ and EQ5D after 52 weeks were $€ 9$ (CI 6$16), € 40(\mathrm{CI}-4-57)$ and $€ 2846(\mathrm{CI}-2.765-3.763)$, respectively.

\section{Discussion}

GET patients showed statistically significantlly greater improvement than UC patients on the main complaint instrument directly after the 12-week treatment, and these improvements lasted for at least 52 weeks. Improvements on the SDQ were greater with GET than with UC, but the differences between the groups never reached statistical significance. No statistically significant differences were found on the EQ5D. Patients allocated to GET showed statistically significantly lower direct health care costs and direct non-health care costs during the follow-up period (week 12-52) compared to patients allocated to UC. Nevertheless, since the costs of the GET programme were higher than those of UC, total costs for GET patients were significantly higher than for UC patients.

As expected, GET significantly improved the performance of daily activities as assessed by the main complaints measure. This means that patients' ability to perform the three most important daily activities improved significantly, both in the short term and after one year of follow-up. However, the SDQ, which measures pain and functional limitations in daily activities, did not show a significant difference between the GET and UC groups. Since the aim of GET is to improve the performance of daily activities irrespective of pain experiences, changes measured on the SDQ might be expected to be relatively small. No statistically significant differences were found on the five dimensions of the EQ5D measured at a threepoint level. It is very likely that improvements in individual daily activities due to GET were too specific to be detected by this generic health-related quality of life measure.

Patients were taught self-management of their complaints and how to deal with a new episode of shoulder complaints. We hypothesised that behavioural changes during the treatment period, relating to improvement of self management due to GET, would reduce the utilisation of health care services during the follow-up period and reduce sick leave in patients allocated to GET. The results show that the utilisation of health care services during the follow-up period was indeed significantly lower in patients allocated to GET. However, there was no statistically significant difference between groups regarding sick leave from paid work. The first reason for this was the low number of patients that reported sick leave from paid work in both groups ( 11 in GET versus 15 in UC), so these results need to be interpreted with considerable caution. A related explanation could be that return to work was not an 
explicit aim in this study. Patients were asked to identify daily activities that interrupted their daily lives and the ones they preferred to improve. These goals were not predominantly related to work and patients were only stimulated to apply to their work settings what they had learned from the therapy.

As expected, the intervention costs of the GET programme ( $€ 268$ ) were significantly higher than those of UC ( $E$ 61). This difference is mainly accounted for by the number of visits to physiotherapists for group treatment (on average 17.2 visits) compared to the number of visits to other health care providers (general practitioners, physiotherapists, manual therapists and Cesar/Mensendieck exercise therapists), mainly accounts for these differences. The incremental cost-effectiveness ratio (CER) of the main complaints instrument, for GET compared to UC, shows that it costs $€ 17$ to increase performance of daily activities with $1 \%$. Recently the CER of the main complaints instrument, for manipulative therapy as add-on to UC compared to UC alone was calculated at $€ 22$ for a $1 \%$ increase in the performance of daily activities in patients with shoulder complaints and concomitant neck problems (Bergman et al 2005). This indicates that cost-effectiveness ratios for GET in patients with chronic shoulder complaints and for manipulative therapy as an add-on to UC in patients with shoulder complaints and concomitant neck problems are comparable. The costs per patient to improve the performance of daily activities by $25 \%$, which was the aim of this trial, were calculated to be $€ 425$. When adjusted for one outlier these costs were $€ 225$.

We conclude that GET is more cost-effective than UC for patients with chronic shoulder complaints in primary care. GET is clinically more effective than UC in restoring daily activities in these patients after the 12-week treatment period, and these effects last for at least 52 weeks. GET significantly reduces direct health care costs and direct non-health care costs in patients with chronic shoulder complaints. However, total costs during the one-year follow-up period were significantly higher due to the higher costs of the intervention itself.

\section{POLICY IMPLICATIONS}

It is recommended to use GET to restore daily activities in patients with chronic shoulder complaints in primary care. GET is effective in restoring daily activities in patients with chronic shoulder complaints in long term in a primary care setting and might as such prevent more intensive and more expensive multidisciplinary treatment of these patients in secondary or tertiary care settings. We recommend that the programme should focus more on work-related goals and work-related activities in patients having paid work, which might improve the social benefits of GET. 


\section{REFERENCES}

Bergman GJD, MW xan Tulder, JC Winters et al. In Bergrnan GD ed. Manipulative therapy for shoulder complaimts in general practice. Groningen: Stichting Drukkerij C. Regenboog $2004: 6377$.

Beurskens AJHM, Vet HCW de, Köke AJA et al. A patient-specific approndh for meastiring functional status in low back pain. J Manipulative Physiol Ther 1999; 22:144-8

Brooks R. EuroQol: The current state of play. Health Policy 1996; 37: $53-72$.

Campbell MK, Torgerson DJ. Bootstrapping, estimating confodence intervals for cost-effectiveness ratios. QIM 1999; 92: 177-82.

Geraets IIXR, Goossens EJB, Bruijn CPC de, et al. A behavioural treatment for chronic shoulder complaints: concepts, development, and study design. Aust J Physiother. 2004; 50: 33-38.

Gerats JJXR, Goossens EIB, Groot IJM de et al. Effectiveness of a graded exercise therapy programme for patients with chronic shoulder complaints. Aust J Phystother. 2005; 51:87-94.

Genets JJXR, Goossens EJB, Hatstregt I wan et al. Implications of process exaluation for clinical effectiveness and clinical prattice in a trial on chronic shoulder complaints. Pat Educ Couns 2006 (accepted for publication)

Goossens MEJB, Evers SMAA. Economic evaluation in back pan interventions. I Occup Rehabil 1997; 7: 1532

Goossens ME, Rutten van Molken MP, Vlaeyen JW et al. The cost diary: a method to measure direct and indirect costs in cost-effectiveness research. J Clin Epidemiol 2000; 53(7):688-695.

Guzmàn J, Esmail R, Karjalainen K ef all. Multidisciplinary rehabilitation for chronic low back pain: systematic rewiew. Br Med J. 2001; 322:511-516.

Heijden GIMG van der, Leffers P. Bouter LM. Shoutder Disability Questionnaire design and responsiveness of a functional status measure. I Clin Epidemiol 2000; 53:29-38.

Luime JJ, Koes BW. Henriksen IJ et al. Prevalence and incidence of shoulder pain in the general population; a systematic review. Scand J Rheumatol. 2004;33:73-81.

Meeding WJL, Bonnew $L_{2}$ Polder II el al. Demographic and epidemiological determinants of healthcare costs in the Netherfands: a cost of illness study. Br Med I 1998; 317: $1111-115$.

Morley $S$, Eccleston C and Williams A. Systematic review and meta-analysis of randomized controlled trials of cognitive betawiour theraps and behaviour therapy for chronic pain in aditts, excluding headache. Pain. 1999; 88: 1-13.

Nygren A, Berglund A, won Koch M. Neck and shoulder pain, an increasing problem. Strategies for using insurance material to follow trends. Scand J Rehabil Med Supp] 1995; 32:107-12. 
Oostenbrink JB, Bouwnans C, Koopmanschap MA et al. Handleiding woor kostenonderzok, methoden en standaard kostprizzen voor economische evaluaties in de gezondheidszorg. College voor zorgverzekeringen: 2004.

$O^{\prime} B$ rien B), Brigg AH, Analysis of uncertainty in health care cost-effectiveness studies; an introduction to statistical issues and methods. Stat Methods Med Res 2002; 11: 455-68.

Pieavet HSI, Schouten 1SAG. Musculoskeletal pain in the Netherlands: prevalences, consequences and risk groups; the DMC (3) - study. Pain 2003;102:167-178.

Tulder MW yan, Ostelo RWIG, Vlaeyen JWS et al. Asystematic rewiew within the framestork of the Cochrane Back Review Group. Spine. 2001; 26: 270-281.

Waddell G. The back pain revolution. London. Churchill Livingstone 1998. 103-117, 351-367

Winters $I C$, Jongh AC de, Windt DAWM van der et al. NHG-Standaard Schouderkachten. Huisarts en Wetenschap. 1999; 42: 222-231. 



\section{CHAPTER 6}

\section{Process evaluation}

Accepted for publication as

Geraets JIXR, Goossens EIB, Haastregt I van, Groot IM de, Bruijn CPC de, Bie RA de, Köke AJA, Heuvel WJA van den. Implications of process evaluation for clinical effectiveness and clinical practice in a trial on chronic shoulder complaints. Pat Educ Couns 2006 
ABSTRACT

Objective: The intervention process was evaluated in a randomised clinical trial on the effectiveness of a behavioural Graded Exercise Therapy (GET) programme for patients with chronic shoulder complaints in primary care settings. This process evaluation was done for three reasons: first, to know whether the programme was performed as planned, second, to know whether or not this treatment is feasible in normal practice, and third, to identify needs for improvement of the protocol to facilitate implication.

Methods: We evaluated the extent to which the programme is being applied according to protocol, patient adherence to the programme, and the suitability of the programme according to patients and physiotherapists. Twenty participating physiotherapists and 87 patients allocated to GET were asked to evaluate the intervention process. Furthermore, a sample of ten patients, taken from the total number of 87 patients allocated to GET, was invited to take part in a focus group interview at the end of the study. We evaluated the intervention process using a treatment registration form filled in by the physiotherapists during treatment, evaluation forms filled in independently by physiotherapists and patients 26 weeks after the start of the treatment period, and information gathered during the focus group interview at the end of the study.

Results: GET was applied according to protocol to an acceptable extent, and participating patients showed satisfactory adherence to the programme.

Conclusions: Clinical effectiveness of GET in this trial is not influenced by flaws in the application of the programme or by lack of patient adherence.

Practice implications: The programme could be improved in terms of the process of goal-setting, and the implementation of GET could be facilitated if the programme is embedded in a multidisciplinary approach in primary care.

Key words: Evaluation study, shoulder complaints, behavioural therapy, randomised clinical trial. 


\section{INTRODUCTION}

In the past decade, increasing attention is being paid to quality of life outcomes and costeffectiveness of treatment programmes, in order to support policy decisions (Gerszten 1998, Urden 2002). Unfortunately, however, still little attention is paid to the evaluation of the intervention process in trials (Haastregt et al 2002). Effectiveness of a treatment under study is not only determined by its content, but also by its application and by participants" experiences, adherence, beliefs and attitudes (Kvien and Heiberg 2003, Thomas et al 2004, Goossens et al 2005, Jensen et al 2004, Keefe et al 2004, Lackner et al 1996, Keith 1998, Westbrook et al 1993). Therefore, information on the intervention process is essential for the interpretation of the results of a trial (Haastregt et al 2002). For example, if an intervention turns out to be ineffective or less effective than expected, this could be due to weaknesses in or unsuitability of the intervention, but also to flaws in its application (protocol deviations). In addition, gathering information about the intervention process is useful for further improvement of the intervention and for its implementation in regular practice when it proves successful.

This process evaluation study was embedded in a trial on clinical effectiveness of a Graded Exercise Therapy (GET) programme in patients with chronic shoulder complaints in a primary care setting. Shoulder complaints (SC) are a major health problem in the Netherlands. In 1998, the prevalence of chronic SC lasting more than three months in the Dutch general population (upwards of 25 years of age) was 15\% (Picavet and Schouten 2003). Patients with chronic SC suffer from disability and pain (van der Heijden 1999). About a quarter (27\%) of all patients with SC report persisting pain, and $29 \%$ mention limitations in the performance of daily activities (Picavet and Schouten 2003). Approximately $50 \%$ of all patients with SC still have complaints 6 months after their first visit to the General Practitioner (GP), despite treatment as usual (van der Windt et al 1996).

Because SC can have a considerable impact on daily life and often develops into a chronic disorder, it is important to assess options for further optimising the treatment of patients with SC. In the last decades, behavioural therapy principles have proven to be effective in the management of musculoskeletal pain problems among low back pain patients (Guzmán et al 2001, Linton 1999, Morley et al 1999, van Tulder et al 2001, Vlaeyen and Linton 2000). It is likely that behavioural therapy will also be effective in the treatment of patients with clironic SC (Linton 1995), although specific evidence on this issue is still lacking. We therefore developed a GET prograrnme for chronic SC patients (Geraets et al 2004). This behavioural programme is administered by a physiotherapist (PT). The programme is currently being evaluated on its effectiveness and cost-effectiveness in a randomised clinical trial. GET is compared with usual care for $\mathrm{SC}$ according to the guideline for shoulder complaints issued by the Dutch College of General Practitioners (DCGP) in 1999 (Winters et al 1999).

The present process evaluation was done for three reasons: first, to know whether the GET programme was performed as planned, second, to know whether or not this treatment is feasible in normal practice, and third, to identify needs for improvement of the protocol to facilitate implication. Therefore, we describe the extent to which the intervention is being applied according to protocol, the adherence of patients to the programme, and the suitability of the programme according to patients and physiotherapists. 


\section{GRADED EXERCISE THERAPY}

GET is a behavioural programme developed for chronic SC in a primary care setting, administered by a physiotherapist. The main elements of the programme are listed in table 1 .

Tible 1. Main elements of the Graded Lxercise Therapy programme

\section{Start-up period (approximately 6 sessions over a 2 -week period)}

- Rrationale pror to the star of the programne, patients receive a shor brochure explaining the rationale behind it.

- Reconceptualsalion pain and pain related disabilfy are reviewed to ensure that patients are conwhed they are able 10 control and ofluence their pain experience and improve leves of activity

- Goal-settrig Treatiment goals are set, related to the patient's own prefered daily activitles.

\section{Treatment plus generalisation period (approximately 12 sessions over a 10 -week period)}

- Graded Acrivity Levels of activity are increased in a step wise lashion.

- Time contingency Levels of activiy are structured in time and not according to pain experience

- Operant conditioning Environmental reinforcement is used to promote and improve healthy behavour.

- Generalisation: What hiss been learned is applied to everyday life.

An important aim of GET is to increase levels of daily activity by learning from the consequences of behaviours. Pain behaviour is expected to be consolidated when patients experience the consequences of this behaviour as pleasant and to extinguish when they experience it as unpleasant. Operant learning principles are used to promote and improve healthy behaviour by changing the consequences of behaviour (Fordyce 1976, Skinner 1953). Positive reinforcement of the preferred behavioural changes is given to increase and maintain the desired behaviour. In graded activity, levels of activity increase in a step-wise time-contingent fashion. This means that the intensity of exercises increases gradually over time, irrespective of pain experience, towards preset goals and with fixed quota agreed upon at the start of the programme. The GET programme consists of a maximum of 18 group sessions of approximately 60 minutes over a period of 12 weeks. GET is administered in small groups of three to five persons. During the 'start-up period', the rationale is explained, pain and pain-related disability are discussed, baseline levels of activities are established, and treatment goals are set. The 'treatment plus generalisation' period involves the performance of operant conditioning and time-contingent graded exercises. At the start of the programme, the frequency of sessions is fixed at three times a week, after which it gradually decreases to one session every two weeks. Generalisation to everyday life is strongly emphasized at the end of this phase.

Prior to the start of the study, physiotherapists participating in the GET group took part in a one-day workshop and two booster sessions under the supervision of experts in the field of cognitive-behavioural treatment. More details of the development and content of GET have been presented elsewhere (Geraets et al 2004).

\section{METHODS}

\section{Participants}

Patients were eligible for participation in the randomised clinical trial if they had suffered from shoulder complaints for at least three months. Patients suffering from systemic diseases, 
referred pain or severe biomedical or psychiatric disorders were excluded. Since we considered PT experience as a putative prognostic factor, participants were pre-stratified at the level of the nearest physiotherapy practice before randomisation. Eighty-nine patients were allocated to the control group (usual care by the general practitioner). Because these patients did not receive the GET-programme they did not participate in the processevaluation. Eighty-seven patients were allocated to the GET programme administered on ten locations by twenty physiotherapists (two physiotherapists per location). All patients allocated to the intervention group and all physiotherapists who administered the GET programme, were asked to participate in the process evaluation. We divided the participating patients into two subgroups that either completed the programme (maximum of 18 sessions or fewer than 18 sessions and no more shoulder complaints at the time the treatment was ended) or did not complete the programme (fewer than 18 sessions and still having shoulder complaints when the treatment was ended).

\section{Outcome measures}

Application of the programme according to protocol

In order to determine whether the GET programme was being applied according to protocol, we assessed the number of treatment sessions and the duration of the programme by means of a registration form (A) filled in by the physiotherapists during the intervention period (table 2, items 1.1 and 1.2). In addition, application of the main elements of the programme was assessed by means of registration form $(A)$ and concealed evaluation forms ( $B$ and $C$ ), filled in independently by all participating physiotherapists (A and B) and patients (C) 26 weeks after the start of the progranme. Physiotherapists and patients received the evaluation forms ( $\mathrm{B}$ and $\mathrm{C}$ ) by post and were asked independently whether the main elements of the programme as listed in table 2 (item 1.3) had been reviewed or applied during the programme. All items were formulated as statements which had to be rated on a five-point ordinal scale (ranging from $\mathbb{1}=$ fully convinced to $5=$ not al all convinced).

Programme adherence by participants

In order to assess adherence by participants, the physiotherapists were asked to rate on a fivepoint ordinal scale whether they were satisfied with the way their patients had participated in the programme, and the patients were asked whether they were satisfied with the way they had participated in the programme (table 2, item 2).

\section{Suitability of the programme}

In order to assess the suitability of the programme, physiotherapists were asked to rate on a five-point ordinal scale whether they considered GET to be suitable for the complaints of each participating patient. In addition, each patient was asked to rate whether he or she had experienced GET to be a suitable treatment for their own SC (table 2, item 3).

\section{Focus group interview}

A sample of ten patients, taken from all patients allocated to GET, was asked to take part in a focus group interview at the end of the intervention period. We aimed at selecting a representative group of all GET patients to participate in this interview. Patients were selected on age and sex, as well as on the physiotherapy practice to which patients had been allocated, in order to gather information from individual strata of the trial. Furthermore, the focus 
group included both patients who had completed the GET programme and patients who had not completed the programme. Matched substitutes were selected if patients were not willing to participate. The aim of this semi-structured interview was to gain additional qualitative information on the most important aspects of the intervention process (table 2). An independent interviewer who was not involved in conducting the trial supervised the intervention. Data were recorded on a form (D) by a research assistant.

\section{Analysis}

Means and standard deviations were calculated for continuous baseline and outcome variables. Medians and cumulative percentage scores were used for ordinal variables (items of the evaluation forms). Qualitative data on the intervention process were analysed and main outcomes are presented.

\section{RESULTS}

\section{Participants}

All twenty physiotherapists filled in registration forms $\mathrm{A}$ and evaluation forms $\mathrm{B}$.

Eighty-seven patients were allocated to GET in this trial. Six patients withdrew from the study within 26 weeks of follow-up (one patient because of the frequency of the sessions, one because of a different treatment preference, one because of neck problems, one for private reasons, one for lack of time and one because of unwillingness to participate in the study any longer). Eighty-one patients were asked to fill in evaluation form C. Seventy-eight patients (96\%) returned this form and participated in the process evaluation.

Characteristics of participants are listed in table 3. Demographic variables, specific disease variables, outcome or process variables, and treatment preferences for patients who participated in the process evaluation were comparable to patients who did not participate. The small group $(\mathrm{N}=9)$ who did not participate in the process evaluations included slightly younger patients, had less concomitant neck problems, and the duration of their complaints was shorter. Five patients who participated in this process evaluation had not completed the GET programme (one for other medical reasons, one for psychological reasons, one because of a trauma, and two because of increased complaints). Table 3 shows that characteristics of patients who completed the programme and those who did not complete the programme were comparable, although the small group who did not complete the programme $(\mathrm{N}=5)$ included more female patients, had less concomitant neck problems, and were more ambivalent in their opinion about physiotherapy.

The items relating to the application of the main elements of the intervention were only rated by the 73 patients who completed the programme. In addition, adherence to the programme and suitability of the programme could not be assessed for one of the patients, who did not complete the programme and ended treatment after one session.

Nine of the ten patients who had been invited to the focus group interview at the end of the intervention period actually participated in the interview (one patient cancelled her appointment at the last minute for medical reasons). These patients had been allocated to seven different physiotherapy practices. Seven of these patients had fully completed the programme. Table 3 shows that characteristics of patients who participated in the focus group were comparable to those of all patients allocated to GET. 
Table 2. Outcome measure

\begin{tabular}{|c|c|c|c|c|}
\hline 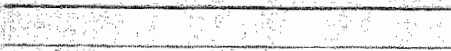 & Physiotherap & & Patients & \\
\hline 3 & $\begin{array}{l}\text { Registration } \\
\text { forms } \mathrm{A}\end{array}$ & $\begin{array}{l}\text { Evaluation } \\
\text { forms }^{\text {B }}\end{array}$ & $\begin{array}{l}\text { Evaluation } \\
\text { forms }^{b} \mathrm{C}\end{array}$ & $\begin{array}{l}\text { Focus group } \\
\text { interview D }\end{array}$ \\
\hline 1. Application according to protocol & & & & \\
\hline 11 Number of sessions & $x$ & & & $\%$ \\
\hline 12 Duration of programme & $x$ & & & \\
\hline 13 Main elements of treatment & & & & 8 \\
\hline Rationale & & & & \\
\hline - Rationale of GET explained & & & & X \\
\hline Reconceptualisation & & & & \\
\hline - Pain-related disability reviewed & & $x$ & $x$ & $x$ \\
\hline$\therefore$ Pain beliefs reviewed & & $x$ & $x$ & $x$ \\
\hline $\begin{array}{l}\text { - Environmental factors at home and } \\
\text { at work revieiwed }\end{array}$ & & $x$ & $x$ & $x$ \\
\hline - Main complaint reviewed & & $x$ & $x$ & $x$ \\
\hline $\begin{array}{l}\text { - Barriers and obstacles towards } \\
\text { recovery reviewed }\end{array}$ & & $x$ & $x$ & $x$ \\
\hline Goal-setting & & & & \\
\hline - Treatment goals defined & $x$ & $x$ & $x$ & $x$ \\
\hline Graded activity & & & & \\
\hline Levels of activities increased stepwise & $x$ & $x$ & $x$ & $x$ \\
\hline Tíme contingency & & & & \\
\hline Levels of activities structured in time & $x$ & $x$ & $x$ & $x$ \\
\hline Operant conditioning & & 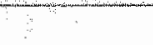 & & \\
\hline $\begin{array}{l}\text { - Reinforcement of pain control } \\
\text { behaviours }\end{array}$ & & $x$ & $x$ & $x$ \\
\hline $\begin{array}{l}\text { Reinforcement of pain-related } \\
\text { activities }\end{array}$ & & $x$ & $x$ & $x$ \\
\hline Generalisation & & & & \\
\hline $\begin{array}{l}\text { - Self-management of complaints. } \\
\text { reviewed }\end{array}$ & & $x$ & $x$ & $x$ \\
\hline - Setting of new goals reviewed & & $x$ & $x$ & $x$ \\
\hline $\begin{array}{l}\text { - Application of treatment principles } \\
\text { after treatment period reviewed }\end{array}$ & & $x$ & $x$ & K \\
\hline 2. Adherence to the programme & & & & \\
\hline $\begin{array}{l}\text { - PT's satisfaction with the way the } \\
\text { patient participated in the programme }\end{array}$ & & $x$ & & \\
\hline $\begin{array}{l}\text { - Patient's satisfaction with the way he or } \\
\text { she participated in the programme }\end{array}$ & & & $x$ & $x$ \\
\hline 3. Suitability of the programme & & & & \\
\hline $\begin{array}{l}\text { Suitability of the programme for } S \mathrm{C} \text { of } \\
\text { patient as perceived by PT }\end{array}$ & & $x$ & & \\
\hline $\begin{array}{l}\text { - Suitability of the programme for own SC } \\
\text { as perceived by patient }\end{array}$ & & & $x$ & $x$ \\
\hline
\end{tabular}

${ }^{a}$ Filled in during treatment by the physiotherapist

${ }^{b}$ Filled in independently by patients and physiotherapists at 26 weeks after the start of the programme

${ }^{c}$ Focus group interview with patients at the end of the study 
Table 3. Charateristics of patients

\begin{tabular}{|c|c|c|c|c|c|c|c|c|}
\hline & $\begin{array}{l}\text { Allocated } \\
\text { to GET }\end{array}$ & $\begin{array}{l}\text { Partidipating } \\
\text { in process } \\
\text { evaluation }\end{array}$ & $\begin{array}{l}\text { Not } \\
\text { participating } \\
\text { in process } \\
\text { evaluation }\end{array}$ & GET & $\begin{array}{l}\text { GET } \\
\text { not } \\
\text { completed }\end{array}$ & $\begin{array}{l}\text { Induded } \\
\text { in focus } \\
\text { group }\end{array}$ & $\begin{array}{l}\text { No } \\
\text { adherence } \\
\text { to GET }\end{array}$ & $\begin{array}{l}\text { GET not } \\
\text { suitablle }\end{array}$ \\
\hline Mumber: & 87 & 78 & 9 & 73 & 5 & 9 & 15 & 7 \\
\hline Enoles $\%$ & 51 & 50 & 56 & 48 & 80 & 33 & 40 & 57 \\
\hline Mear age $(s \mathrm{~d})^{2}$ & $\begin{array}{r}512 \\
01315\end{array}$ & $\begin{array}{c}520 \\
1326\end{array}$ & $\begin{array}{c}45.1 \\
(10.95)\end{array}$ & $\begin{array}{c}52.1 \\
(1298)\end{array}$ & $\begin{array}{r}50.4 \\
118.56) \\
\end{array}$ & $\begin{array}{l}55.6 \\
9.90)\end{array}$ & $\begin{array}{r}50.2 \\
(11.52) \\
\end{array}$ & $\begin{array}{r}58.6 \\
(15.52) \\
\end{array}$ \\
\hline $\begin{array}{l}\text { Curation of complahts } \\
26 \text { nionths }(6 \%)\end{array}$ & 79 & 82 & 56 & 82 & 80 & 100 & 87 & 86 \\
\hline $\begin{array}{l}\text { Concomitant } \\
\text { neck problems ( } \% \text { ) }\end{array}$ & 54 & 55 & 44 & 58 & 20 & 56 & 67 & 14 \\
\hline Quich oniset (\%) & 97 & 17 & 22 & 16 & 20 & 33 & 20 & 14 \\
\hline $\begin{array}{l}\text { Pror episodes } \\
\text { ofscry) }\end{array}$ & 66 & 68 & 67 & 67 & 80 & 78 & 80 & 57 \\
\hline $\begin{array}{l}\text { Sevenity of } \\
\text { main complaint } \\
(0-100)^{b} \text { (sd) }\end{array}$ & $\begin{array}{l}76.2 \\
(19,18)\end{array}$ & $\begin{array}{c}76.4 \\
(18.86)\end{array}$ & $\begin{array}{c}74.4 \\
(22.97)\end{array}$ & $\begin{array}{c}76.3 \\
(18: 97)\end{array}$ & $\begin{array}{c}78.0 \\
19.24)\end{array}$ & $\begin{array}{c}68.9 \\
(13.64)\end{array}$ & $\begin{array}{c}78.7 \\
(13.02)\end{array}$ & $\begin{array}{l}80.00 \\
(11.55)\end{array}$ \\
\hline $\begin{array}{l}\text { Functional limitations } \\
\text { in daily activities } \\
(0-100)^{\circ} \text { (sd) }\end{array}$ & $\begin{array}{c}66.0 \\
(18.06)\end{array}$ & $\begin{array}{c}66.0 \\
(18.33)\end{array}$ & $\begin{array}{c}65.93 \\
(16.48)\end{array}$ & $\begin{array}{c}65.9 \\
(18.71)\end{array}$ & $\begin{array}{c}68.3 \\
(12.87)\end{array}$ & $\begin{array}{c}75.7 \\
(14.47)\end{array}$ & $\begin{array}{c}69.6 \\
(16.38\}\end{array}$ & $\begin{array}{c}63.5 \\
(24.42)\end{array}$ \\
\hline $\begin{array}{l}\text { Shoulder pain } \\
(728)^{\text {d (sd) }}\end{array}$ & $\begin{array}{l}17.9 \\
(4.43)\end{array}$ & $\begin{array}{c}17.7 \\
(4.46)\end{array}$ & $\begin{array}{l}19.89 \\
(3.86)\end{array}$ & $\begin{array}{c}17.6 \\
(4.50)\end{array}$ & $\begin{array}{r}18.6 \\
(4.16)\end{array}$ & $\begin{array}{c}19.2 \\
(4.84)\end{array}$ & $\begin{array}{r}19.0 \\
(4.31)\end{array}$ & $\begin{array}{c}17.0 \\
(4.28)\end{array}$ \\
\hline $\begin{array}{l}\text { Catastrophising } \\
(116)^{6}(\mathrm{sd})\end{array}$ & $\begin{array}{c}2.4 \\
(0.84) \\
\end{array}$ & $\begin{array}{r}25 \\
0.86\} \\
\end{array}$ & $\begin{array}{c}1.9 \\
(0.46) \\
\end{array}$ & $\begin{array}{c}2.4 \\
(0.84) \\
\end{array}$ & $\begin{array}{c}2.8 \\
(1.09) \\
\end{array}$ & $\begin{array}{c}2.2 \\
10.721\end{array}$ & $\begin{array}{r}2.4 \\
(0.9) \\
\end{array}$ & $\begin{array}{r}2.6 \\
(1.01) \\
\end{array}$ \\
\hline $\begin{array}{l}\text { Coping with pain } \\
(1-6)^{e} \text { (sd) }\end{array}$ & $\begin{array}{c}3.0 \\
(0.97)\end{array}$ & $\begin{array}{c}3.0 \\
(0.94)\end{array}$ & $\begin{array}{c}3.5 \\
(1.10)\end{array}$ & $\begin{array}{c}3.0 \\
(0.95)\end{array}$ & $\begin{array}{c}3.1 \\
(0.92)\end{array}$ & $\begin{array}{c}2.5 \\
(0.98)\end{array}$ & $\begin{array}{l}2.9 \\
(0.9)\end{array}$ & $\begin{array}{c}2.5 \\
10.88)\end{array}$ \\
\hline $\begin{array}{l}\text { Internal locus of } \\
\text { conitrol }(1-6)(\mathrm{sd})\end{array}$ & $\begin{array}{c}3.3 \\
(0.94)\end{array}$ & $\begin{array}{c}3.3 \\
(0.94) \\
\end{array}$ & $\begin{array}{c}3.2 \\
(1.04)\end{array}$ & $\begin{array}{c}3.3 \\
(0.95)\end{array}$ & $\begin{array}{c}3.4 \\
(0.79)\end{array}$ & $\begin{array}{c}3.4 \\
(0.93)\end{array}$ & $\begin{array}{c}3.2 \\
10.87)\end{array}$ & $\begin{array}{c}3.0 \\
(1.93)\end{array}$ \\
\hline $\begin{array}{l}\text { Externial locus of } \\
\text { control }(1.6)^{\mathrm{e}}(\text { isd })\end{array}$ & $\begin{array}{c}2.9 \\
(0.84)\end{array}$ & $\begin{array}{c}2.9 \\
(0.81)\end{array}$ & $\begin{array}{c}2.7 \\
(1.11)\end{array}$ & $\begin{array}{c}2.9 \\
(0.84)\end{array}$ & $\begin{array}{c}2.7 \\
10.38)\end{array}$ & $\begin{array}{c}2.7 \\
(0.64)\end{array}$ & $\begin{array}{c}3.0 \\
(0.86)\end{array}$ & $\begin{array}{c}2.9 \\
(0.53)\end{array}$ \\
\hline \multicolumn{9}{|c|}{ Texatment preferences (yes undear hol $(\%)$} \\
\hline$-\mathrm{GET}$ & 61886 & 68816 & $0 / 100 / 0$ & 78697 & $0 / 10000$ & $0,89 ! 11$ & $0193 / 7$ & $0 / 10010$ \\
\hline - physiotherapy & 561386 & $56 / 3816$ & $56 / 4410$ & $60 / 33 / 7$ & $0 / 10010$ & $33: 2245$ & $54 / 33 / 13$ & $43 / 15710$ \\
\hline - manual therapy & 1318017 & $13: 8017$ & $13 / 7413$ & 1418016 & 0180120 & $11 / 79811$ & $7 / 1380$ & $0 / 100 / 0$ \\
\hline - analgetics & 4129167 & $5 / 27168$ & $0 / 4456$ & 4127169 & $20 / 20160$ & $0 / 1189$ & 6,27167 & $07 / 1 / 29$ \\
\hline - NSADS & 7136597 & $7 / 39160$ & $11 / 55133$ & $5 B 3 / 62$ & 2040140 & 0111189 & $717 / 86$ & $0 / 43 / 57$ \\
\hline - injection & $3 / 26971$ & 42317 & $0 / 4456$ & $3 / 2572$ & $20 / 0 / 80$ & $011 / 89$ & $0 / 20 / 80$ & $0 / 43157$ \\
\hline - surgery & 2122176 & 321176 & 0.67733 & $2 / 22176$ & $2010 / 80$ & $0 / 01100$ & 7160133 & 0129171 \\
\hline
\end{tabular}

\footnotetext{
standard deviation

11-point Likert Scale

Shoulder Disablity Questionnaire (van der Heijden et al 2000)

Shoulder Pain Score Whinters et al 1996)

- Pain Coping and Cognition List (Berg et al 2001)
} 


\section{Outcome measures}

Application of the programme according to protocol

Results on application of the programme are presented in table 4 and table 5. Table 4 shows numbers of sessions and the duration of the programme, listed per PT practice. The mean number of sessions and mean duration of the programme for all patients who completed the programme were 17.2 and 12.8 weeks respectively. The number of patients allocated and treated per PT practice ranged from two to 14.

Table 4 . Numbers of sessions, durdion of progtamme, allocated patients per PT practice

\begin{tabular}{|c|c|c|c|c|c|}
\hline PT practice & $\begin{array}{l}\text { Number of } \\
\text { patients }\end{array}$ & $\begin{array}{l}\text { Number of } \\
\text { sessions }(\mathrm{sd})^{\mathrm{b}}\end{array}$ & $\begin{array}{l}\text { Duration of } \\
\text { programme }\end{array}$ & $\begin{array}{c}\text { Females } \\
(\%)\end{array}$ & $\begin{array}{l}\text { Mean age } \\
(\mathrm{sd})^{\mathrm{b}}\end{array}$ \\
\hline 1 & 8 & $1801000)$ & $150(346)$ & 37 & $549(810)$ \\
\hline 2 & 9 & $17.8(0.44)$ & $134(251)$ & 33 & $482(128)$ \\
\hline 3 & 8 & 17311501 & $149(285)$ & 75 & $449(1004)$ \\
\hline 4 & 2 & $140(5.66)$ & $951071)$ & 50 & $385(354)$ \\
\hline 5 & 18 & $180(0,00)$ & $126(2.84)$ & 69 & $490(1404)$ \\
\hline 6 & 8 & $15.6297)$ & $110(151)$ & 50 & $605(13.43)$ \\
\hline 7 & 7 & $173(1,16)$ & $97(058)$ & 57 & $51.4111 .40^{\circ}$ \\
\hline 8 & 10 & $16.0(3.42)$ & $13.6(4.50)$ & 60 & $575(12.51)$ \\
\hline 9 & 8 & $177(082)$ & $128(1,11$ & 37 & $4500(1626)$ \\
\hline 10 & 14 & $174(222)$ & $121299)$ & 36 & $52.4(13.57)$ \\
\hline Overall & 87. & $17.2(2.08)$ & $128(303)$ & 51 & 512013.15 \\
\hline Per protocol & 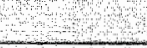 & 18 & 12 & 4 & 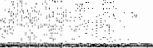 \\
\hline
\end{tabular}

number of sessions and duration of progranme in weeks

biandard deviation

Analysis of treatment registration forms A showed that for all patients, treatment goals had been defined and agreed upon at the start of the programme, quota of activities had been set, and graphs or tables had been used during the treatment period to evaluate the progress of activities and reinforce patient behaviour.

Analysis of median scores on evaluation forms $B$ and $C$ showed that most physiotherapists and most patients were strongly or fully convinced that the main ellements of the programme had been applied (table 5). Patients were in general more certain about the degree of application of the main elements of the programme than physiotherapists. Both physiotherapist and patients were very certain that pain-related disability had been reviewed at the start of the programme (92\%). They gave equal ratings for the reconceptualisation of barriers and obstacles towards recovery at the start of the programme $(78 \%)$ and $81 \%$ of both groups were strongly or fully convinced that graded activity principles were applied during the treatment period. Physiotherapists were less certain about the process of goal setting $(59 \%)$ and the application of time contingency principles $(60 \%)$ than patients ( $85 \%$ and $82 \%$ respectively). Both physiotherapists $(86 \%)$ and patients $(78 \%)$ reported that the emphasis of reinforcement during treatment had been on pain-related disability. Patients were less certain that management of new goals had been reviewed as part of the generalisation process (62\%). 
Table 5. Main elements, adherence and surtability

Evaluation forms PTs (B)

Evaluation forms pratients (C)

1. Application of programme according to protocal

1.3 Main elements of treatment $N=73$

\begin{tabular}{|c|c|c|c|c|c|c|c|c|}
\hline Scores & $1 \cdot 2^{\text {a }}$ & $3^{b}$ & $4 \cdot 5^{c}$ & Median & $1-2^{2}$ & $3^{6}$ & $4 \cdot 5^{c}$ & Median $^{\mathrm{d}}$ \\
\hline \multicolumn{9}{|l|}{ Reconceptualisation } \\
\hline \multicolumn{9}{|l|}{ Pain related disability } \\
\hline$N(\%)$ & $92)$ & (8) & 101 & $(1-2)^{e}$ & $(92)^{f}$ & (8) & (0) & $(1-2)^{e}$ \\
\hline \multirow{2}{*}{ Pain beliefs. } & 49 & 18 & 6 & 2 & 58 & 10 & 5 & 1 \\
\hline & (67) & $(25)$ & (8) & $(1-3)$ & (79) & (14) & (7) & $(1-2)$ \\
\hline \multirow[t]{2}{*}{ Sodal factors } & 62 & 11 & 0 & 2 & 57 & 11 & 5 & 1 \\
\hline & $(85)$ & (15) & (0) & $(1-2)$ & $(78)$ & $(15)$ & (7) & $(1-2)$ \\
\hline \multirow[t]{2}{*}{ Main complaint } & 53 & 17 & 3 & 2 & 64 & 6 & 3 & 1 \\
\hline & $(73)$ & (23) & (4) & $(1-3)$ & $(88)$ & (8) & (4) & $(1-2)$ \\
\hline \multirow[t]{2}{*}{ Barfiers and obstacles } & 57 & 10 & 6 & 2 & 57 & 10 & 6 & 2 \\
\hline & $(78)$ & (14) & (8) & $(1-2)$ & (78) & (14) & (8) & $(1-2)$ \\
\hline \multirow[t]{2}{*}{ Goal-setting } & 43 & 18 & 12 & 2 & 62 & 8 & 3 & 1 \\
\hline & (59) & (25) & (16) & $(1-3)$ & (85) & (11) & (4) & $(1-2)$ \\
\hline \multirow[t]{2}{*}{ Graded activity } & 59 & 12 & 2 & 2 & 59 & 9 & 5 & 2 \\
\hline & (81) & (16) & (3) & $(1-2)$ & $(81)$ & (12) & (7) & $(1-2)$ \\
\hline \multirow[t]{2}{*}{ Time contingency } & 44 & 13 & 16 & 2 & 60 & 8 & 5 & 2 \\
\hline & $(60)$ & (18) & (22) & $(11-3)$ & $(82)$ & (11) & (6) & $(1-2)$ \\
\hline \multicolumn{9}{|l|}{ Operant conditioning } \\
\hline \multirow{2}{*}{ Pain behaviours } & 51 & 11 & 11 & 2 & 49 & 9 & 15 & 2 \\
\hline & $(70)$ & (15) & (15) & $(1-3)$ & $(67)$ & (12) & $(21)$ & $(1-3)$ \\
\hline \multirow[t]{2}{*}{ Pain-related activities } & 63 & 10 & & 2 & 57 & 3 & 13 & 2 \\
\hline & (86) & (14) & (0) & $(1-2)$ & $(78)$ & (4) & (18) & $(1-2)$ \\
\hline \multicolumn{9}{|l|}{ Generalisation } \\
\hline \multirow[t]{2}{*}{ Self-management } & 59 & 10 & 4 & 2 & 61 & 8 & 4 & 1 \\
\hline & (81) & (14) & (5) & $(11-2)$ & $(84)$ & (11) & (5) & $(1-2)$ \\
\hline \multirow[t]{2}{*}{ Mew goals } & 50 & 13 & 10 & 2 & 45 & 21 & 7 & 2 \\
\hline & (68) & $(18)$ & (14) & $(1-3)$ & (62) & (29) & (9) & $(1-3)$ \\
\hline Application of treatment & 52 & 13 & 8 & 2 & 54 & 6 & 13 & 2 \\
\hline Pinciples after treatment. & (71) & (18) & (11) & $(1-3)$ & (74) & (8) & (18) & $(1-3)$ \\
\hline \multicolumn{9}{|c|}{ 2. Adherence to the programme $N=77$} \\
\hline & 59 & 7 & 11 & 2 & 55 & 7 & 15 & 2 \\
\hline & $(77)$ & (9) & (14) & $(1-2)$ & (7) & (9) & (20) & $(1-3)$ \\
\hline \multicolumn{9}{|c|}{ 3. Suitability of the programme $\mathrm{N}=77$} \\
\hline & 53 & 8 & 16 & 2 & 62 & 8 & 7 & 1 \\
\hline & $(69)$ & $(10)$ & $(21)$ & $(1-3)$ & (81) & $(10)$ & (9) & $(1-2)$ \\
\hline
\end{tabular}

Score 1-2 = fully or strongly convinced

"Score 3 = reasonably convinced

'Score $4.5=$ little or not at all convinced

Median

Eercentiles (25-75) 
Patients who participated in the focus group interview mentioned that the rationale of the programme had been appropriately explained at the start of the programme. Eight of the nime participants confirmed that the items listed under the heading of "reconceptualisation" had been reviewed, mainly in the first session.

Participants to the focus group interview mentioned that clear treatment goals related to daily activities had been defined and agreed upon at the start of the programme. However, five of them had experienced difficulties in setting treatment goals and reported that their aims had been strongly influenced by the physiotherapists' experience. Two patients reported that goals had been adjusted several times during the treatment period. For one patient, these adjustments had been made because of lack of progress, while for the other patient it had been because of successful progress.

All participants in the focus group confirmed consistent application of graded activity and time-contingent principles during the treatment period and reported clear advantages of the systematic approach to their complaints. Four participants, however, had also experienced difficulties in the performance of time-contingent exercises during the treatment, especially in situations of unsatisfactory progress and conflicting recommendations by health care providers. Participants reported that the items relating to generalisation had not always been reviewed in detail, but there was an ongoing process of applying what they had learned in everyday life.

\section{Patient adherence}

Analysis of evaluation forms B and C showed that $77 \%$ of the physiotherapists and $71 \%$ of the patients were fully or strongly convinced that patients had satisfactorily adhered to the programme (table 5), indicating that physiotherapists were more confident about the way patients had participated in the programme than patients were confident of their own participation. Characteristics of patients who were not confident of their adherence were comparable to those of all patients allocated to GET (table 3).

Participants of the focus group interview were all confident about their adherence to the programme. They mainly attributed their adherence to the efforts they had made to attain preset levels of daily activities.

Suitability of the programme

Sixty-nine percent of the physiotherapists and $81 \%$ of the patients were fully or strongly convinced that the programme was suitable for $\mathrm{SC}$ patients (table 5 ). Physiotherapists rated the programme as unsuitable for $21 \%$ of the patients, and $9 \%$ of the patients considered the programme to be unsuitable for their own SC. Table 3 shows that patients who considered the programme to be unsuitable had less concomitant neck problems and were comparable to other patients allocated to GET in terms of their other characteristics.

Seven patients participating in the focus group interview assessed GET as a suitable treatment for their own complaints, irrespective of the outcomes in terms of effectiveness. One patient was doubtful about the suitability for her own complaints because her levels of activities had not increased as expected. One patient was doubtful because she had experienced more complaints and had ended the programme after eight sessions. All patients reported they would recommend the programme to other patients suffering from SC. 


\section{DISCUSSION AND CONCLUSION}

\section{Discussion}

Process evaluation is of utmost importance in studies on clinical effectiveness: first, to know whether the treatment under study was performed according to protocol, second, to know whether the treatment is feasible in normal practice, and third, to identify needs for improvement of the protocol to facilitate implication. However, still little attention is paid to process evaluation in trials. Possible explanations for a lack of information on the intervention process were reported earlier by wan Haastregt et al (van Haastregt et al 2002). Firstly, there is a lack of measurement instruments for evaluating intervention processes and these evaluations are mostly time-consuming. Secondly, only little attention is paid to detailed description of the intervention process in trials in the most recent version of the CONSORT statement (Consolidated Standards of Reporting Trials). Thirdly, since researchers and publishers pay most attention to publication of clinical results of a trial, information on the intervention process often remains unpublished. We recommend developing of measurement instruments for evaluating intervention processes and reporting on process evaluations in trials and on implications for clinical effectiveness and for clinical practice.

The present process evaluation was embedded in our study on clinical effectiveness of GET in patients with chronic SC. We reported on the application of the programme, its perceived suitability and on patient's adherence. We mainly focused on quality assurance of treatment outcomes at this stage of the evaluation and suggest that more detailed qualitative assessment on satisfaction with the programme has to be performed if it shows to be effective.

We conclude that in this trial, the GET programme was applied according to the protocol to an acceptable extent and that the programme is feasible in normal practice, as participants in the focus group interview confirmed. First, the number of sessions (17.2) and duration of the programme ( 12.8 weeks) were applied according to the protocol to an acceptable extent. These findings are comparable to the completion rate of scheduled exercise sessions in an other recently performed study on the effectiveness of an exercise programme for shoulder disorders (McNeely et al 2004). Second, with regard to the application of main elements of the programme, results show that $75 \%$ of the physiotherapists and $79 \%$ of the patients who completed the programme were strongly or fully convinced that these were applied. We found that $85 \%$ of the physiotherapists and $84 \%$ of the patients were fully or strongly convinced that the main elements pertinent to pain-related disability had been applied (reconceptualisation of pain-related activities, gradually rising levels of pain-related activities, reinforcement on pain-related activities and self-management of complaints). Given the aim of the programme to increase levels of daily activities, we consider these items to be very important in our evaluation of the intervention process. Third, with regard to patient adherence to the programme: $77 \%$ of the physiotherapists and $71 \%$ of all patients were confident of the way the patients had participated in the programme. These findings were very much similar to adherence rates reported in other recently performed studies on effectiveness of exercise programmes (Messier et al 2004, Lin et al 2004, van Santen et al 2002, Wullink 2001). Given that this was a pragmatic trial, an adherence rate of more than $70 \%$ reasonably allows the conclusion that patient adherence to the programme was as expected. Fourth, with regard to the suitability of the programme: $69 \%$ of the physiotherapists and $81 \%$ of the patients was fully or strongly convinced that the programme was indeed suitable for the participants. Physiotherapist rated the programme as unsuitable for $21 \%$ of the 
included patients, while $9 \%$ of the patients rated the programme as unsuitable. All participants in the focus group interview would recommend the programme to other patients with $\mathrm{SC}_{3}$ irrespective of the effectiveness experienced at the time of the interview. However, two participants in the focus group interview considered the programme unsuitable for their own complaints due to unsuccessful progress or to more complaints. Patients who considered the programme unsuitable $(\mathrm{N}=7)$, reported less concomitant neck problems, but since numbers are small, we suggest that these findings on perceived suitability have to be linked with outcomes on clinical effectiveness, before recommendations on suitability for (subgroups of) patients with SC can be given.

Two elements need further attention in the implementation of GET: the process of goalsetting and management of new goals after treatment, and the application of time-contingent principles. Reports showed that treatment goals were indeed set for all participants, however, physiotherapists were little or not at all convinced of the application of goal-setting as planned in $16 \%$ of the patients, and participants in the focus interview reported difficulties in defining achievable treatment goals and management of new goals after treatment. An earlier study on this topic showed that only $32 \%$ of patients selected exactly the same three main complaints from a list of 36 activities during the first and second intake visits in a study on low back pain (Beurskens et al 1999). The GET programme could therefore be improved by reviewing treatment goals more than once during the start-up period and by emphasising and evaluating the management of (new) goals more often during the treatment periodl. In $22 \%$ of all patients, the physiotherapists were little or not at all convinced of the application of time contingency principles as planned. Patients in the focus group mentioned difficulties with this item in situations of unsatisfactory progress and conflicting recommendations by other health care providers, such as the general practitioner. Application of the principles of time contingency seems to be more difficult in a primary care setting if the approach of other health care providers (e.g. general practitioners) is based on pain contingency principles. Implementation in regular practice could be facilitated if the principles of graded exercise are enbedded in a multi-disciplinary approach and reinforcement of patients' pain behaviours is uniform. Physiotherapists should be aware of these difficulties with application in clinical practice.

In the present process evaluation, there are some methodological weaknesses. First, since indirect methods were used, we can only present reports, and have no evidence of what actually happened. Second, since providers are involved in the assessments, scores might be flawed (higher). Third, reports on the quantitative application of the programme do not provide information about the quality of its application. Fourth, these data might be affected by the physiotherapists' and patients' perception of the improvement on the complaints. Fifth, adherence and suitability in this study were assessed by single items only. In order to avoid bias and to overcome interference of the assessment with the treatment process, data were taken from physiotherapists and patients independently and in concealment after the treatment period was ended. However, we suggest that validity of these evaluations could be improved by additional assessments of treatment sessions by an independent observer and by using more detailed and standardised measurement instruments.

\section{Conclusion}

Process evaluation of a clinical study is essential to interpret the extent of clinical effectiveness as is shown in this trial on the GET programme. We expect that the effectiveness of the programme as applied in the trial will not be influenced by flaws in its application or by lack 
of patient aherence. The programme was considered suitable for 79 to 91 percent of the participants in this trial.

\section{Practice implications.}

Process evaluation gives indication for improvement. In the case of the GET it could be improved in terms of the process of goal-setting, and the implementation of the GET programme could be facilitated if the programme is embedded in a multidisciplinary approach in primary care. We suggest that more detailed qualitative assessment on satisfaction with the programme and on optimising the treatment is needed, if it proves to be effective.

\section{ACKNOWLEDGEMENTS}

The authors would like to thank Suus Benjaminsen and Natali de Bruijn for their contributions to the focus group interview. 


\section{REFERENCES}

Beurskens AJHM, Yet HCW de, Köe AlA, Lindeman E, Heilden GMG wan der,

Regtop W, Knipschild PG. A patient-specific approach for measuring functional status in low back pair. J Manipulative Ptysiol Ther $1999 ; 22: 144-8$

Fordyce WE. Behaworal methods for chronic pain and illness. Samt Louis: Mosby, 1976.

Geraets J]XR, Goossens EJB, Bruin CPC de, Köki AJA, Bie RA de, Relt RAGB,

Heuvel WIA van den, Heijden GJMG van der. A behavioural treatment for chronic shoulder complaints: concepts, development, and study design. Aust J Physiother, 2004;50:33-8.

Gerszten PC. Outcomes research: a review. Néurosurgery. 1998;43:1146-56

Goossens EJB, Vlaeyen IWS, Hidding A, Kole-Snijdets A, Evers SMAA. Treatment expectancy affect the outcome of cognitive-behavioral interventions in chronic pain. Clin J Pain. 2005;21:18-26

Guzmán I, Esmail R, Kanjalainen $K_{*}$ Irvin E Bombadier C. Multidisciplinary

sehabilitation for chronic low back pain: Systematic review. Br Med J. 2001;322:511-6.

Haastregt ICM van, Rossum E van, Diederiks IPM, Witte LP van, Voorhoeve PM,

Crebolder HFIM. Proces evaluation of a multifactorial hone visit programme to prevent falls and mobility impaiments among elderly people at risk. Pat Educ Couns. 2002;47:301-9.

Haastregt van JCM, Rossum Ei van, Diederiks IPM, Witte LP van, Voorhoeve PM,

Crebolder HFTM. Lack of information on the intervention process in randomised controlled

trials. In Haastregt wan JCM (Ed): Preventing falls and mobility impairments in elderly

people living in the community. Maastricht: Datawyse, 2002;93-103

Heijden GIMG van der. Shoulder disorders: A state-of-the-art review. Ballieres

Clin Rheumatol. 1999;13:287-309.

Jensen MP, Nielson WR, Turner JA, Romano $\mathrm{L}$, Hill ML. Changes in readiness to self-manage pain are associated with improvement in multidisciplinary pain treatment and pain coping. Pain. 2004:111:84-65.

Keefe H, Rumble ME, Scipio CD, Giordano LA, Perri LM. Psychological aspects of persistent pain: current state of the science. I Pain. 2004,5:195-211.

Keith RA. Patent satisfaction and rehabilitation services. Arch Phys Med Rehabil. 1998;79:1122-8.

Kvien TK. Heiberg T. Patient perspectives in outcome assessments-perception or something more? I Rheumatol. 2003;30: 873-6

Lackner IM, Carosella AM, Fenerstein M. Pain expectancies, pain, and functional selfefficacy expectancies as determinants of disability in patients with chronic low back disorders. J Consul Clin Psychol 1996;64:212-20. 
Lin SY, Davey $R C$, Cochrane T. Community rehabilitation for older adults with osteoarthritis of the lower linb: a controlled clinical trial. Clin Rehabil. 2004:18:92-101.

Linton S). An owerview of psychosocial and behavioural factors in neck-and-shoulder pain. Scand J Rehabil Med. 1.995;32:67-77.

linton SJ. Prevention with special reference to chronic musculoskeletal disorders. In Gatchel RI and Turk DC (Eds): Psychosocial Factors in Pain. New York: Guilford Publications. 374-89.1999.

MeNeely ML, Parliament M, Coumeya KS, Seikaly $H_{\text {, }}$, tha $N$, Scrimger $R$, Hanson 1 . A pilot study of a randomized controlled trial to evaluate the effects of progressive resistance exercise training on shoulder dysfunction caused by spinal accessory neurapraxia/neurectomy in head and neck cancer survivors. Head Neck. $2004 ; 26: 518-30$.

Messier SP, Loeser RF, Miller GD, Morgan TM, Rejeski WJ, Sevick MA, Ettinger WH Jr, Pahor M, Willianson JD. Exercise and dietary weight loss in overweight and obese older adults with knee osteoarthritis: the Arthritis, Diet, and Activity Promotion Thial. Arthritis Rheum. 2004;50:1501-10.

Morley S, Eccleston C and Wiliams A. Systematic rewiew and meta-analysis of randomized controlled trials of cognitiwe behaviour therapy and behaviour therapy for chronic pair in adults, excluding headache. Pain. 1999; 88: $1-13$.

Picavet MSJ and Schouten ISAG. Musculoskeletal pain in the Netherlands: prevalences, consequences and risk groups, the DMC (3) - study. Pain. 2003;102:167-78.

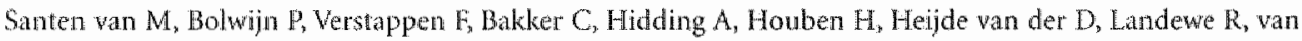
der Linden $S$. A randomized dinical trial comparing fitness and biofeedback training versus basic treatment in patients with fibronyalgia. I Rheumatol. 2002;29:575-81.

Skinner 1 Science and human betavion. New York: Macmillan, 1953.

Thoms: E, Croft PR, Paterson SM, Dxiedzic K. Hay EM. What infuences participants' treatment preference and cary it influence outcome? Results fron a primary care-based randomised trabl for shonlder pain. Br f Gera Pact 2004;54:93\%6

Tulder MW van, Ostelo RWIG, Vhayen IWS, Linton S1, Morley SI and Assendelft WII. Behavional treatment for chronic low back pain. A spstematic review within the framework of the Codnune Back Revew Group. Spine. 2001:26:270-81.

Urden 1D. Patient satisfation measutement: current issues and implications. Outcomes Manag. 2002;6:125-31.

Wheyen WS and Linton SI. Fear-Awotance and its consequences in chronic musculoskeletal pain: Astate of the art. Pain. 2000,85:317-32.

Westbrook M. Patient watisfaction: methodological issues and research findings. Aust Fealth Rev 1993;6:75-88. 
Windt DA wan der, Koes BW, Boeke AJ, Deville W, Jong BA de and Bonter UM.

Shoullder disorders in general practice: Prognostic indicators of ontcome. $\mathrm{Br}$ I Gen Pract.

$1996 ; 46: 519-23$.

Winters JC, Jongh AC de, Windt DAWM van der, Jonquiere $M$, Winter AF de, Heijden GIMG van der, sobel IS and Goudsward AN: MHG-Standaard Schouderklachten. Huisarts en Wetenschap 1999;42:222-31.

Wullink M, Stoffers HE, Kuipers $H$. A primary care walking exercise program for patients with intermittent clandication. Med Sci Sports Exerc. 2001;33:1629-34. 



\section{CHAPTER 7}

\section{Comparison of two}

recruitment strategies for

patients with chronic

shoulder complaints

Accepted for publication as

Comparison of two recruitment strategies for patients with chronic shoulder complaints

Geraets JJXR, de Groot IMJ, Goossens MEJB, de Bruijn CPC, de Bire RA, van den Heuvel WJA, Dinant GI. Br J Gen Pract. 2006. 
ABSTRACT

Background: Recruiting adequate numbers of participants represents a major problem to the completion of randomised clinical trials in primary care. Information on different recruitment strategies applied in one trial is scarce.

Aim: To evaluate the application of two recruitment strategies in one trial.

Design of study: The study was performed within the framework of a randomised clinical trial on the effectiveness of a behavioural treatment for patients with chronic shoulder complaints.

Setting: Thirty-two general practices in the Netherlands.

Methods: Patients recruited during a consultation with their general practitioner (GP) for chronic shoulder complaints were compared with patients recruited by advertisement in a local newspaper as regards baseline characteristics, withdrawals (drop-outs and losses to follow-up) and post-treatment clinical outcomes.

Results: Patients recruited by the general practitioners $(\mathrm{N}=83)$ were similar to those recruited by advertisement $(\mathrm{N}=93)$ in terms of demographic characteristics and clinical outcome measures at baseline, but differed slightly in disease characteristics and treatment preferences. Recruitment strategy was not related to reasons for or numbers of withdrawals. Improvements on outcome measures were greater in patients recruited by the general practitioners, irrespective of allocated treatment. Results on the clinical effectiveness of treatments at the end of the treatment period or during follow-tup were neither modified by recruitment strategy, nor

by differences between the two strategy groups in patient characteristics found at baseline.

Conclusion: Using two recruitment strategies did not influence the outcomes on clinical effectiveness in this trial. However, recruitment strategy should be considered as a putative modifying factor in the design of a study.

Key words: patient selection, family practice, randomised clinical trial, behavioural therapy, shoulder. 


\section{INTRODUCTION}

Recruiting adequate numbers of participants currently represents a major problem to the completion of randomised clinical trials, in particular in primary care (Foy et al 2003). Several studies on recruitment in primary care have been done so far, mainly focusing on preventing and overcoming recruitment problems before starting a study. Common outcome measures in these studies are numbers of referrals and recruitment rates.

Several studies have reported on characteristics of patients, the general public or general practitioners (GP) and on methodological options to overcome recruitment problems in primary care settings. Willingness to participate and attendance among patients seem to be associated with demographic factors (age, gender, marital status, social class, occupation, education), attitudes (readiness to change), and disease characteristics (clinical measures, health status, risk factor status) (Boles et al 2000, Damush et al 2002, Lloyd-Williams et al 2003, Nazemi et al 2001, Saunders et al 2000, Thorogood et al 1993, Trauth et al 2000). In general, demographic characteristics and attitudes seem to be better predictors of recruitment rates and attendance than disease characteristics. Treatment preferences of participants might influence the outcome in non-blinded studies (van Schaik et al 2004, Thomas et al 2004, van der Windt et al 2000). Patient recruitment by general practitioners seems largely determined by the general practitioners' motivation, involvement, forgetfulines, time pressure and financial reimbursement (Gurwitz et al 2001, Pearl et al 2003, Peto et al 1993, de Wit et al 2001). Methods and strategy of recruitment, e.g. screening by a general practitioner, waiting room screening, or recruitment by advertisements, seem to be related to the yield in numbers of qualified patients and the costs per recruited patient (de Wit et al 2001, Davey et al 2003). Organisational characteristics and the simplicity of printed information for the patients and general practitioners seem to influence recruitment rates as well (Foy et al 2003, Bell-Seyer and Moffet 2000, Prout et al 2003).

One question, which has not been answered so far, is what should be done if, despite all efforts, the recruitment stage delays or hampers the proper conduct of a trial. The present study evaluated the application of two recruitment strategies in one trial examining the effectiveness of a behavioural treatment for patients with chronic shoulder complaints. Since the numbers of patients recruited during general practitioner consultations were smaller than expected, subjects were also invited to enrol by means of advertisements in a local newspaper. Since patient inclusion and exclusion criteria were similar for both strategies, one might assume that the characteristics of patients enrolled by both strategies would be comparable and that the recruitment method would not influence the course and outcomes of the trial. To evaluate this assumption, we compared the effects of these two strategies with respect to baseline characteristics, withdrawals (drop-outs and llosses to follow-up) and post-treatment outcomes.

\section{METHODS}

\section{Design}

This study was performed within the framework of a trial on the effectiveness of a behavioural Graded Exercise Therapy programme for patients with chronic shoulder complaints. The programme aims to improve performance of daily activities and healthy behaviours and to reduce health care utilisation during the treatment period and the one-year follow-up period. More details of the design and the results of this trial have been presented elsewhere (Geraets et al 2004, Geraets et al 2005). 
Two strategies were used to enrol patients in this trial: recruitment by general practitioners during consultations for shoulder complaints (from January 2002 until July 2003) and recruitment by advertisement in a local newspaper (from March 2003 until July 2003). We used block randomisation, with blocks of 10 patients, to allocate participants either to Graded Exercise Therapy or to usual care. To compare the effects of the two recruitment strategies, we assessed patient characteristics at baseline, number of withdrawals (drop-out rate and losses to follow-up), reasons to withdraw, and the influence on primary outcome measures (main complaint instrument and Shoulder Disability Questionnaire) at the end of the treatment period ( 12 weeks) and during follow-up (26 and 52 weeks).

\section{Participants}

Patients with shoulder complaints for at least three months, at least 18 years old, and living in the Province of Limburg (the Netherlands), were invited to participate in the study.

\section{Recruitment strategies}

Recruitment during consultation in general practice

Forty-nine general practitioners working in the area of the twenty physiotherapists involved in the study, were invited to participate. Thirty-two general practitioners agreed to participate and recruited patients who visited their surgery and met the selection criteria. A research assistant visited potential participants at home within two weeks after the general. practitioner had seen them.

Recruitment by advertisement in a local newspaper

An advertisement in a local newspaper (circulation rate 159.000 addressees) was used to enrol patients. After the research assistant had checked their eligibility by telephone, patients received written information about the content of the study. The research assistant then contacted the patient's general practitioner. If the general practitioner was not able or did not want to check the selection criteria, an independent general practitioner associated with the trial team checked these. If patients met the selection criteria, a research assistant visited them at home within two weeks.

\section{Outcome measures}

Baseline characteristics

Demographic variables, disease characteristics, putative prognostic factors, treatment preferences and outcome variables of clinical effectiveness were determined at baseline.

\section{Drop-out rate and loss to follow-up}

Drop-out rates during treatment and losses to follow-up were assessed. We also determined reasons to withdraw for both strategies in relation to allocated treatment.

\section{Outcomes after treatment and during follow-up}

Differences between the two recruitment strategy groups in terms of clinical outcome measures were established for both treatments at 12,26 and 52 weeks. We assessed the influence of the recruitment strategy and possible confounders or modifying factors on the primary outcome measures of clinical effectiveness of treatments. 


\section{Statistical analysis}

Analyses were carried out with SPSS statistical software (version 12.0) according to the intention-to-treat principle. A p-value of $<0.01$ was considered to be statistically significant (two-tailed) for all comparisons.

First, the sample size was calculated based on figures of perceived recovery (van der Windt et al 1996). Since we aimed to increase the recovery rate from $25 \%$ to $50 \%$, at a 1 -sided alpha of $5 \%$, a statistical power (1-beta) of 0.90 , and a $10 \%$ dropout rate, we needed 66 persons per treatment group.

Subsequently, the standardized difference (the ratio of the differences between groups to the standard deviation of the observations) was determined according to the sample size of the trial as a measure of the expected differences in outcome post treatment (Altman 1991). The standardized difference was determined to be 0.52 . The differences between recruitment groups on clinical outcome measures at baseline were considered with respect to the determined standardized difference to evaluate the influence of recruitment strategy at baseline.

Then, effect sizes (the ratio of the differences in mean change scores to the standard deviation of the average change scores of the total population) were calculated to evaluate the differences between recruitment groups on clinical outcome measures after treatment and during follow-up. Effect-sizes of $0.2,0.5$, and 0.8 were considered as small, medium and large beneficial effects respectively (Cohen 1977). Confidence intervals (95\%) of the mean differences were determined and analysed by Student's T-tests for data with a Gaussian distribution, and by Mann-Whitney tests for non-Gaussian distributions. Furthermore, we analysed the differences between the recruitment groups for both treatments.

Finally, the influence of recruitment strategy and possible confounding or modifying factors which differ between recruitment groups at baseline on the primary outcome measures, was analysed using multivariate linear regression and a stepwise forward procedure $(p<0.10)$. Covariates that were significantly associated with the primary outcome measure after the variable 'treatment' was included in the model, remained in the final model and were considered as confounders. If the interaction term (the product of the covariate and 'treatment') was significantly associated as well, the covariate was considered as a modifying factor. Adjusted estimates were reported in case of confounding or effect modification.

\section{RESULTS}

Ninety patients were recruited by the general practitioners during consultations (figure 1). Seven of these patients ( $8 \%$ ) were excluded before randomisation (for reasons, see figure 1). One-hundred-and-two patients recruited by advertisement were eligible to participate according to their general practitioners. Nine of these patients (9\%) were excluded before randomisation. A total of 176 patients were randomised and allocated to either Graded Exercise Therapy $(\mathrm{N}=87)$ or usual care $(\mathrm{N}=89)$.

Table 1 shows that the two recruitment groups were comparable on most demographic variables and all clinical outcome variables at baseline. Patients recruited by advertisement had a higher average educational level. Duration of complaints was longer for these patients, whereas periods of sick leave were shorter.

Figure 1 shows that reasons to withdraw from the study, drop-out rates, and losses to follow-up at 52 weeks were similar for both recruitment strategy groups ( $16 \%$ for general practitioner recruitment versus $17 \%$ for recruitment by advertisement). 
Higure 1. Flow-chart"

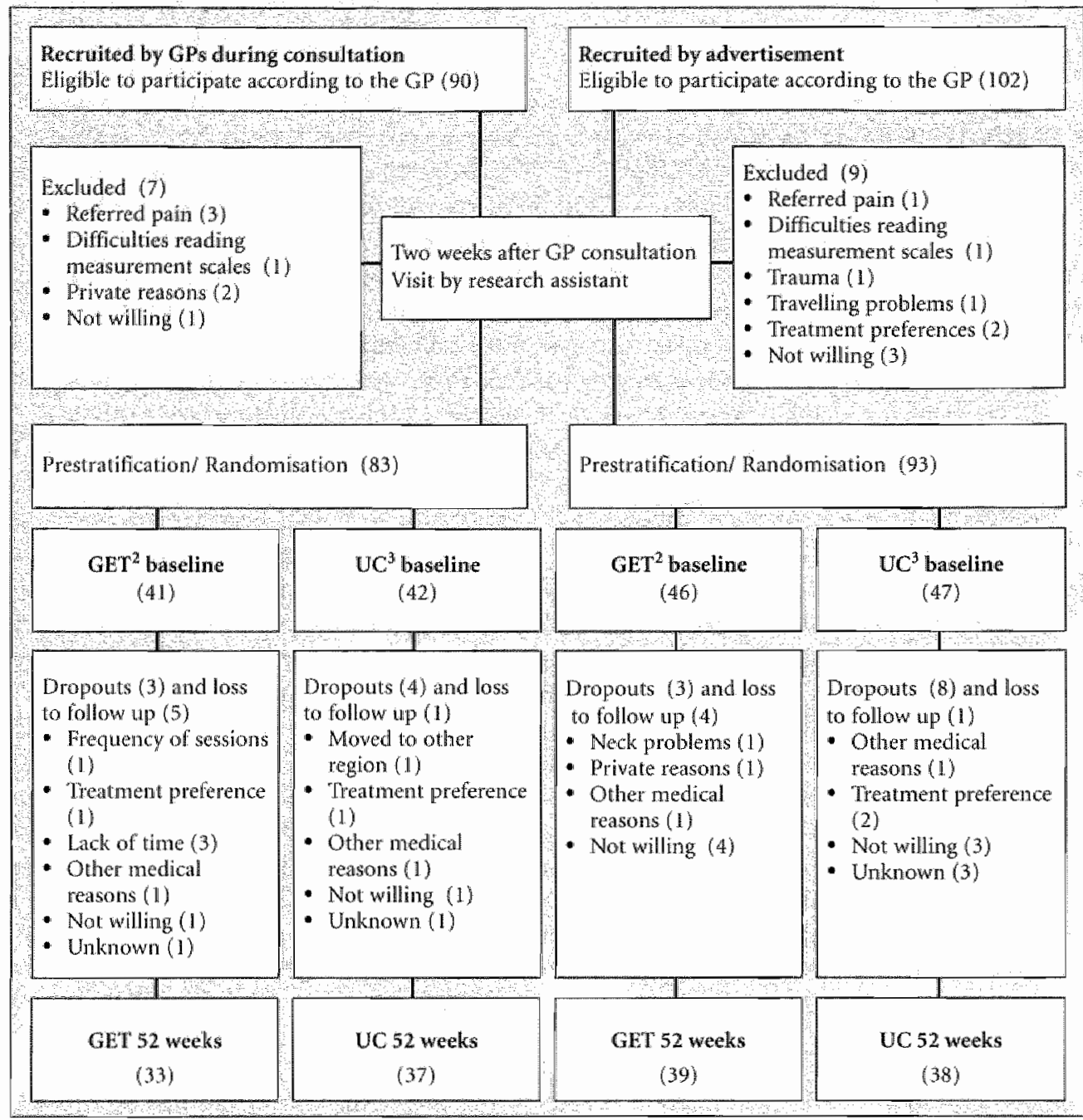

- Number between brackets is number of patients

: GET=Graded Exercise Therapy

"UC=usuall care

Patients recruited by advertisement were slightly less ambivalent in their preferences for commonly applied shoulder complaints treatments and prior treatments had been less successful in these patients (table 2).

Table 3 shows that mean improvements among patients recruited by the general practitioners were statistically significantly greater for the main complaints instrument at 52 weeks ( $p=0.001$; effect-size 0.50) and for the Shoulder Disability Questionnaire at 26 weeks $(p=0.005$; effect-size 0.43 ) and 52 weeks ( $p=0.004$; effect-size 0.44$)$. 
Table 1. Baseline characteristics

\begin{tabular}{|c|c|c|}
\hline & $\begin{array}{l}\text { Recruited by } \\
\text { the GPS }\end{array}$ & $\begin{array}{l}\text { Recruted by } \\
\text { advertisement }\end{array}$ \\
\hline Number & 83 & 93. \\
\hline \multicolumn{3}{|l|}{ Demographic variables } \\
\hline Age (years) (sd) & $52,12,4$ & $52(12.6)$ \\
\hline females $(\%)$ & 54 & 55 \\
\hline Employed $(\%)$ & 58 & 56 \\
\hline Education (low) $(0)$ & 77 & 67 \\
\hline \multicolumn{3}{|l|}{ Specific disease variables } \\
\hline Duration of shoulder pain $(>6$ monthis $)(\%)$ & 69 & 87 \\
\hline Sick leave (if employed) in past 8 weeks $(>1$ week) $(\%)$ & 15 & 2 \\
\hline Concomitant neck problems $(\%)$ & 46 & 48 \\
\hline Prior episodes of shoulder complaints of at least 1 week in past year $(05)$ \% & 70. & 68 \\
\hline \multicolumn{3}{|l|}{ Primary outcome measures } \\
\hline Performance of dally activities: & $753(1830)$ & $12.9(20.51)$ \\
\hline Severity of main comp aints $(0-100)$ & $669(1836)$ & $649(99.49)$ \\
\hline \multicolumn{3}{|l|}{ Eunctional limitations to daily activities $(S D O)(0-100)$} \\
\hline \multicolumn{3}{|l|}{ Secondary outcome measures } \\
\hline Shoulder pain (SPS) 728$)$ & $173(4)$ & $17.6(4.22)$ \\
\hline Pain intensily $(11$ point scale) $(0-10)$ & $5.5(198)$ & $5.6(2.00)$ \\
\hline quality of life (Euroool 50$)(1$ to 1$)$ & $0.67(0224)$ & $0.67(0.212)$ \\
\hline Kinesiophobia (2 tems TSK $(17)$ & $29(199)$ & $2.7(1.94)$ \\
\hline Fear-Avoidance Beliefs (5 item sulbscale $\mathrm{ABBQ})(17)$ & 431137 & $45(1.20)$ \\
\hline Catastroplising $(12$ tem sibscole PCCI $(1-6)$ & $2,3(0,82)$ & $2.4(0.82)$ \\
\hline Coping with Pain $(11$ item subscale PCCQ $(1-6)$ & $30(1,02)$ & $3.1(0.83)$ \\
\hline Internal locus of control $(11$ ten subscale $\mathrm{P}(\mathrm{Cl})(1-6)$ & $35093)$ & $3,4(0.89)$ \\
\hline External locus of control ( 7 item subseale PCC) (1 b) & $30(088)$ & $29(0.81)$ \\
\hline
\end{tabular}

1 PCcl subscale scores: very low $(1.0-1.9)$, low $(2.0-3.4)$, high $(35-5.0)$, wey high $(5.1 .60)$

Table 4 shows that patients recruited by the general practitioners showed greater improvement on both primary outcome measures, irrespective of treatment allocation.

Multivariate linear regression analyses (table 5) shows that recruitment strategy was significantly associated with both primary outcome measures (the main complaint instrument at 52 weeks and the Shoulder Disability Questionnaire at 26 and 52 weeks). This indicates that recruitment strategy was a confounding factor. There was no interaction between Graded Exercise Therapy and recruitment strategy (the interaction term of recruitment and "treatment" failed to reach significance and was excluded from all models). The lack of interaction indicates that the clinical effectiveness of the programme, as assessed by the primary outcome measures at the end of treatment and during follow-up, was not modified by the recruitment strategy. Other possible modifiers (educational level, duration of pain, duration of limitations, sick leave or treatment preferences) were not significantly alssociated with these clinical outcome measures and were excluded from all models. 
Table 2. Freatment experiences and preferences

\begin{tabular}{|c|c|c|c|c|}
\hline & \multicolumn{2}{|c|}{ Experienced success-rate of treatment } & \multicolumn{2}{|c|}{ Treatment preference } \\
\hline & GP & Advertisement & GP & Advertisement \\
\hline Treatment. & $1 \%$ & (\%) & (notunclearlyes) $(\%)$ & (nolundearyes)(or): \\
\hline - Behavioural theragy & & 10 & $2 / 90 / 8$ & $15 / 73 / 12$ \\
\hline - chinsiatherapy & 47 & 27 & $10 / 34 / 46$ & 1183815 \\
\hline - Manual Therapy & 64. & 31 & 1017713 & 18161121 \\
\hline- Analgesics & 59 & 48 & $69126 / 5$ & $11116: 7$ \\
\hline - WSAIIS & 60 & 48 & $66 / 30 / 4$ & $65 / 26 / 9$ \\
\hline - Corticostercid injection & 47 & 42 & $68 / 29 / 3$ & 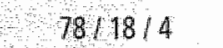 \\
\hline - Surgery & 64 & 39 & $79 / 2011$ & $81 / 1613$ \\
\hline
\end{tabular}

4 Patlents who had prior experiences with common treatments for shoulder complaints were asked whether they had experienced these treatments as successfull

2 Patients were asked to rate their treatment pieference on a 5-point scale $(1-2=$ no, $3=$ undlear $4-5=$ yes)

Table 3. Mean improvement for both recreitment groups on puimaty outcome neasures after 12,26 and 52 weeks

\begin{tabular}{|c|c|c|c|c|c|c|c|}
\hline & $\begin{array}{l}G P \\
N=83\end{array}$ & $\begin{array}{l}\text { Adwertisement } \\
\mathrm{N}=93\end{array}$ & & Differe & ices bety & en groups & \\
\hline & Mean (sd) & Mean (sd) & $\begin{array}{l}\text { Mean } \\
\text { diff }\end{array}$ & $\begin{array}{l}95 \% 0 \\
\text { lower }\end{array}$ & $\begin{array}{l}1 \text { of diff } \\
\text { upper }\end{array}$ & P-value & $\begin{array}{l}\text { Effect } \\
\text { size }\end{array}$ \\
\hline \multicolumn{8}{|c|}{ Main complaints $(0-100)$} \\
\hline 12 weeks & $323(25)$. & $260(24.7)$ & 63 & 12 & 13.8 & 0098 & 0.25 \\
\hline 26 weeks & 39.1028 & $309(265)$ & 82 & 00 & 163 & 0,049 & 0.30 \\
\hline 52 weeks & $43.4(285)$ & $301(24.8)$ & 133 & 53 & 21.2 & 0001 & 0.50 \\
\hline \multicolumn{8}{|c|}{ SDQ $(0-100)$} \\
\hline 12 weeks & $209(239)$ & $120(230)$ & 89 & 19 & 15.9 & 0.013 & 0.38 \\
\hline 26 weens & $277(28,8)$ & $157(268)$ & 12,0 & 31 & 20.3 & 0,005 & 0.43 \\
\hline 52 weeks & 2792944 & $156(27)$ & 123 & 39 & 20.7 & 0.004 & 0.44 \\
\hline
\end{tabular}

1 Ater unconditional mean imputation

$25 \%$ confidence interval of difference

$P$ Statisticallys significant $8<001$

\section{DISCUSSION AND CONCLUSIONS}

\section{Summary of main findings}

Patients recruited for a randomised clinical trial by general practitioners and by advertisement were comparable in terms of most baseline characteristics and numbers of withdrawals (drop-outs and losses to follow-up). Patients recruited by the general 
Table 4. Mean improvenent for both recruitnent groups and both intervention groups on primary outcome measures after 12,26 and 52 weeks

\begin{tabular}{|c|c|c|c|c|c|c|c|}
\hline \multicolumn{8}{|c|}{ Mean improvement on primary outcome measures for Graded Exercise Therapy } \\
\hline & $\begin{array}{l}\mathrm{GP} \\
\mathrm{V}=41\end{array}$ & $\begin{array}{l}\text { Advertisement } \\
\mathrm{N}=46\end{array}$ & & \multicolumn{4}{|c|}{ Differences between groups } \\
\hline & Mean (sol) & Mean (so) & Mean & $95 \% c$ & $\begin{array}{l}\text { of diff' } \\
\text { upper }\end{array}$ & Pvalue & $\begin{array}{l}\text { Efled } \\
\text { sire }\end{array}$ \\
\hline \multicolumn{8}{|c|}{ Main complaints $(0-100)$} \\
\hline 12 weeks & $358(28.3)$ & 30.012301 & 58 & 51 & 168 & 0.294 & 0.23 \\
\hline 26 weeks & $43.6(279)$ & $337(25,0)$ & 99 & 14 & 211 & 0.085 & 0.37 \\
\hline 52 weeks & $491(281)$ & $33.9(23,3)$ & 153 & 43 & 262 & 0.007 & 060 \\
\hline \multicolumn{8}{|c|}{ SDQ $(0-100)$} \\
\hline 12 weeks & $22.2(26.1$ & $124(253)$ & 99 & 11 & 20.8 & 0,077 & 039 \\
\hline 26 weeks & $272(281$ & $185(295)$ & 87 & 3,6 & 210 & 0.62 & 0,30 \\
\hline 52 weeks & $271(26.2)$ & $183(259)$ & 8.8 & 23 & 199 & 0,120 & 034 \\
\hline \multicolumn{8}{|c|}{ Mean improvement on primary outcome measures for Usual Care } \\
\hline & $\begin{array}{l}\mathrm{GP} \\
\mathrm{N}=42\end{array}$ & $\begin{array}{l}\text { Advertisement } \\
\quad N=47\end{array}$ & & Differe & res betw & ingroups & \\
\hline & Mean (sd) & Mean $(s)$ & $\begin{array}{l}\text { Mean } \\
\text { diff }\end{array}$ & $95 \% \mathrm{C}$ & $\begin{array}{l}\text { of dif? } \\
\text { upper }\end{array}$ & Pvalue & $\begin{array}{l}\text { Effed } \\
\text { size }\end{array}$ \\
\hline \multicolumn{8}{|c|}{ Main complaints $(0-100)$} \\
\hline 12 weeks & $289(22.7)$ & $22.1259)$ & 68 & 35 & 171 & 0.192 & 0.28 \\
\hline 26 weeks & 34728.0 & $282(28.0)$ & 65 & 53 & 184 & 0274 & 023 \\
\hline 52 weeks & $378(281)$ & $25.5(259)$ & 114 & 03 & 227 & 0.051 & 0.42 \\
\hline \multicolumn{8}{|c|}{$\operatorname{SDQ}(0-100)$} \\
\hline 12 weeks & $196(220)$ & $116(20.7)$ & 80 & 10 & 170 & 0.080 & 0.37 \\
\hline 26 weeks & $283(29.8)$ & $131(240)$ & 152 & 39 & 266 & 0,009 & 057 \\
\hline 52 weeks & $287(325)$ & $1300(28.2)$ & 157 & 29 & 28.5 & 0.017 & 0.52 \\
\hline
\end{tabular}

1 After uncomititional mean mputation

$295 \%$ contidence interval of difference

3 Statist cally significant $\mathrm{P}<0$ : 1

practitioners showed greater improvement on both primary outcome measures, irrespective of treatment allocation. Multivariate regression analyses showed that clinical effectiveness at the end of the treatment or during follow-up was not modified by the recruitment strategy, or by baseline differences between the two recruitment strategy groups.

\section{Strengths and the limitations of this study}

Our results show that findings on effectiveness in the trial are applicable to both patients who consulted their general practitioners for their complaints and patients who did not intend to visit their general practitioners. However, the use of two recruitment strategies did introduce a confounding factor. Although multivariate regression analyses showed that the recruitment strategy did not modify the outcome of the trial in terms of effectiveness, we found that mean 
Table 5. Adjusted analyses on pinmary outcoine measues

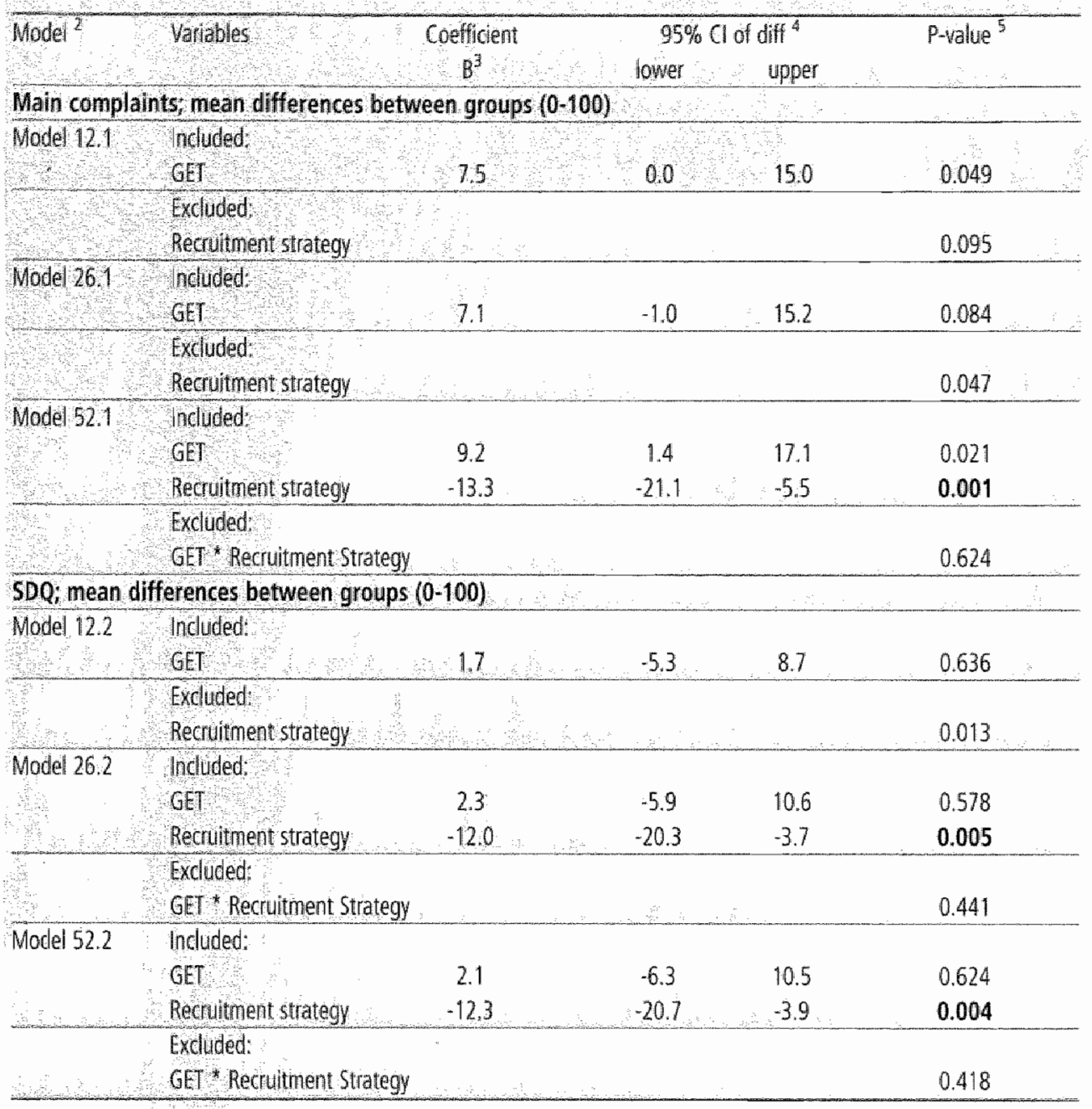

"After imputation of the overall mean

${ }^{2}$ Adjusted analyses of the main complaint instrument (model 12.1, 26.1, 52.1) and SDQ (model 12.2, 26.2, 52.2) after 12 weeks of treatment and during follow up at 26 and 52 weeks respectively

3 Regression coefficient for GET (GET=1; $\cup C=0$ ) and for recrutment strategy (Advertisement $=1 ; G P=0)$.

$495 \%$ confidence interval of difference

${ }^{5}$ Statistically significant $P<0,01$

improvements among patients recruited by the general practitioners were greater, irrespective of treatment allocation. In our trial, clinical effectiveness was not influenced, because patients recruited by the general practitioners and by advertisement, were allocated by block randomisation and equally balanced for both treatment groups. If this had not been the case, outcomes could have been biased. For example, small differential effects between recruitment 
groups would have been more pronounced if $75 \%$ of patients had come from advertisement and. $25 \%$ from the general practitioner.

Patients recruited by the general practitioners and those enrolled by advertisement turned out to be only slightly dissimilar with respect to level of education, duration of complaints, sick leave and treatment preferences. Sick leave among patients recruited by the general practitioners during consultations was longer, which suggests that sick leave might be a reason for patients to visit their general practitioners because of shoulder complaints. Since blinding was not feasible at the patient or provider level, treatment preferences may have influenced outcome measures of effectiveness (Thomas et al 2004; van der Windt et al 2000). However, multivariate linear regression showed that these possible modifiers did not alter the results on clinical effectiveness.

Patients recruited by the general practitioners showed greater mean improvements on the primary outcome measures than those recruited by advertisement, irrespective of treatment allocation. Effect-sizes between recruitment groups reached up to the level of the expected difference in outcome post treatment $(0.50)$. We were unable to explain these findings by possible confounders or modifying factors in our dataset.

\section{Comparison with existing literature}

Several studies on the effectiveness of cognitive behavioural treatment have reported on influences of pre-treatment attitudes (readiness to change, motivation) and beliefs (expectancies) on pain and pain disability (Dijkstra et al 2001, de Gier et al 2004, Goossens et al 2004, Jensen et al 2003, Jensen et al 2004, Keefe et al 2004, Lackner et al 1996). These studies showed that pain-catastrophising, pain anxiety, pain-related fear, helplessness and unsuccessful prior treatment experiences seem to be associated with over-predicting actual pain and under-predicting abilities to perform plysical tasks and to adjust pain behaviour, and these patients have low treatment expectancies. By contrast, self-efficacy, better pain coping and control, pain acceptance and readiness to change seem to be associated with decreased pain ${ }_{n}$ improved physical performance and better adjustment to pain. Those patients probably have higher treatment expectancies.

Since the primary outcome measures in our trial were subjective, we assume that pretreatment attitudes and beliefs may also have influenced the prognosis of patients in this study. We considered the possibility that pre-treatment expectancies and readiness to change in patients recruited by the two strategies in this trial may have been dissimilar. To begin with, patients recruited by the general practitioners had decided to visit their general practitioners for their complaints, whereas patients recruited by advertisement did not intend to contact their general practitioners. Patients recruited by the general practitioners were asked to participate, whereas those recruited by advertisement reacted spontaneously to an announcement in a local newspaper. Furthermore, we found that patients recruited by the general practitioners had had more successful experiences with all treatments commonly applied for shoulder complaints. As a result, their expectations about shoulder treatments in general may have been higher, whereas expectations among patients recruited by advertisement were probably lower as regards commonly applied treatments and probably only higher as regards the new behavioural programme. Unfortunately, detailed information on these attitudes and beliefs, as possible prognostic factors, was not available in our dataset.

Eighty-three patients were enrolled by the general practitioners over a period of fourteen months, whereas 93 patients were recruited by advertisement over a period of four months. 
In terms of efficiency, the recruitment rate for advertisements was thus considerably higher. These findings confirm that recruitment strategies in which the general practitioner plays an active role as gatekeeper are less efficient (Gurwitz et al 2001, Davey et al 2003).

\section{Implications for future research}

Demographic and disease characteristics are important variables with respect to recruitment rates, as has been reported above. In the present study, however, these factors did not account. for differences we found in the prognosis of patients recruited by different strategies. Therefore, we recommend that more specific potential modifiers relating to recruitment strategy (e.g. beliefs and attitude) should be included in the design of studies and recruitment strategies (in addition to the above-mentioned demographic and putative disease-specific prognostic factors). We conclude that using two recruitment strategies did not influence the outcomes on clinical effectiveness of our trial. However, this conclusion is based only on analyses of our data and differential effects might be different if other groups have to be adopted. Recruitment strategy should be considered as a putative modifying factor in the design of a study and we recommend further research into this phenomenon.

\section{ACKNOWLEDGMENTS}

The authors wish to thank all participating general practitioners and physiotherapists for their contributions, Marlies Smeulders for her contribution to the selection process, and Natali de Bruijn and Sjan Heijkers for data collection. 


\section{REFERENCES}

Altman DG. Practical statistics for medical research. London: Chapnan and Hall press Inc. 1991.

Bell-Seper SE and Moffet JA. Recruiting patients to randomized trials in primary cares principles and case study. Fam Pract 2000; 17: 187-191.

Boles M, Getchell WS, Feldman G, McBride R, Hart RG. Primary prevention studies and the healthy elderly: evaluating barriers to recruitment. I Community Health 2000; 25; 279-292.

Cohen 1. Statistical power analysis for the behaviorat sciences. London: Academic press Inc: 1977.

Damush TM, Weinberger M, Clark DO, Tierney WM, Rao JK, Perkins SM, et al. Acute low back pain selimanagement intervention for urban primary care patients: rationale design, and predictors for participation. Anthritis Rheum 2002; 47:372-379.

Dawey R, Edwards SM, Cochrane 'T. Davey R, Edwards SM, Cochrane T. Recruitment strategies for a clinical trial of community-based water therapy for osteoarthritis. Br I Gen Pract 2003; 53:315-7.

Dijkstra A, Maeyen IW, Rijnen H, Nielson W. Readiness to adopt the self-management approach to cope with chronic pain in fibromyalgic patients. Tain 2001: 90:37-45.

Foy R, Parry I, Duggan A, Delaney B, Wilson S, Lewin-van den Broek NT, et al. How evidence based are recruitment strategies to randomized controlled trials in primary care? Experience from seven studies. Fam Pract 2003; 20: 83-92.

Geraets JIXR, Goossens EJB, Bruijn CPC de, Köke ATA, Bie RA de, Pelt RAGB, et al. A behavioural treatment for chronic shoulder complaints: concepts, development, and study design. Aust J Plysiother 2004; 50: 33-38.

Geraets JJXR, Goossens EJB, Groot IJM de, Bruijn CPC de, Bie RA de, Dinant G], Heijen GMMC van der, Heuvel WJA van den. Effectiveness of a graded exercise therapy programme for patients with chronic shoulder complaints. Aust I Plysiother, 2005; 51: 87-94.

Gier de M, Peters ML, Vlaeyen JWS. Fear of pain, physical performance and attentional processes in patients with fibromyalgia, Pain 2003; 104:121-130.

Goossens EIB, Vheyen IWS, Hidding A, Kole-Snijders A, Evers SMAA. Treatment expectancy affects the outcome of cognitive-behavioral interwentions in chronic pain. Clin J Pain 2004 (in press).

Gurwitz IH, Guadagnoli E, Landrum MB, Silliman $R A$, Wolf R, Weeks JC. The treating physician as active gatekeper in the recruitment of research subiects. Med Care 2001; 39: 1339-1344.

Jensen MP, Nielson WR, Kerns RD. Towards the development of a motivational model of pain selfmanagement. I Pain 2003; 4: 477-492.

Jensen MP, Nielson. WR, Tumer IA, Romano LL, Hill ML. Changes in readiness to self-manage pain are associated with improvement in multidisciplinary pain treatment and pain coping. Pain 2004; 11: 84-95. 


\section{Chapter 7}

Keffe IP, Rumble ME Scipio CD, Giondano LA, Perri LM. Psychological aspects of persistent pain: current gtate of the science. I Pain 2004: $5: 195.211$.

Lackner M, Carosella AM, Feuerstein M. Pain expectancies, pain, and functional self-efficacy expectancies as determinants of disability in patients with chronic low back disorders. J Consult Clin Psychol 1996; 64: 212-220.

Loyd-Willams $\mathrm{F}$, Mair F, Shiels $\mathrm{C}$, Hanraty $\mathrm{B}$, Goldstein P, Beaton $\mathrm{S}_{\mathrm{u}}$ er al. Why are patients in clinical trials of heart fallure not like those we see in eweryday practice? I Clin Epidemiol 2003; 56: 1157-1162.

Nazemi $H_{3}$ Larkin $A_{4}$ Sullivan $\mathrm{ND}_{3}$ Katon Wethodological issues in the recrutment of primary care patients with depression. Int J Psychiatry Med 2001; 31:277-288.

Pearl $A$, Wright $S$, Gamble $\mathrm{G}_{4}$ Doughty $\mathrm{R}$, Sharpe $\mathbb{N}$. Randomised trials in general practice - a New Zealand experience in recruitment. $\mathrm{NZ}$ Med I 2003; 21: 116.

Peto V, Coulter A, Bond A. Factors affecting general practitioners' recruitment of patients into a prospective study. Fam Pract 1993; 10: 207-211.

Prout $\mathrm{H}$, Butler $\mathrm{C}$, Kinnersley $\mathrm{p}$, Robling M, Hood K, Tudor-Jones R. A qualitative evaluation of implementing a randomized controlled trial in general practice. Fam Pract 2003; 20:675-68.1.

Saunders KW, Von Korff MV, Grothaus LC. Predictors of participants in primary care group-format back pain self-care interventions. Clin I Pain 2000; 16: 236-243.

Schaik van DJ, Klijn AF, Hout van HP, Marwijk van HW, Beekman AT, Haan cte M, et al. Patients' preferences in the treatment of depressive disorder in primary care. Gen Hosp Psychiatry 2004; 26: 184-189.

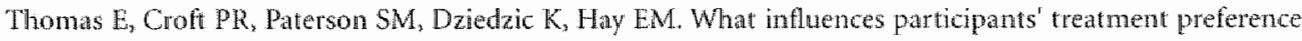
and can it influence outcome? Results from a primary care-based randomised dinical trial for shoulder pain. Br I Gen Pract 2004; 54: 93-96.

Thorogood M, Coulter A, Jones L, Yuckin P. Muir J, Mant D. Factors affecting response to an invitation to attend for a health check.) Epidemiol Community Health 1993; 47:224-228.

Trauth IM, Musa D, Siminoff $L_{2}$ Jewell $I K$, Rica $E$. Public attitudes regarding willingness to participate in medical research studies. J Health Soc Policy 2000; 12:23-43.

Windt DA wan der, Koes BW, Boeke A, Deville W, Jong BA de and Bouter LM. Shoulder disorders in general practice: prognostic indicators of outcome. Br J Gen Pract 1996; 46: 519-523.

Windt DA van der, Koes BW, Aarts wan M, Heenskerk MA, Bouter LM. Practical aspects of conducting a pragmatic randomised trial in primary care: patient recruitment and outcome assessment. Br I Gen Pract $2000 ; 50: 371-374$.

Wit de NI, Quartero AO, Zuithoff AP, Numans ME. Participation and successful patient recruiment in primary care. I Farn Pract 2001; 50: 976. 

स

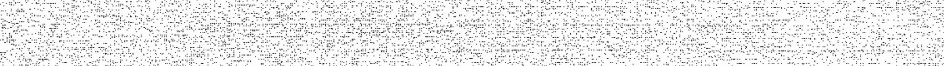

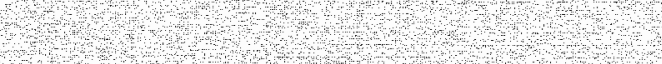

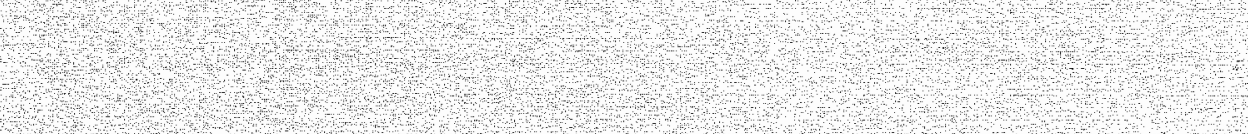
\begin{tabular}{ll}
\hline \\
\hline
\end{tabular}

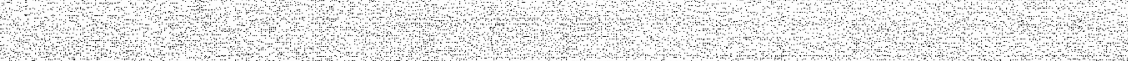

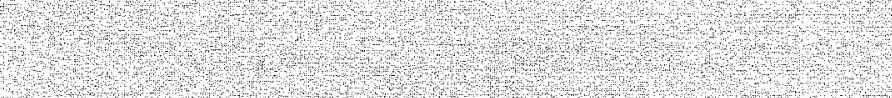

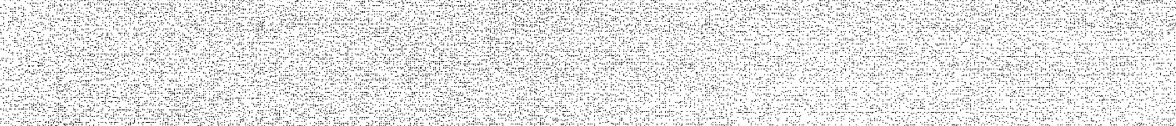

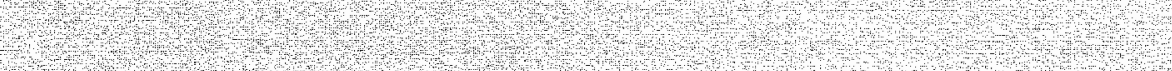

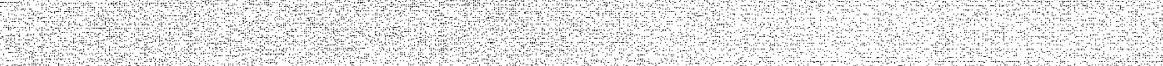
\begin{tabular}{lll}
\hline 4 \\
\hline 4
\end{tabular} \begin{tabular}{lll}
\hline \\
\hline
\end{tabular}

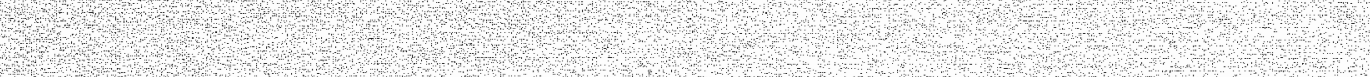

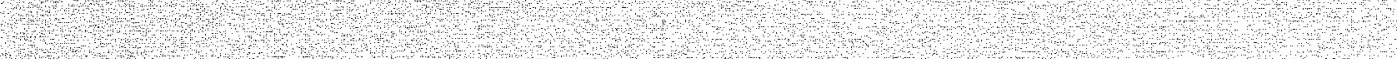
\begin{tabular}{lll}
\hline \\
\hline
\end{tabular} \begin{tabular}{lllll}
\hline \\
\hline
\end{tabular} \begin{tabular}{l}
1 \\
\hline
\end{tabular} Pᄂ

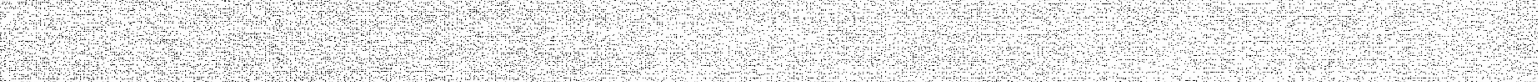

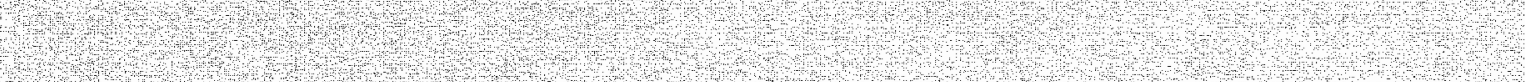

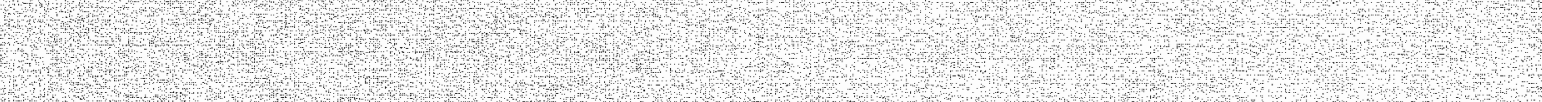
I 


\section{Chapter 8}

\section{General discussion}




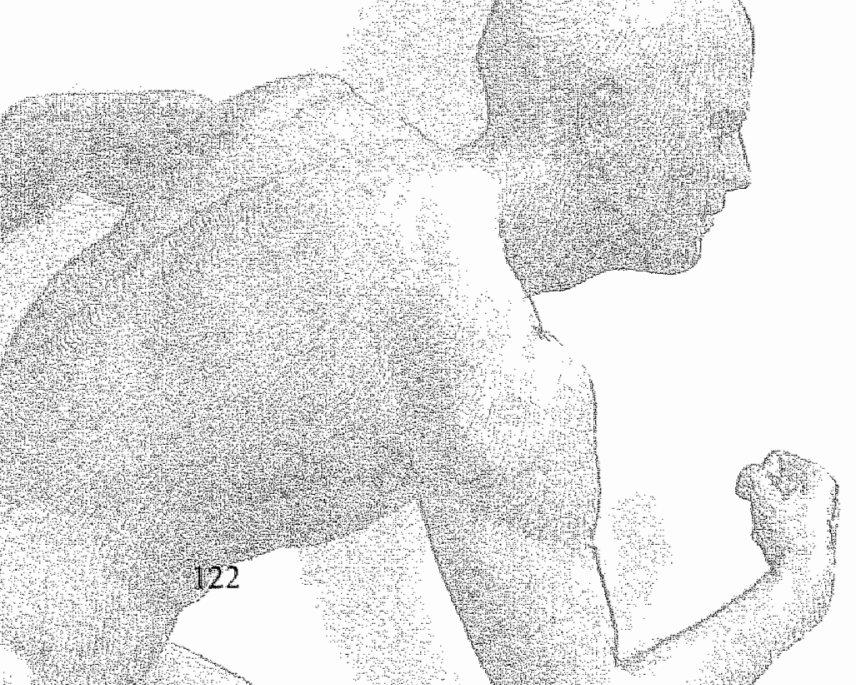


This thesis reports on a study evaluating the effectiveness and cost-effectiveness of a behavioural Graded Exercise Therapy programme, in comparison with usual care, for patients with chronic shoulder complaints in a primary care setting. This final chapter summarises the main findings of the randomised clinical trial and the answers to the research questions presented in the first chapter. Also methodological and practical issues, including the recruitment of patients and the intervention process, will be discussed. Finally, the implications for clinical practice will be considered and recommendations are made for future research and practice developments.

\section{MAIN FINDINGS}

In total 176 patients are recruited, either by their general practitioner $(N=83)$ or through advertisements ( $N=93$ ). Block randomisation is used (blocks of ten patients each) to allocate patients to Graded Exercise Therapy (GET) (N=87) or to usual care (UC) (N=89) according to the guidelines for shoulder complaints issued by the Dutch College of General Practitioners (Winters et al 1999). Two primary outcome measure are used to assess the performance of daily activities: the 'main complaints' instrument and the Shoulder Disability Questionnaire (SDQ) (Beurskens et al 1999, van der Heijden et al 2000). The experimental GET method was characterised by graded activity, time contingency and operant conditioning, while usual care consisted of information, recommendations and pain-contingent medical or pharmaceutical therapy (see chapter 2 for details).

\section{Short-term and long-term clinical effectiveness}

The first and second research questions are concerned with the short-term and long-term clinical effectiveness of GET (chapters 3 and 4).GET patients showed statistically significantly greater improvement than UC patients on the 'main complaints' instrument immediately after the 12-week treatment, and these improvements lasted for at least 52 weeks. Improvements on the SDQ were greater with GET than with UC, but the differences between the groups failed to reach statistical significance. Explorative analyses showed that GET was more effective in patients not reporting pain reduction over time and in patients showing no painful arc during physical examination. Significantly greater improvements with GET were found for catastrophising at 12 weeks and for fear-avoidance beliefs and kinesiophobia at 52 weeks.

\section{Cost-effectiveness}

The third research question is related to the cost-effectiveness of GET (chapter 5). Patients allocated to GET showed statistically significantly lower direct health care costs and direct non-health care costs during the follow-up period compared to patients allocated to UC. Nevertheless, since the costs of the GET programme were higher than those of $\mathrm{UC}_{\mathrm{s}}$ total costs for GET patients were significantly higher than for UC patients. The costs per patient to improve the performance of daily activities by $25 \%$, which was the aim of this trial, were calculated to be $€ 425$.

\section{Process evaluation}

The fourth research question deals with the intervention process (chapter 6). The clinical effectiveness of GET in this trial was not influenced by flaws in the application of the 
programme or by lack of patient adherence. GET can be administered successfully by physiotherapists in a primary care setting. The programme could be improved in terms of the process of goal-setting, and the implementation of the GET programme could be facilitated if recommendations on pain-behaviours and pain-related disability given by health care providers in primary care are better matched.

\section{Recruitment strategy}

The final research question is related to the two recruitment strategies used in this trial (chapter 7). Results in terms of the clinical effectiveness of the treatments at the end of the treatment period or during follow-up are not modified by the recruitment strategy used. However, patients recruited by a general practitioner showed greater improvements on both primary outcome measures, irrespective of the allocated treatment. Therefore, recruitment strategy should be regarded as a putative modifying factor in the design of further studies.

\section{METHODOLOGICAL AND PRACTICAL ISSUES}

This study was a pragmatic randomised clinical trial, studying the effectiveness of the behavioural Graded Exercise Therapy programme compared with usual care in an everyday primary care setting. Opting for a pragmatic study has several methodological and practical consequences related to the design and implementation of the study. Aspects discussed below include the study population, recruitment of patients, blinding, contamination, intervention process, outcome measures and explorative analyses.

\section{Study population}

A first comment needs to be made on the selection of participants. We intended to include a representative sample of patients with chronic shoulder complaints in primary care in this trial, but as a consequence the study population was rather heterogeneous. A broad range of patients with shoulder complaints were included, and no restrictions were made for social aspects such as patients' work status. Furthermore, patients are included who visited their general practitioner for their shoulder complaints as well as those who initially did not intend to consult their general practitioner. The strength of this procedure is that the results can be easily generalised to an everyday prumary care setting. However, its weakness might be an inadequate match between the GET programme and patient characteristics. As a consequence beneficial treatment effects for specific subgroups might have been underestimated.

\section{Recruitment of patients}

An other comment needs to be made about the recruitment of our patients. Because the recruitment rate of patients during general practitioner consultations turned out to be lower than expected, subjects were also invited to enrol by means of advertisements in a local newspaper. Since recruitment strategy had to be regarded as a putative confounding or modifying factor, patients were pre-stratified for recruitment strategy before block randomisation. The results showed that the number of patients allocated to GET and to UC were equally balanced between both recruitment strategies and the total numbers of patients recruited by the general practitioners and by advertisement were very similar. However, patients recruited by a general practitioner showed greater improvement in terms of both 
primary outcome measures, irrespective of the allocated treatment. We learn from this study that through prestratification and randomisation the results of this trial were not biased by recruitment strategy, but the effectiveness of both treatment groups in terms of the clinical outcome measures used in this study has been underestimated.

One might argue that patients who intended to visit their general practitioner had more severe complaints, a longer duration of complaints or other treatment preferences. However, these factors did not modify the results of the trial, so no explanation was available for the differential effects of recruitment strategies by putative confounding or modifying factors in the dataset. Other variables related to pre-treatment beliefs (expectancies) and attitudes (readiness to change or motivation) may explain the differences between the patients recruited by these two strategies. Unfortunately, more detailed information on attitudes was lacking in this trial, though recent studies suggest that these factors might play important roles in this context (Goossens et al 2005, Jensen et al 2004, Keefe et al 2004).

\section{Blinding}

As a consequence of the pragmatic design of the trial, patients and health care providers could not be blinded, though the persons assessing the outcome measures and analysing the data were unaware of treatment allocation. The fact that patients were not blinded may have introduced withdrawal bias. However, results showed that the numbers of patients who withdrew because of the nature of the interventions (frequency of treatment sessions and treatment preferences) were small and simillar for both groups ( 2 GET versus $3 \mathrm{UC}$ ). Furthermore, the lack of blinding may have caused treatment preferences to influence the results of the trial (van Schaik et al 2004, Thomas et al 2004, van der Windt et al 2000). However, treatment preferences were found to have no influence on the effectiveness of treatments in this trial. Since no more than $5 \%$ of the patients in this study had prior experiences with behavioural treatments and $82 \%$ had no clear preference on this intervention, we consider that treatment preferences were less likely to have influenced the results in this study. We learn from this study that treatment preferences are probably more involved in unblinded studies in which participants have more explicit treatment preferences.

\section{Contamination}

The content of the treatments received by patients allocated to GET and usual care showed that none of the patients allocated to GET were treated with usual care physiotherapy during the treatment period. By contrast, 19 patients allocated to usual care were treated by a physiotherapist, but none of these were treated with behavioural therapy as such. Since the principles of the biopsychosocial model are nowadays more commonly applied in usual care, the differences between treatments might have become less distinct than intended. Earlier studies focused on the interaction between health care providers and pain patients and found that health care providers' attitudes and beliefs influenced their recommendations regarding activities for patients with chronic low back pain (Rainville et al 1995, Linton 2002). Health care providers seemed to be either more behaviourally oriented or more biomedically oriented, and physiotherapists who had attended a biopsychosocial education course proved to be more behaviourally oriented (Ostelo et al 2003). Furthermore, behavioural or biomedical orientation among physiotherapists was associated with perceived harmfulness of physical activities and recommendations for return to work (Houben et al 2005). Further research is needed to explore the influence of attitudes and beliefs among health care providers in trials. 


\section{Evaluation of the intervention process}

The process evaluation is of utmost importance in studies on clinical effectiveness: first, to know whether the treatment under study was performed according to protocol, second, to know whether the treatment is feasible in normal practice, and third, to identify any need to improve the protocol to facilitate its implementation. Chapter 6 describes a process evalluation of GET. Patients and physiotherapists were involved in the development and evaluation of GET, as this would stimulate the implementation of the programme. Nevertheless, three comments should be made on the methods used in the present process evaluation. First, since indirect methods were used, based only on reports, no evidence is available of what actually happened during the treatment sessions. Second, since the physiotherapists and the patients were involved in the assessments, scores might be flawed. Third, reports on the quantitative application of the programme do not provide information about the quality of its application.

\section{Outcome measures}

The outcome measures of this study might be critically considered. Firstly, there is at present no consensus on the outcome that is the most appropriate for shoulder complaints (Green et al 2000). In the 'main complaints' instrument, patients were asked at baseline to select three daily activities they regarded as most important in relation to their shoulder complaints, but not necessarily related specifically to pain. Since activities, and their relevance or importance in daily life, can vary widely between patients with shoulder complaints, and the GET programme is tailored to the patient's goals and needs, this measure is considered to be appropriate to assess the performance of daily activities in this trial.

Secondly, some outcome measures used in this trial turned out to be inappropriate. At the level of participation, we assessed sick leave and generic health-related quality of life. Only $56 \%$ of all participants reported having paid work at baseline, and only $8 \%$ of all patients with paid work reported having been on sick leave from paid work. The margin for improvement as regards to sick leave from paid work was relatively small, and given the small numbers of patients with paid work, the trial had insufficient power to yield feasible data on 'return to work'.

Generic health-related quality of life was rated on the EQ5D (Brooks 1996) to enable the outcomes to be compared with those of other trials in terms of effectiveness and costeffectiveness. The EQ5D consists of a descriptive system for health status, related to five dimensions of health (mobility, self-care, usual activities, pain/discomfort and anxiety/ depression) and a visual analogue scale. However, this measure turned out not to be sensitive enough to detect changes in both treatment groups. It is very likely that improvements in individual daily activities were too specific to be detected by this generic health-related quality of life measure. These findings on the lack of responsiveness of the EQ5D are comparable with those of earlier studies on musculoskeletal disorders (Dawson et al 2001, Marra et al 2005). We suggest that future cost-effectiveness studies on musculoskeletal disorders should use more responsive quality of life instruments (e.g., the Medical Outcome Study Short-Form (SF-36) Health Survey) and incremental cost-effectiveness ratios of disease-specific instruments (e.g., the 'main complaints' instrument or perceived recovery), to enable generalisation of outcomes.

A final comment on outcome measures relates to the strengths and weaknesses of the outcomes used. This trial was embedded in a research programme on shoulder complaints, 
including a comprehensive prognostic cohort study with three trials in subcohorts. The strength of this programme is the ability to pool the outcomes of the subcohort trials. A weakness might be a lack of outcome measures relewant to subcohorts. Unfortunately, pretreatment attitudes (readiness to change, motivation) and beliefs (expectancies) on pain and pain disability were not assessed in the present trial. As was also mentioned above, we consider these outcome measures worthwhile as a means to explore in more detail the behavioural changes we found in patients with chronic shoulder complaints.

\section{Explorative analyses}

Further comments should be made on the explorative analyses in this trial. Patients allocated to GET showed statistically significantly higher scores for improvement on pain-catastrophising, kinesiophobia and pain-related fear. Since GET is an operant-behavioural treatment (and not a cognitive treatment), it could be assumed that patients gradually learned from positive experiences in performing daily activities during treatment and their improved performances contributed to a reduction of pain-catastrophising, kinesiophobia and pain-related fear in the long term. This interpretation is in line with those of earlier studies of chronic low back pain patients, in which pain-catastrophising, pain-anxiety and pain-related fear were associated with the lack of performance of activities through over-predicting actual pain and under-predicting abilities to perform physical tasks and to adjust pain behaviour (Vlaeyen and Linton 2000, Keefe et al 2004).

\section{IMPLICATIONS AND RECOMMENDATIONS FOR CLINICAL PRACTICE AND FUTURE RESEARCH}

\section{From health care perspective}

The present study shows that GET is more effective than UC in restoring the performance of daily activities in patients with chronic shoulder complaints in primary care and reduces direct health care costs and direct non-health care costs, although beneficial effects are small. Based on these results, it is recommended to use GET to restore daily activities in patients with chronic shoulder complaints in primary health care.

Beneficial effects of GET are greater in patients with prolonged pain. Predicting which patients are at risk of persistent shoulder pain in the long term in primary care is of great interest if we want to achieve a better match between the GET programme and patient characteristics. Recently, high pain intensity at onset was found to be a consistent predictor of prolonged pain in patients with shoulder complaints in primary care (Kuipers et al 2004). Therefore, we recommend the use of the GET programme in patients with more severe shoulder pain at onset.

The study has also shown that beneficial effects are smaller in patients showing a painful arc during physical examination. Painful arc is a well-known sign associated with subacromial impingement, as the initial stage of rotator cuff injuries, with rotator cuff tears as the final stage (Neer and Welsh 1977, Pyne 2004). No recommendations can be given to either support or refute the use of GET in patients showing a painful arc. We recommend more research on the phenomenon of painful arc, to elucidate the value of exercise programmes in general for patients with shoulder impingement in primary care.

Furthermore, this study shows that GET is effective in restoring daily activities in patients with chronic shoulder complaints in long term in a primary care setting and might as such 
prevent more intensive and more expensive multidisciplinary treatment of these patients in secondary or tertiary care settings. .

GET reduced direct health care costs and direct non-health care costs in patients with chronic shoulder complaints, although total costs for GET were higher due to higher programme costs. We recommend that the programme should focus more on work-related goals and work-related activities in patients having paid work, which might improve the social benefits of GET.

GET fits well into developments in primary care physiotherapy in the Netherlands in which consultation of a primary care physiotherapist for (graded exercise) group therapy was introduced only recently and is paid for by Dutch health insurance companies.

We recommend revision of the practice guidelines for shoulder complaints of the Dutch College of General Practitioners. We suggest that the GET programme should be considered as an effective treatment in restoring activities in patients with chronic shoulder complaints in the long term, predominantly in patients with severe pain at onset.

\section{From patient's perspective}

From a patient's point of view, this study shows that patients with chronic shoulder complaints can derive short- and long-term benefit from GET in terms of improved performance of daily activities. The GET programme is "personality"-based, in that it is tailored to patients' individual needs in terms of treatment goals and levels of activity, and focuses on patients' behaviour to meet these goals and improve their activities. We recommend that patients should be very explicit in defining the treatment goals and should be well aware that the programme does not primarily aim to reduce pain. This requires a clear explanation to the patients before starting the treatment.

GET fits well into the policy trend to put the patients" preferences as the start of the treatment in non acute situations. Furthermore, GET fits well into the trend towards acceptance-based treatments in patients with chronic pain, in which the focus is not on reducing pain but on reducing the distressing and the disabling influence of pain in chronic pain patients (Mc Cracken et al 2005) .

\section{From providers' perspective}

From the point of view of practitioners, education and training of health care providers, this study shows that GET can be administered successfully in a primary health care setting by physiotherapists. Implementation of GET could be promoted if it is embedded in a multidisciplinary biopsychosocial approach of health care providers on shoulder complaints in primary care. Since attitudes and beliefs of health care providers correlate with their recommendation about activities, special attention should be paid to these attitudes. More research is needed into the interactions between health care providers and patients with shoulder complaints, to elucidate the mechanisms involved in treatments.

\section{From research perspective}

Further research is needed to optimise the effectiveness of behavioural treatment in patients with chronic shoulder complaints. More research is needed on the cognitive and behavioural aspects of pain prediction in patients with chronic shoulder pain at the onset of complaints, as it could provide new insights into the prognosis and course of complaints. We assumed the GET programme most suitable for patients with discrepant pain behaviour and pain beliefs, 
who might either postpone activities because they believe activity may cause damage or reinjury, or ignore the pain and consequently exceed suitable levels of activity. More research is needed to explore the beneficial effects of GET in "avoiders" and "overusers".

More research is also needed on the specific biobehavioural mechanisms for the transition from acute to chronic pain and disability in patients with shoulder complaints to optimise treatment. Recent developments in behavioural pain research, focussing in greater detail on pain-related fear in chronic pain patients, have shown that education and exposure in vivo, with behavioural experiments for patients who report fear of movement/(re)injury, might be more effective than gradual operant learning in terms of reducing pain-related fear and improving the performance of daily activities (de Jong et al 2005). Since GET asks patients to select specific relevant daily activities, this might exclude activities they have been avoiding for a long time. In exposure in vivo, patients are exposed to these threatening activities, leading directly to fear-reduction. More research is needed to elucidate whether or not the operant-behavioural GET programme administered by a physiotherapist should be applied or combined with education and exposure administered by a psychologist in highly fearful patients with shoulder complaints in primary care.

Finally, we consider process evaluation to be of the utmost importance in future studies of clinical effectiveness and recommend the development of measurement instruments to evaluate intervention processes and report on process evaluations in trials and on implications for clinical effectiveness and clinical practice. 


\section{REFERENCES}

Beurskens AIHM, Vet HCW de, Kake AIA, Lindeman F, Heajden GIMG van der, Regtop W, Kaipschild PG. A patient-specific approach for measuring functional status in low back pain. I Manipulative Physiol Ther $1999 ; 22: 144-8$

Brooks R (1996): Euroqol: The current state of play. Health Policy 37: 53-72.

Dawson I, Fitzpatrick R, Frost S, Gundle R, MeLardy-Smith P, Murrag D. Evidence for the validity of a patientbased instrument for assessment of outcome after revision hip replacement. I Bone foint Surg Br. $2001 ; 83: 1125-9$.

Goossens MEIB, Vhaeyen JWS, Hidding A, Kole-Snijders A, Evers SMAA. Treatment expectancy affects the outcome of cognitive-behavioral interventions in chronic pain. Clin] Pain. 2005;21:18-26.

Green S, Buchbinder $R$, Glazier $\mathbb{R}$, borbes A. Interventions for shoulder complaints. Cochrane Database Syst Rev. $2000 ;(2): C D 001156$.

Heijden GIMG van der, Leffers P and Bouter LM (2000): Shoulder Disablity Questionnaire design and responsiveness of a functional status measure. I Cin Epidemiol;53: 29-38.

Houben RM, Ostelo RW, Vlaeyen IW, Wolters PM, Peters M, Stomp-wan den Berg SG. Health care providers' orientations towards common low back pain predict perceived harmfulness of physical activities and recommendations regarding return to normal activity. Eur J Pain. 2005:9:173-83.

Jensen $M P_{n}$ Nielson $W R$, Turner JA, Romano $\| L$, Hill ML. Changes in readiness to self-manage pain are associated with improvement in muttidisciplinary pain treatment and pain coping. Pain 2004; 111:84-95.

Jong de JR, Vlaeyen WS, Onghena P, Goossens MEIB, Geilen M, Mulder H. Fear of movement/(re)injury in chronic low back pain; education or exposure in vivo as mediator to fear reduction. Clin I Pain 2005; $21: 9-17$.

Keefe FJ, Rumble ME, Scipio CD, Giondano LA. Perri LM. Psychological aspects of persistent pain: current state of the science. If Pain 2004; 5: 195-211.

Kuipers T, Windt van der DA, Heijden GIMG van der, Bouter LM. Systematic review of prognostic cohort studies on shoulder disorders. Pain. 2004; 109:420-431.

Linton SI, Vaeyen IWS, Ostelo R. The back pain beliefs of health care providersa are we fear-awoidant? Jecup Rehabil. 2002:12:223-32.

Marra CA, Rashidi AA, Guh D, Kopec IA, Abrahamowicz M, Esdaile JM, Brazier JE, Fortin PR, Anis AH. Are indirect uthity measures reliable and responsive in theumatoid arthritis patients? Qual Life Res. $2005 ; 14: 1333-44$.

McCracken LM, Vowles KE, Eccleston C. Acceptance-based treatment for persons willy complex, long standing chronic pain: a preliminary analysis of treatment outcome in comparison to a wating phasc. Bchay Res Ther $2005 ; 43: 1335-46$. 


\section{Chapter 8}

Neer $\mathrm{C}$ and Welsh Re. The shoulder in sports. Orthop Clin North Am 1977; 8:583-591.

Ostelo RW, Stomp-wan den Berg SG, Vlaeyen IW, Wolters PM, de Vet HC. Health care provider's attitades and beliefs towards chronic low back pain: the development of a questionnaire. Man Ther 2003 Nov:8:214-22.

Pyne SW. Diagnosis and current treatment aptions of shoulder impingement. Curr Sports Med Rep. 2004; 5: 251.5 .

Rainville J, Bagnall D, Phalen L. Health care providers' attitudes and beliefs about functional impairments and chronic back pain. Clin J Pain 1995:11:287-95.

Schaik wan DJ, Klin AF, Hout van HP, Marwijk van HW, Beekman AT, Haan de M, et al. Patients' preferences in the treatment of depressive disorder in primary care. Gen Hosp Psychiatry 2004; 26: 184-189.

Thonas ${ }^{2}$ Croft PR, Paterson SM, Dziedzic K, Hay EM. What influences participants" treatment preference and can it influence outcome? Results from a primary care-based randomised clinical trial for shoulder pain. Bri J Gen Pract 2004; 54: 93-96

Vheyen JWS and Linton SJ. Fear-Avoidance and its consequences in chronic musculoskeletal pain: A state of the art. Pain $2000 ; 85: 317-332$.

Wind DA wan der, Koes BW, Aarts van M, Heemskerk. MA, Bouter LM. Practical aspects of conducting at pragnatic randomised trial in primary care: patient recruitment and outcome assessment. Br I Gen Pract 2000; $50: 371-374$.

Winters $J C$, Jongh AC de, Windt DAWM van der, Jonquiere M, Winter AF de, Heijden GIMG van der, Sobel JS and Goudswaard AN. NFHG-Standaard Schouderklachten. Huisarts en Wetenschap. 1999; 42: 222-231. 



\section{Summary \\ Samenvatting}




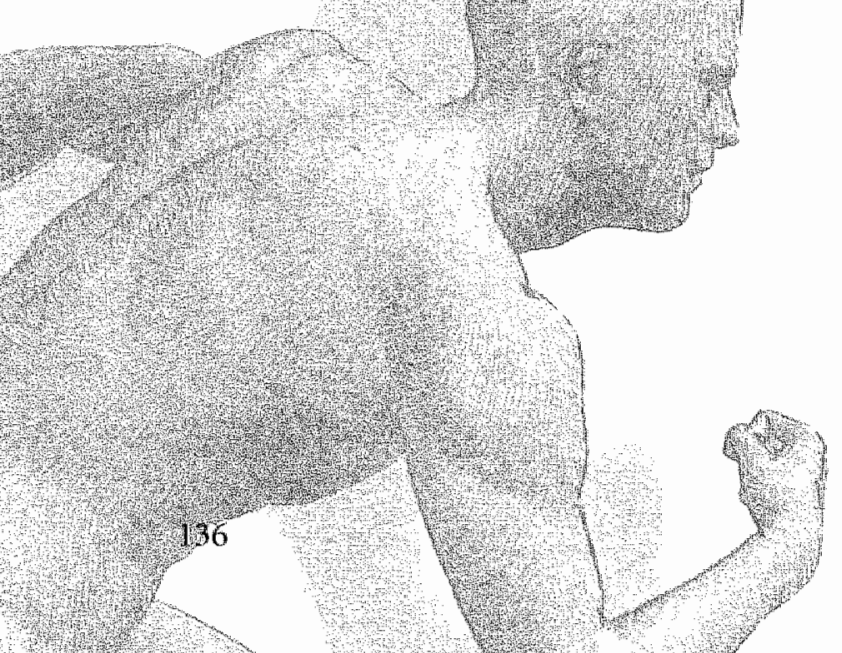




\section{SUMMARY}

This thesis reports on a study of the clinical effectiveness and cost-effectiveness of a behavioural Graded Exercise Therapy (GET) programme for patients with chronic shoulder complaints in a primary care setting. Shoulder complaints are serious musculoskeletal problems in view of their occurrence, course and persistence. Shoulder complaints manifest themselves as pain and limitations in the performance of daily activities. At present, there is limited evidence that commonly applied interventions for shoulder complaints speed up recovery in the short term, though there is no or conflicting evidence on long-term effects of conservative treatments. Behavioural treatments have proved to be effective mostly for chronic low back pain patients and in multidisciplinary settings. We assumed that behavioural treatment might be an effective means of optimising the course of chronic shoulder complaints in a primary care setting as well. We therefore initiated a randomised clinical trial to compare the clinical effectiveness and cost-effectiveness of a behavioural Graded Exercise Therapy programme with usual care in patients with chronic shoulder complaints.

Chapter 1 reports on the personal and economic burden imposed by shoulder complaints, on the lack of evidence about the aetiology, prognosis and management of shoulder complaints, and on the need to optimise treatment. It also presents the objectives of the research project described in this thesis. It has been estimated that about $40 \%$ of all patients who visit their general practitioner with a new episode of shoulder complaints endure complaints for up to 12 months. Musculoskeletal disorders, of which shoulder complaints constitute the second largest group after low back pain, account for the second largest share in healthcare costs in the Netherlands. At present, it is unclear what factors contribute to the initiation of shoulder complaints, what factors are involved in the transition from acute to chronic complaints or what factors play a role in the persistence of chronic complaints. However, there is general agreement that psychological factors are involved in the course of chronic pain. A behavioural Graded Exercise Therapy (GET) programme was developed to optimise the course and to reduce healthcare costs for patients with chronic shoulder complaints in primary care. The main objective of the studies reported on in this thesis was to evaluate the short-term and long-term clinical effectiveness and the cost-effectiveness of the GET programme in terms of restoring the performance of daily activities by patients with chronic shoulder complaints, compared with usual care in a primary care setting. We also evaluated the intervention process and the feasibility of the newly developed GET programme in a primary care setting. Finally, we evaluated whether the use of two recruitment strategies in this trial had influenced its outcomes.

Chapter 2 describes the concepts and the development of the GET programme and the design of the pragmatic randomised clinical trial to evaluate its clinical effectiveness and costeffectiveness. The chapter focuses on the reconceptualisation of pain in research and practice during the past decades and the development of a new biopsychosocial model, which assumes that biological, psychological and social factors might be involved in the persistence or reduction of chronic pain. It describes the operant conditioning principles for the management of chronic pain and the way in which pain behaviour and pain-related inactivity are acquired and can be modified by changing the consequences of this behaviour. Furthermore, it discusses the content and the main components (graded activity, time contingency and operant conditioning) of the GET programme and the content of the 
Guidelines for Shoulder Complaints of the Dutch College of General Practitioners (waitand-see policy possibly supplemented with analgesics and NSAIDS, corticosteroid injections and referral to physiotherapy, which is considered in complaints persisting for six weeks or more). Finally, it presents the design of this pragmatic randomised clinical trial, induding the methods and the statistical analyses.

Chapter 3 presents short-term results on the clinical effectiveness of the GET programme. A total of 176 patients were randomised and allocated either to GET (N=87) or usual care $(\mathrm{N}=89)$. The short-term effects were assessed after 12 weeks of treatment. Primary outcome measures were the Main Complaints instrument and the Shoulder Disability Questionnaire (SDQ). The secondary outcome measures included shoulder pain scored on the Shoulder Pain Scores (SPS), perceived recovery measured on an eight-point ordinal scale (0 fully recovered - 7 very much deteriorated), generic health-related quality of life rated on the EQ5D, catastrophising, coping with pain, internal locus of control and external locus of control as assessed by the Pain Coping and Cognition List (PCCL), kinesiophobia rated on 2 items of the Tampa Scale for Kinesiophobia (TSK) and fear-avoidance beliefs scored on the subscale of fear-awoidance beliefs about physical activity, adjusted for SC, of the Fear-Avoidance Beliefs Questionnaire (FABQ-DV). GET led to a larger improvement in the performance of daily activities than usual care. However, only the mean differences between groups in the performance of activities related to the main complaints reached statistical significance $\left(P=0.049,95 \% \mathrm{CI}^{*} 0.0,15.0\right)$. The observed beneficial effects were considered to be small (calculated effect sizes: 0.30 for the Main Complaints instrument and 0.07 for the SDQ). Subgroup analysis showed greater improvements in the mean scores on the Main Complaints instrument for patients not reporting pain reduction over time. GET seemed to be just as effective as usual care in restoring the performance of daily activities, as assessed by the SDQ, in patients showing a painful arc during physical examination. We concluded that GET is more effective than usual care in restoring the performance of daily activities in patients with chronic shoulder complaints in the short term, although beneficial effects at the end of the treatment period were small.

Chapter 4 presents long-term results on the clinical effectiveness of GET. These effects were assessed atter 26 and 52 weeks. GET showed statistically significantly greater improvements than usual care on the Main Complaints instrument immediately after 12 weeks of treatment, and these improvements lasted for at least 52 weeks ( $\mathrm{P}=0.025,95 \% \mathrm{CI}: 1.2,17.3)$. GET was equally effective as usual care in patients with a painful arc during physical examination and more effective than usual care in patients with no pain reduction during the treatment period. Statistically significantly greater improvements with GET were found for catastrophising at 12 weeks $(\mathrm{P}=0.028,95 \% \mathrm{CI}: 0.0,0.4)$ and for fear avoidance beliefs $(\mathrm{P}=0.043,95 \% \mathrm{CI}: 0.0,0.8)$ and kinesiophobia $(\mathrm{P}=0.003,95 \% \mathrm{CI}: 0.3,1.3)$ at 52 weeks. Calculated effect sizes were rather modest (up to 0.45 ). We concluded that the effectiveness of GET compared with usual care in restoring daily activities in patients with chronic shoulder complaints, as assessed immediately after treatment, persists in the long term (at least 52 weeks), although clinical benefits are rather modest.

Chapter 5 presents results of the cost-effectiveness study that was performed alongside the randomised clinical trial. Clinical outcomes (main complaints, shoulder disability (SDQ) and 
generic health-related quality of life (EQ5D)) and costs (intervention costs, direct health care costs, direct non-health related costs and indirect costs) were assessed during the 12 -week treatment period and during 52 weeks of follow up. Results showed that GET significantly reduced direct health care costs $(p=0.000)$ and direct non-health care costs $(p=0.029)$ in these patients. Nevertheless, total costs during the one-year follow-up period were significantly higher $(\mathrm{p}=0.001 ; € 530$ for $G E T$ versus $€ 377$ for UC) due to the higher costs of the intervention. Incremental cost-effectiveness ratios for the severity of the main complaints $(0-100), S D Q(0-100)$ and $\operatorname{SQSD}(-1.0-1.0)$ were $€ 17, € 74$, and $€ 5278$ per unit of improvement, respectively. We conclude that GET is more effective than usual care in the short and long term and reduces direct health care costs and direct non-health care costs, but is associated with higher costs of the intervention itself.

Chapter 6 reports on the evaluation of the intervention process. This process evaluation was done for three reasons: first, to know whether the programme had been administered as planned, second, to know whether this treatment would be feasible in normal practice, and third, to identify the need for improvements to the protocol to facilitate its implication. We evaluated the degree to which the programme had been applied according to protocol, patient adherence to the programme, and the suitability of the programme according to patients and physiotherapists. Twenty participating physiotherapists and 87 patients allocated to GET were asked to evaluate the intervention process. Furthermore, a sample of 10 patients, taken from the total number of 87 patients allocated to GET, were invited to take part in a focus group interview at the end of the study. We evaluated the intervention process using a treatment registration form filled in by the physiotherapists during treatment, evaluation forms filled in independently by physiotherapists and patients after the treatment period, and information gathered during the focus group interview at the end of the study.

Results showed that GET had been applied according to protocol to an acceptable degree, and participating patients showed satisfactory adherence to the programme. The programme could be improved in terms of the goal-setting process, and the implementation of GET could be facilitated by embedding the programme in a multidisciplinary approach in primary care. We conclude that the clinical effectiveness of GET in this trial was not influenced by flaws in the administration of the programme or by lack of patient adherence.

Chapter 7 reports on an evaluation of the use of two recruitment strategies in this trial. Since the numbers of patients recruited during general practitioner consultations for chronic shoulder complaints were smaller than expected, subjects were also invited to enrol by means of advertisements in a local newspaper. Patients recruited by their general practitioners were compared with those recruited by advertisement as regards baseline characteristics, withdrawal (drop-outs and losses to follow-up) and post-treatment clinical outcomes. Results showed that patients recruited by the general practitioners $(N=83)$ were similar to those recruited by advertisement $(\mathrm{N}=93)$ in terms of demographic characteristics and clinical outcone measures at baseline, but differed slightly in disease characteristics and treatment preferences. Recruitment strategy was not related to reasons for withdrawal or numbers of withdrawals. Improvements on outcome measures were greater in patients recruited by the general practitioners, irrespective of allocated treatment. Results on the clinical effectiveness of treatments at the end of the treatment period or during follow-up were neither modified by recruitment strategy, nor by differences between the two strategy groups in patient 
characteristics found at baseline. We concluded that using two recruitment strategies did not influence the trial's clinical effectiveness outcomes. However, recruitment strategy should be regarded as a putative modifying factor in the design of a study.

Chapter 8 presents a general discussion, focussing on the answers to the research questions presented in the first chapter. It reviews the main findings of the randomised clinical trial, and deals with some general methodological and practical issues concerning the study, including the recruitment of patients and the evaluation of the intervention process. Finally, it presents some implications of this trial for clinical practice and future research. 


\section{SAMENVATTING}

Dit proefschrift gaat over een studie naar de klinische effectiviteit en de kosteneffectiviteit van een gedragsmatig Graded Exercise Therapy (GET) programma voor patiënten met chronische schouderklachten in de eerste lijn. Schouderklachten vormen een omvangrijk gezondheidsprobleem door het vórkomen, het beloop en het aanhoudende karakter ervan. Schouderklachten worden gekenmerkt door pijn en door beperkingen in het uitvoeren van dagelijkse activiteiten. Op dit moment is de bewijskracht dat de gebruikelijke behandelingen voor schouderklachten het herstel bespoedigen beperkt en er is geen of tegengesteld bewijs dat deze behandelingen effectief zijn op de lange termijn. Gedragsmatige behandelingen blijken effectief te zijn in de behandeling van patiënten met lage rugklachten in een multidisciplinaire setting. Wij veronderstelden dat een gedragsmatige behandeling tevens effectief zou kunnen zijn in het verbeteren van dagelijkse activiteiten bij patiënten met chronische schouderklachten in de eerste lijn. Daarom hebben we in een pragmatische gerandomiseerde studie, de klinische effectiviteit en de kosteneffectiviteit van een gedragsmatig Graded Exercise Therapy programma vergeleken met die van de standaard behandeling voor schouderklachten (conform de Standaard Schouderklachten van het Nederlands Huisartsengenootschap) bij patiënten met chronische schouderklachten in de eerste lijn.

Hoofdstuk $I$ beschrijft allereerst, de persoonlijke hinder die patiënten met schouderklachten ondervinden en de economische en maatschappelijke gevolgen van schouderproblematiek. Verder wordt ingegaan op het gebrek aan bewijs over het ontstaan, de prognose en de behandeling van schouderklachten en de behoefte om de behandeling voor schouderklachten verder te verbeteren. Ten slotte worden de onderzoeksvragen die in dit proefschrift aan bod komen gepresenteerd.

Circa $40 \%$ procent van alle patiënten die voor een nieuwe episode van schouderklachten de huisarts bezoekt, heeft na 12 maanden nog restklachten. Schouderklachten vormen na lage rugklachten de op één na grootste groep van klachten van het bewegingsapparaat. Klachten van het bewegingsapparaat nemen in Nederland het op één na grootst aandeel in de kosten voor gezondheidszorg voor haar rekening. Op dit moment is nog onduidelijk welke factoren betrokken zijn bij het ontstaan van schouderklachten, welke factoren betrokken zijn bij de overgang van acute naar chronische klachten of welke factoren een rol spelen bij het voortbestaan van chronische schouderklachten. Echter, er is consensus dat psychologische factoren betrokken kunnen zijn bij het beloop wan chronische pijnklachten van bet bewegingsapparaat. Daarom werd een gedragsmatig GET programma ontwikkeld voor patiënten met chronische schouderklachten in de eerste lijn met het doel het activiteitenniveaut voor deze patiènten te verbeteren en de gezondheidskosten te verminderen. In deze studie zijn de klinische effectiviteit en de kosteneffectiviteit van GET, in het verbeteren van dagelijkse schouderactiviteiten op de korte en de lange termijn bij patiënten met chronische schouderklachten in de eerste lijn, vergeleken met die van de standaard behandeling. Verder werd het behandelproces geëvalueerd en de uitvoerbaarheid van het nieuw ontwikkelde GET programma in een eerste lijn setting onderzocht. Tot slot hebben we onderzocht of het gebruik van twee strategieën om patiënten te werven voor deelname aan deze studie, de resultaten van deze trial heeft beïnvloed.

Hoofdstuk 2 beschrijft de achtergronden en de ontwikkeling van het GET programma en het ontwerp van dit pragmatisch gerandomiseerd klinisch onderzoek waarin de klinische 
effectiviteit en de kosteneffectiviteit van dit programma zijn onderzocht. Het gaat in op de veranderde opvattingen over pijn in onderzoek en praktijk gedurende de laatste decennia en de ontwikkeling van een nieuw biopsychosociaal model, waarin biologische, psychologische en sociale factoren betrokken kunnen zijn bij het voortbestaan of bij het verminderen van chronische pijnklachten. Het beschrijft de principes van operante conditionering in de behandeling van chronisch pijn en de wijze waarop pijngedrag en inactiviteit door pijn aangeleerd zijn en gernodificeerd kunnen worden door het veranderen van de consequenties wan dit gedrag. Verder wordt de inhoud en de belangrijkste elementen (gradueel oefenen, tijdcontingentie en operante conditionering) wan het GET programma en de inhoud van de Standaard Schouderklachten van het Nederlands Huisartsengenootschap (afwachtend beleid, eventueel aangevuld met pijnstillers of NSAID's, corticosteroid injecties en verwijzing naar de fysiotherapeut, dat overwogen wordt bij langer dan 6 weken bestaande klachten) besproken. Tot slot wordt het ontwerp van dit pragmatisch gerandomiseerd klinisch onderzoek, inclusief de methoden en de statistische analysen, gepresenteerd.

Hoofdstuk 3 beschrijft de klinische effectiviteit van het GET programma op de korte termijn. Honderdzesenzeventig patiënten werden gerandomiseerd en toegewezen aan GET ( $N=87)$ of aan de standaard behandeling ( $N=89$ ). De korte termijn resultaten werden direct na afloop van de 12 weken durende behandeling bepaald. De belangrijkste uitkomstmaten waren de Patiënt Specifieke Klacht (PSK) en de Shoulder Disability Questionnaire (SDQ). Overige uitkomstmaten waren schouderpijn, gescoord op de Shoulder Pain Score (SPS), ervaren herstel, gemeten op een acht-punten ordinale schaal ( 0 volledig herstel -8 zeer veel verslechterd), kwaliteit van leven, gemeten met de EQ5D, catastroferen, pijncoping, interne pijnbeheersing en externe pijnbeheersing, gemeten met de Pain Coping and Cognition List (PCCL), kinesiofobie, gemeten met de Tampa Scale for Kinesiophobia (TSK), en pijngerelateerde vrees, gemeten met de subschaal pijngerelateerd vrees voor fysieke activiteiten van de Fear-Avoidance Beliefs Questionnaire (FABQ). GET liet een grotere vooruitgang zien in het uitwoeren van dagelijkse schouder activiteiten dan de standaard behandeling voor schouderklachten. Echter, alleen de verschillen tussen de beide groepen gemeten met de PSK waren statistisch significant $(P=0.049,95 \%$ BI: $0.0,15.0)$. De omvang van de verschillen tussen de groepen waren kliniscli gezien klein (berekende effectsizes: 0.30 voor de PSK en 0.07 voor de SDQ). Subgroepanalysen lieten een grotere vooruitgang zien op de PSK voor patiënten warin de pijn in de loop van de tijd niet was verminderd. GET is even effectief in het verhogen van dagelijkse schouderactiviteiten gemeten met de SDQ bij patiënten die tijdens het lichamelijk onderzoek een pain-ful arc vertoonden. Wii concludeerden dat GET op de korte termijn effectiever is dan de standaard behandeling in het verhogen van dagelijkse activiteiten bij patiënten met chronische schouderklachten, ook al zijn de waargenomen verschillen in klinisch opzicht klein.

Hoofdsfuk 4 beschrijt de effectiviteit van GET op de lange-termijn. Deze effecten werden gemeten na 26 en 52 weken. GET liet statistisch significant grotere verschillen zien dan de standaard behandeling op de PSK direct na afloop van de behandeling en deze verschillen beklijifden op zijn minst voor de periode tot 52 weken ( $P=0.025,95 \%$ BI: 1.2, 17.3). GET was even effectief als de standaard behandeling voor patiënten met een pain-ful arc tijdens het lichamelijk onderzoek en effectiever dan de gebruikelijke behandeling voor patiënten die geen pijnvermindering in de loop van de tijd lieten zien. Statistisch significant grotere 
verschillen voor GET werden gezien voor catastroferen na 12 weken $(\mathrm{P}=0.028,95 \% \mathrm{BL}: 0.0$, 0.4 ) en voor pijngerelateerde vrees ( $P=0.043,95 \%$ BI: $0.0,0.8$ ) en kinesiofobie ( $P=0.003,95 \%$ BI: $0.3,1.3$ ) na 52 weken. De berekende effectsizes waren bescheiden (tot 0.45 ). We concludeerden dat de grotere effecten van GET, vergeleken met de standaard behandeling, op het verhogen van dagelijkse activiteiten bij patiënten met chronische schouderklachten gemeten direct na afloop van de 12 weken durende behandeling, beklijven op de lange termijn na 52 weken, ook al zijn de verschillen klinische gezien bescheiden.

Hoofdstuk 5 beschrifft de resultaten van de kosteneffectiviteit studie die parallel an het gerandomiseerd klinisch onderzoek werd uitgevoerd. Klinische uitkomstmaten (PSK, SDQ en EQ5D) en kosten (interventiekosten, directe gezondheidsgerelateerde kosten, directe nietgezondheidsgerelateerde kosten en indirecte kosten) werden gemeten gedurende de 12 weken durende behandelperiode en gedurende de follow-up periode tot 52 weken. De resultaten lieten zien dat de directe gezondheidsgerelateerde kosten $(P=0.000)$ en de directe nietgezondheidsgerelateerde kosten $(\mathrm{P}=0.029)$ voor GET patiënten statistisch significant verminderden. Desondanks waren de totale kosten gedurende de 52 weken follow-up periode significant hoger ( $\mathrm{P}=0.001 ; € 530$ voor GET tegen $€ 377$ voor de standaard behandeling) door de hogere kosten voor de interventie. De kosten-effectiviteitsratio's voor de PSK (0-100), de SDQ $(0-100)$ en de EQ-5D (-1.00 - 1.00) bedragen respectievelijk $€ 17, € 74$ en $€ 5278$ per eenheid verbetering. We concludeerden dat GET effectiever is in het verbeteren van dagelijkse activiteiten op de korte en lange termijn en GET de directe gezondheidsgerelateerde kosten en directe niet-gezondheidsgerelateerde kosten voor patiënten met chronische schouderklachten verminderd, maar geassocieerd is met hogere interventiekosten.

Hoofdstuk 6 beschrijft de resultaten van het onderzoek naar het interventie proces. Deze procesevaluatie werd uitgevoerd on drie redenen: ten eerste, om te onderzoeken of het programma is uitgevoerd zoals gepland, ten tweede, om te onderzoeken of het programma uitvoerbaar is in de dagelijkse praktijk, ten derde, om te onderzoeken op welke punten het programma verbeterd kan worden om de implementatie ervan te fasciliteren. We hebben onderzocht in hoeverre het programma is uitgevoerd volgens het behandelprotocol, de patiënten trouw waren aan het programma en de patiënten en fysiotherapeuten het programma geschikt vonden voor de behandeling van iedere patiënt affonderlijk. De 20 deelnemende fysiotherapeuten en de 87 patiënten die werden toegewezen aan GET, werden gevraagd het behandelproces te evalueren. Verder werd een steekproef van 10 patiënten, genomen uit de 87 patiënten die werden toegewezen aan GET, uitgenodigd woor deelname aan een focusgroep interview na afloop van de studie. Het behandelproces werd geëvalueerd aan de hand van de behandelverslagen ingevuld door de fysiotherapeuten gedurende de behandelperiode, aan de hand van de evaluatieformulieren die de patienten en de fysiotherapeuten onafhankelijk van elkaar hebben ingevuld na afloop van de behandelperiode en aan de hand van de informatie verzameld tijdens het focusgroep interview aan het eind van de studie. De resultaten lieten zien dat GET op een acceptabel niveau is uitgevoerd volgens het behandelprotocol en de deelnemende patiënten voldoende trouw waren aan het programma. Het GET programma kan verbeterd worden met betrekking tot het proces van het stellen van de behandeldoelen en de implementatie van GET kan gefascilliteerd worden als het programma ingebed zou worden in een multidisciplinaire benadering van patiënten met chronische schouderklachten in de eerste lijn. We concludeerden dat klinische 
effectiviteit van het GET programma in deze studie niet beünvloed is door onvolkomenheden in de uitvoering van het programma of door gebrek an therapietrouw onder de deelnemende patienten.

Hoofdstuk 7 beschrijft het onderzoek naar de toepassing van twee strategieën voor de werving van patienten in deze studie. Omdat het aantal patiènten, gerekruteerd door de huisarts tijdens het bezoek aan de praktijk voor schouderklachten, geringer was dan verwacht, werden tevens patiënten met chronische schouderklachten uitgenodigd voor deelname aan de studie via een advertentie in een plaatselijk nieuwsblad. Patiënten gerekruteerd door de huisarts en patiënten gerekruteerd via advertenties werden met elkaar vergeleken met betrekking tot de karakteristieken van de patiënten gemeten bij het vooronderzoek, het aantal uitvallers tijdens de studie en gedurende de follow-up periode en met betrekking tot de klinische uitkomstmaten na de behandeling. Resultaten lieten tijdens het vooronderzoek geen verschillen zien tussen de patiënten gerekruteerd via de huisarts $(N=83)$ en patiènten gerekruteerd via advertenties $(N=93)$ met betrekking tot demografische factoren en klinische uitkomstmaten en slechts geringe verschillen met betrekking tot ziektekenmerken en behandelvoorkeuren. Wervingstrategie was niet gerelateerd aan het aantal uitvallers of aan de redenen voor uitval in deze studie. Patienten gerekruteerd via de huisarts lieten een grotere vooruitgang zien op de belangrijkste klinische uitkomstmaten, ongeacht de behandeling waaraan patiënten werden toegewezen. De resultaten op de belangrijkste klinische uitkomstmaten werden niet gemodificeerd door wervingstrategie of door de gevonden verschillen tussen de groepen bij het wooronderzoek. We concludeerden dat het gebruik van twee wervingsstrategieën de resultaten op de belangrijkste uitkomstmaten in deze studie niet heeft beinvloed. Echter, wervingstrategie moet beschouwd worden als een mogelijke effectmodificator in het ontwerp van een studie.

Hoofdstuk 8 gaat in op de antwoorden op de onderzoeksvragen zoals beschreven in het eerste hoofdstuk. Het beschrijft de belangrijkste resultaten van dit gerandomiseerd klinisch onderzoek. Verder komen enkele methodologische en praktische aspecten met betrekking tot de ustwoering van deze studie aan bod, zoals de werving van patiënten en de procesevaluatie. Tot slot worden de implicaties voor de klinische praktijk and voor verder onderzoek beschreven. 



\section{Dankwoord}




\section{DANKWOORD}

Na vier-en-een-half jaar, is dit eindelijk het moment om jullie allen van harte te BEDANKEN voor jullie inspanningen, jullie tijd, jullie energie, jullie begrip, jullie vertrouwen en jullie steun gedurende de afgelopen periode!!!!!!!! GEWELDIG MENSEN!!!!

Alle patiënten die hebben deelgenomen aan dit onderzoek...van harte bedankt!!! Dit boekje gaat over u!!!...U bent weliswaar ingedeeld in én wan de groepen (waarin u zich mogelijk zult herkennen). Maar, mijn woord van dank wil ik richten tot u persoonlijk!! Ik hoop van harte dat het nu goed met $u$ gaat!! Mogelijk hebt $u$ nu geen hinder meer van uw schouderklachten, of heeft u een betere manier gevonden hier nu mee om te kunnen gaan. Verder hoop ik dat uw persoonlijke bijdrage aan dit onderzoek zal bijdragen tot meer inzicht in de behandeling van andere patiënten met chronische schouderklachten. Bedlanken wil ik ook alle huisartsen en fysiotherapeuten die naast hun zeer drukke werkzaamheden in de praktijk, bereid zijn geweest om aan dit onderzoek deel te nemen. Subliem!! Gedegen klinisch onderzoek is slechts mogelijk door jullie actieve participatie vanuit het praktijkveld. Daarvoor mijn dank!!!!

Marielle.....Natuurlijk wil ik jou, als mijn eerste copromotor, als eerste bedanken. Je weet hoe fijn dat ik het vond toen jij vier jaar geleden besloten hebt mij te willen begeleiden. We hebben in deze vier jaar veel gedeeld. Ik heb je leren kennen als een bijzonder fijne collega, een uiterst bekwaam en kritisch onderzoekster, als degene die met zachte stem en harde hand mijn agenda bewakte, als de fantastische moeder van jullie Job!!! Kortom... ik ben er zeer trots op jouw eerste promovendus te mogen zijn!!!

Imelda...Als copromotor ad interim wil ik jou bedanken voor de gedrevenheid waarmee je mij gedurende de afwezigheid van Marielle hebt begeleid en gemotiveerd in een fase dat veel cruciale beslissingen genomen moesten worden. Jouw leidinggevende capaciteiten, jouw scherp analytische blik en jouw sterk relativeringsvermogen hebben mij in deze periode zeer gesteund. Jouw inbreng vanuit het perspectief van de klinische praktijk heb ik als zeer waardevol ervaren. Ik vind het heel fijn dat jouw betrokkenheid met de voortgang van het project en met mijn vorderingen in het schrijven van dit proefschrift is blijven bestaan ook nadat je het "Hoensbroekse en Maastrichtse" hebt geruild voor het "Nijmeegse".

Geert....Als programmaleider en copromotor van het eerste uur weet ik nog zeer goed hoe jij voor mij op een mooie voorjaarsdag in Maastricht, de "dominosteentjes" op een rij hebt gezet. Jammer dat mijn komst naar Hoensbroek en het vallen van de dominosteentjes, gecombineerd werd met jouw vertrek naar Utrecht. Van afstand heb je echter als epidemioloog pur sang vooral de methodologische aspecten van deze trial goed weten te bewaken. Daarvoor mijn dank!!!.

Wim....Als eerste promotor ben jij bovenal de manager geweest die naast de inhoudelijke discussies, vooral het doel en de voortgang van dit promotietraject scherp voor ogen heeft gehouden. Jammer dat het niet gelukt is mijn promotie te combineren met jouw emiraat. Jouw tomeloze energie, luistervaardigheid en zeer goed geheugen voor de kleine details zullen mij bijblijven. Bedankt!!!

Geert-Jan....Als tweede promotor heb ik jou als een zeer prettige collega leren kennen, die de kunst verstaat zijn promovendi ook in minder goede tijden te blijven motiveren en stimuleren. Jouw grote ervaring met onderzoek in de eerste lijn, gecombineerd met jouw klinische deskundigheid uit de huisartspraktijk, heb ik als zeer waardevol ervaren!!! 
Natali, Mariannne, Sjan, Iwerna en Sabine....Als onderzoeksassistenten wil ik jullie bedanken voor al het vele werk en al jullie inspanningen met betrekking tot het vooronderzoek, de selectie van patiênten en de dataverzameling. Het was een hele klus die jullie op eern voortreffelijke manier hebben weten te klaren. Hartstikke bedankt!! Sjan....Heel fijn dat jij hebt toegezegd vandaag mijn paranimf te willen zijn!!!

Camiel..... Onderzoeksmaatje!!! We hebben in de afgelopen jaren veel ups and downs in onderzoeksland meegemaakt. ik wond het heel fijn dat je voor zoveel vragen mijn klankbord wilde zijn; inhoudelijke discussies, praktische problemen, beslissingen ten aanzien van methodologie of statistiek. Jij bent betrokken geweest bij iedere zin in dit proefschrift. Ik bewonder jouw doorzettingsvermogen en jouw inspanningen ook op de momenten dat dit voor anderen soms onopgemerkt bleef. Ik wil je bedanken voor de wijze waarop je altijd als collega voor mij hebt klaar gestaan!!!!! Bedankt!!!

Rob... Onze wegen blijven elkaar in de loop der jaren steeds kruisen. Het feit dat ik jouw emailadres tegenkom in zoveel groepen op mijn PC, toont aan hoe veelzijdig jii bent. Vandaag wil ik jou bedanken yoor jouw inbreng binnen de projectgroep en de wijze waarop jij na het vertrek van Geert samen met Marielle de draad hebt opgepakt. Hartstikke goed!!!

Albère....Ook wij kennen elkaar nu meer dan 25 jaar. Ieder die jou kent weet hoe fijn het is om jou in de projectgroep te mogen hebben. Als inhoudsdeskundige en ervaren onderzoeker, heb jii, samen met Rob, een grote invloed gehad op de wijze waarop dit programma tot stand is gekomen en een belangrijke bijdrage gelleverd aan de verschillende publicaties. Daarvoor bedankt!!!

Rob... Als tweede inhoudsdeskundige binnen de projectgroep, wil ik jou bedanken voor jouw bijdrage tijdens de training en tijdens de boostersessies voor de deelnemende fysiotherapeuten. Daarnaast heb ik het als zeer prettig ervaren dat je samen met Albère in de aanloop van deze studie de projectgroep hebt willen adviseren.

Jan.....Bedankt dat jij wanuit Glimmen (Groningen rechtsaf, over de Hondsrug tot net voor de Duitse grens) tot drie maal toe bent afgereisd naar Hoensbroek om de deelnemende huisartsen op te frissen in het toepassen van de NHG-standaard schouderklachten. Geweldig!! Daarnaast wil ik jou bedanken voor de prettige samenwerking en de leuke discussies die we gevoerd hebben in het kader van dit programma.

Nandus... Vanaf het eerste uur ben jij als adviserend huisarts betrokken geweest bij de projectgroep. Daarvoor mijn dank!!!

Jelle.... Over de vraag of jij de taak van vertrouwensarts voor de duur van de studie voor jouw rekening wilde nemen, heb jij niet lang getwijfeld. Gelukkig is alles goed verlopen. Bedankt!!!

Marlies..... Heel fijn dat jij hebt toegezegd om het geneeskundig vooronderzoek te doen bij de patiënten die gerekruteerd werden via advertenties. Daarnaast vond ik het heel fijn om ook in de praktijk samen met jou als huisarts samen te werken. Het gaat jullie goed in Helmond!!!

Judith...Voor jou een zeer speciaal woord van dank voor al het werk dat jij in de voorbereidende fase van deze studie hebt gedaan met betrekking tot de ontwikkeling van de vragenlijsten. Prima!!!

Suus.. Bedankt voor jouw enthousiasme en jouw bijdrage aan de focusgroep interviews!! 
Jolanda......Bedankt voor al jouw inspanningen gedaan rondom de procesevaluatie. Ik vond het heel fijn om met jou in die periode te mogen samenwerken. Niet alleen wanwege jouw deskundigheid, maar tevens vanwege jouw vrolijkheid en altijd gulle lach!!

Jeroen.....Als expert op het gebied van exposure vond ik het heel prettig om met jou samen te werken en een pilot te starten. Door tijdgebrek en te lage instroom hebben we dit project in de ijskast moeten zetten. Maar wie weet? In ieder geval bedankt!!

Lex....Bedankt voor jouw inspanningen met betrekking tot het literatuuronderzoek. Het was prettig om in die fase op jouw deskundigheid te kunnen terugvallen!!

Sasha, Henk, Albère en Marcel....Als referenten voor de kwaliteitscommissie, een speciaal woord van dank voor jullie deskundige en kritische commentaren bij de publicaties opgenomen in dit proefschrift!!

Maureen en Constance........ Bedankt voor jullie hulp met betrekking tot de (soms eén minuut voor twaalf) stukken voor de METC en de kwaliteitscommissie.

Jack en Ger....Jullie wil ik bedanken voor de hulp bij alle administratieve zaken rondom dit project.

Mia ....Bedankt voor het beantwoorden van de vele telefoontjes. Zeker gedurende de periode van de "open werving" hebben we veel van jullie gevraagd. Daarvoor bedankt!!!

Mark, Robert, Roland en Frank... Bedankt voor jullie hulp bij de presentaties, trainingen, boosstersessies en het minisymposium georganiseerd in het kader van het NSO.

De leden van de leescommissie.....Job, Klaas, Hans, Johan en Danielle......van harte bedankt voor jullie snelle beoordeling. Jammer Klaas, dat jij op deze dag niet aanwezig kunt zijn, maar zeer bedankt voor jouw positieve woorden. Bedankt Job, voor de moeite die je genomen hebt om vandaag voor deze gelegenheid vrij te plannen (het is immers jouw praktijkdag). Ook Hans bedankt dat je vandaag wilt opponeren. Johan....Het is een voorrecht om met jou samen te werken en, zoals Stephen Morley het ooit in Praag verwoordde, deel uit te mogen maken van de "Maastricht clan". De zeer waardevolle inhoudelijke discussies, maar ook de vele fijne wandelganggesprekken in Maastricht of in een Californisch visrestaurant, blijven me bij.

Danielle....Ook jij van harte bedankt voor alle fijne gesprekken die we in de afgelopen jaren hebben mogen voeren en natuurlijk ook vanwege jouw deskundige inbreng vanuit het EMGO met betrekking tot methodologie en onderzoek in de eerste lijn. Ik vind het echt heel fijn dat jij vandaag erbij bent on te opponeren.

Ton en Gert......samen met Camiel waren jullie de andere promovendi binnen het NSO. Ik heb de samenwerking met jullie altijd als zeer prettig ervaren. Het meeste overleg tussen Groningen, Amsterdam en Hoensbroek verliep natuurlijk via email. Maar, prettige herinneringen blijf ik zeker ook houden aan onze momenten van overleg op één van de vele terrasjes in Amsterdam, Utrecht, Nijmegen, Maastricht of Avignon.

Betty, Klaas en Lex....promotoren in Groningen en Amsterdam. Ook jullie wil ik van harte bedanken voor jullie deskundige inbreng binnen het NSO en voor de prettige discussies die we tijdens onze programma bijeenkomsten in Utrecht hebben gevoerd.

Hanny en Alita.... Jullie wil ik bedanken voor alle hulp en begeleiding vanuit Caphri in de afgelopen periode en alle inspanningen bij de cursussen.

Alle mede onderzoekers uit de "pijn"-groepen in Hoensbroek en Maastricht will ik 
bedanken voor de fijne tijd, de prettige inhoudelijke discussies en de leuke gesprekken tijdens onze momenten wan overleg, of gedurende de cursussen, congressen en symposia in binnenen buitenland .......Jeanine, Marielle, Anja, Eric, Jeroen, Albère, Camiel, Peter, llse, Rob, Madelon, Judith, Maaike, Carolien, Sita, Alita, Claudine, Ruud, Jeffrey, Johan, Piet....Bedankt!!!

Alle iRv-collega's.....Bedankt!!... Onze detachering vanuit Maastricht naar Hoensbroek heb ik altijal als zeer prettig ervaren. Marga, Helma, Yvonne, Carolien, Anja, Henk, Brigitte, Luc, Alita, Derek, Marcel, Roelof, Edith, Olga, Jos, Jolanda, Jeanine, Eric, Jeroen......, de latere collega's van de tweedé etage Petra, Suus, Wilmà, Suzanne, Nathalie, Imke, Sasha, Gert-Jan, Frank, Harry.......en natuurlijk ook alle overige iRv-ers..... zeer zeer hartelijk bedankt!!! Carolien... Bedankt voor de samenwerking rondom onze bijdrage aan de KNGF richtlijn 'beroerte'. Jeanny... Bedankt voor jouw enthousiasme en gedeelde ambitie voor het versterken van de multidisciplinaire samenwerking binnen de eerste lijn. We komen erop terug!!

Sjan, Henk en George...... Jullie wil ik bedanken voor de prettige wijze waarop we de Arm-handfunctie cursussen in Hoensbroek en Utrecht hebben voorbereid en gegeven. Henk, de uiterst gedreven onderzoeker, bedankt voor de vele fijne inhoudelijke discussies en jouw betrokkenheid bij mijn voortgang. George.... Improviseren is een kunst. Het was fijn om met jou te mogen samenwerken.

Deborah... Bedankt voor jouw speciale aandacht, jouw energie en de leuke gesprekken in de afgelopen periode! Op jouw uitnodiging kom ik zeker nog een keer terug!! Magic!!

Iris, John en Eric... Jullie wil ik bedanken voor alle energie die jullie gestoken hebben in de vormgeving van dit proefschrift. Het resultaat mag er zijn!! Geweldig!!

Laura... Bedankt voor jouw begrip en steun!! Je kent de aanleiding. Nu is het af!!

Jan...Bedankt voor het redigeren en corrigeren van de teksten. Fijn dat je in de afgelopen jaren steeds de tijd voor mij hebt willen nemen. Mooi werk!! Thanks!!!

Jessie, Corianne, Natalie, Mark, Ralph, Jeroen, Marie-therese, Karin, Roel, Rene.....en natuurliik ook Hanna, Paula, Til en Albert. Bedankt voor al jullie inspanningen in de praktijk gedurende de afgelopen periode. Zonder jullie gezamenlijke bereidheid om in de afgelopen periode extra inspanningen te leveren was dit boekje nooit tot stand gekomen. Ontzettend bedankt!! Het voelt "goed" nu ook weer overdag vaker onder jullie in de praktijk te kunnen zijn. Ik weet, Paula, hoe graag ook jij er nu op dit moment bij had willen zijn. Het heeft niet zo mogen zijn. Jeroen..... het is een voorrecht dat jij vandaag als "mata" vanuit de geest van onze praktijk mijn tweede paranimf wilt zijn. Bedankt!!!!

Lianne, Harry, Paul, Stefan, Jeroen en Jacques....Bedankt dat jullie mij gedurende de afgelopen periode enigszins ontlast hebben van mijn taken binnen het beheer van het Medisch Centrum. De volgende nieuwjaarsborrel zal ik voor mijn rekening nemen!!!

Anton, Jan, Ruud... collega's op de Hogeschool van Utrecht en Sandra, Pieter, Ruud, Peter, Ton, Marc en alle andere (nieuwe) collega's op de Hogeschool Zuyd... Bedankt voor de prettige samenwerking en fijn dat jullie er zijn!! Conny, Mariet, Pieter, Marc, Rob, Ruud.......Bedankt voor de plezierige wijze watop we in de afgelopen jaren samen het symposium hebben georganiseerd. Alice, Odette, Karin, $\mathbb{H}$ an, Jo en Paul....Het is fijn om met jullie samen te werken binnen de redactie van het Jaarboek Fysiotherapie/Kinesitherapie. 
Mijn familie... pa, ma, schoonpa, Ria, Twan, Anita, Els, Hans, Daco, Yronne, Fanny, Jeroen en Laura....Bedankt voor jullie hulp, begrip en tijd in de afgelopen periode. Heel fijn dat jullie er vandaag bij kunnen zijn!!!

Reinilde, Maarten, Anouk, Jasper, Malou, Patrick en Sanne ...Jullie zijn WERELDS!I ...BEDANKT!!!! 


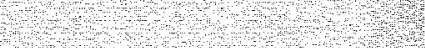

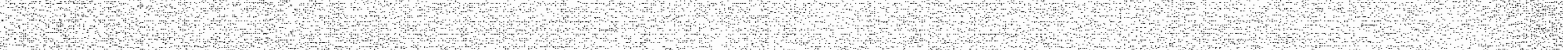
-1
-1 \begin{tabular}{ll}
$l_{1}$ \\
\hline
\end{tabular} \begin{tabular}{l}
$l_{1}$ \\
\hline
\end{tabular} \begin{tabular}{ll}
\hline \\
\hline
\end{tabular} \begin{tabular}{ll}
\hline \\
\hline
\end{tabular} \begin{tabular}{l}
$l$ \\
\hline
\end{tabular} \begin{tabular}{ll}
\hline \\
\hline
\end{tabular}

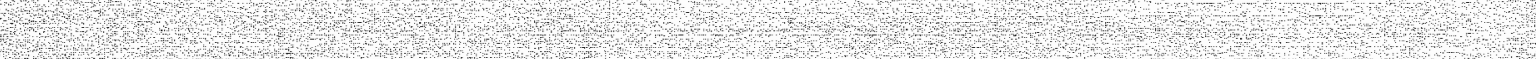
\begin{tabular}{ll}
\hline \\
\hline
\end{tabular} P. \begin{tabular}{l}
\hline \\
\hline
\end{tabular}

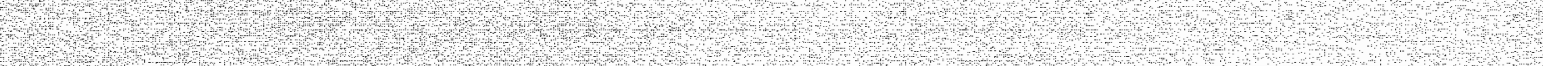
\begin{tabular}{l}
1 \\
\hline
\end{tabular} \begin{tabular}{ll}
\hline \\
\hline
\end{tabular} P
P

ᄂ ४ै।

L

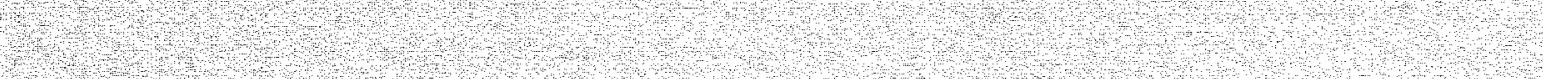
\begin{tabular}{lll}
\hline \\
L
\end{tabular} \begin{tabular}{ll}
\hline \\
\hline
\end{tabular} \begin{tabular}{ll}
\hline \\
\hline
\end{tabular} \begin{tabular}{lll}
\hline \\
\hline
\end{tabular} \begin{tabular}{ll}
\hline \\
\hline
\end{tabular} \begin{tabular}{ll}
\hline \\
\hline
\end{tabular} \begin{tabular}{ll}
\hline \\
\hline
\end{tabular} l. 


\section{Curriculum Vitae}


De Gele Keizer was zo maar op reis ten noorden van het Rode Water, bij de berg Kwen Loen.

Hij keek ower de rand van de Wereld. Op weg naar huis verloor hij zijn donkere parel.

Hij stuurde Wetenschap uit on de parel te vinden: maar deze vond hem niet. Hij stuurde Onderzoek uit om de parel te vinden: maar deze vond hem niet. Hij stuurde Logica uit om de parel te vinden: maar deze vond hem niet. Toen vroeg hij het aan Niets en Niets had hem!

Daarop zei de Gele Keizer:

"Is dat niet merkwaardig: Niets werd niet uitgestuurd

En hij deed niets om de parel te vinden;

Maar hij had hem!"

(Tjwang-tsen) 


\section{ABOUT THE AUTHOR}

Jacques Geraets was born on November 9, 1958 in Brunssum, the Netherlands. After he obtained his VWO diploma at the St.Janslyceum in Hoensbroek, he studied Physiotherapy at the Akademie voor Fysiotherapie in Heerlen and graduated in 1983. Subsequently, he studied Traditional Chinese Medicine at the International Free University in Maastricht/Basel. Since 1983 he has been working as a Primary Care Physiotherapist in Landgraaf. He started his study in Health Sciences at Maastricht University in 1995. He specialised in Movement Science and graduated in 1998. His master's thesis focused on the accuracy and reliability of shouldersonography. Since 1999 he is engaged in teaching methodology in the post-HBO training courses Sports Physiotherapy and Manual Therapy at the Hogeschool van Utrecht. In 2002 he was registered as an epidemiologist. Since 2001 he combined his work as a Physiotherapist with his $\mathrm{PhD}$-project as described in this thesis at the department of General Practice of Maastricht University and the Institute for Rehabilitation Research IRv in Hoensbroek. The studies presented here are embedded in a research programme of the Netherlands Organisation for Scientific Research, including a comprehensive prognostic cohort study on shoulder complaints in primary care, with three randomised clinical trials on the clinical-effectiveness and cost-effectiveness of three treatment modalities in subcohorts. In March 2006, Jacques will also start teaching at the Hogeschool Zuyd in Heerlen. He is married to Reinilde Breuer and father of Maarten, Anouk, Jasper and Malou. 



\section{List of publications}




\section{Publications}

Geraets IXX, de Bruinn CPC, Heilkers IWM, de Brwin N, Pelt RAGB, Köke AJA, Goossens MEJB, de Bie RA. Dinant GJ. Mogellikheden voor cognitief-gedragsmatige behandeling van schouderklachten in de eerste lijn. Stimulus $2003,2,158-171$.

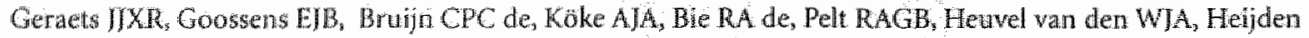
van der GIMG. A behavioural treatment for chronic shoulder complaints: concepts, development, and study. design. Aust J Pliysiother 2004; 50:33-38.

Geratet IJXR, Goossens EIB, Groot IJM de, Bruijn CPC de, Bie RA de, Dinant GJ, Heijden GIMG van der, Heuvel WJA wan den. Effectiveness of a graded exercise therapy programme for patients with chronic shoulder complaints. Aust I Physiother. 2005; 51: 87-94.

Bruijn CPC de, W3ie RA de, Geraets JJXR, Goosens EIB, Köke AJA, Heuvel wan den WJA, Hijden van der GIMG, Dinant GI. Evaluation of an education and activation programme to prevent chronic shoulder complaints: Design of an RCT. BMC Fam Pract. 2005; 16: 7.

Geraets JXXR, Pelt RAGB, Köke AJA. Graded activity als behandeling voor patiënten met chronische schouderklachten in de eerste lijn. In: Marinus HI, Dijkstra PU, Nijs I, van Wilgen P. Jaarboek Fysiotherapie Kinesitherapie 2006. Houten: Bohn Stafleu van Loghum. pp. 212-224.

Genets JJXR, Goossens MEJB, de Britin CPC, de Groot IIM, Köke AJA, Pelt RAGB, van der Heijden GJMG, Dinant $G$, wan den Heuvel WJA. Cost-effectiveness of a graded exercise therapy programme for patients with chronic shoulder complaints. Int I Technology Assess Health Care 2006 (in press).

Gerwets JIXR, Goossens EJB, Haastregt I van, Groot IJM de, Bruijn CPC de, Bie RA de, Köke AJA, Heuvel WIA wan de. Implications of process evaluation for clinical effectiveness and clinical practice in a triall on chronic shoulder complaints. Pat Edic Couns 2006 (in press).

Geraets IIXR, de Groot IMI, Goossens MEIB, de Bruijn CPC, de Bie RA, van den Heuvel WIA, Dinant GI. Comparison of two tectuitment strategies for patients with chronic shoulder complaints. Br I Gen Pract. 2006 (in press). 